ENVASE ACTIVO DE CARTÓN, QUE INCLUYE AGENTES NATURALES ENCAPSULADOS, PARA EL ENVASADO A GRANEL DE TOMATES Y PIMIENTOS FRESCOS

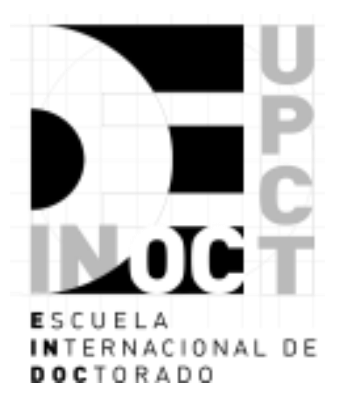

$\mathrm{T}$

E

S

I

S

D

O

C

$\mathrm{T}$

$\mathrm{O}$

R

A

L

2019
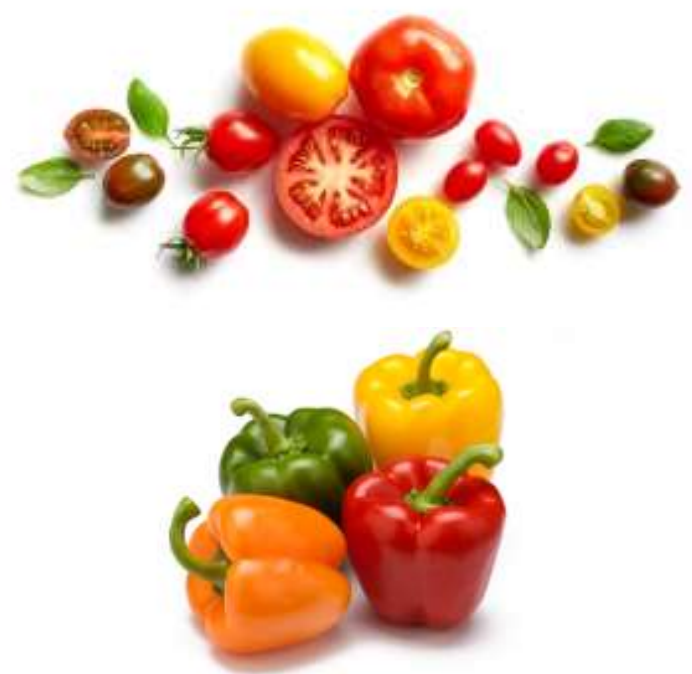

Doctorado en Técnicas Avanzadas en Investigación y Desarrollo Agrario y Alimentario

Laura Buendía Moreno 



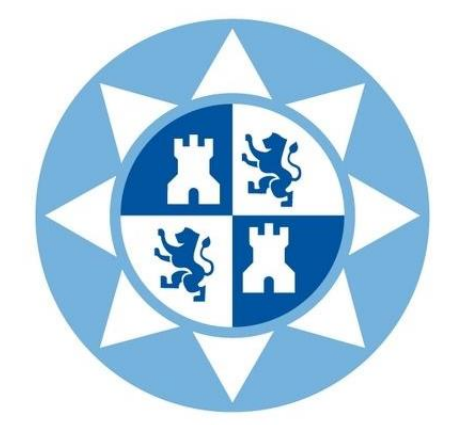

UNIVERSIDAD POLITÉCNICA DE CARTAGENA

\author{
DEPARTAMENTO DE INGENIERÍA AGRONÓMICA
}

Tesis Doctoral

\title{
ENVASE ACTIVO DE CARTÓN, QUE INCLUYE AGENTES NATURALES ENCAPSULADOS, PARA EL ENVASADO A GRANEL DE TOMATES Y PIMIENTOS FRESCOS
}

LAURA BUENDÍA MORENO

Dirigida por

Dr. Antonio López Gómez

Dra. María Ros Chumillas

Dra. Sonia Soto Jover 
Esta tesis se presenta en la modalidad de compendio de publicaciones.

Los artículos que componen la memoria son los siguientes:

Artículos en revistas científicas incluidas en el primer cuartil de su campo, Food Science and Technology (Journal Citation Reports, 2018):

Laura Buendía-Moreno, María Ros-Chumillas, Laura Navarro-Segura, María José Sánchez-Martínez, Sonia Soto-Jover, Vera Antolinos, Ginés Benito MartínezHernández, Antonio López-Gómez. 2019. Effects of an Active Cardboard Box Using Encapsulated Essential Oils on the Tomato Shelf Life. Food and Bioprocess Technology 12(9): 1548-1558, https://doi.org/10.1007/s11947-019-02311-0.

\section{Factor de Impacto: 3,032. Posición: 35/135}

Laura Buendía-Moreno, Sonia Soto-Jover, María Ros Chumillas, Vera AntolinosLópez, Laura Navarro-Segura, María José Sánchez-Martínez, Ginés Benito MartínezHernández, Antonio López-Gómez. 2019. An innovative active cardboard for box bulk packaging of fresh bell pepper extends its shelf life. Postharvest Biology and Technology. Presentado para su publicación: en proceso de revisión.

$>$ Factor de Impacto: 3,927.

Laura Buendía-Moreno, Sonia Soto-Jover, María Ros-Chumillas, Vera Antolinos, Laura Navarro-Segura, María José Sánchez-Martínez, Ginés Benito Martínez-Hernández, Antonio López-Gómez. 2019. Innovative cardboard active packaging with a coating including encapsulated essential oils to extend Cherry tomato shelf life. LWT-Food Science and Technology 116, 108584. https://doi.org/10.106/j.Iwt.2019.108584.

$>$ Factor de Impacto: 3,714. Posición: 23/135

Laura Buendía-Moreno, María José Sánchez-Martínez, Vera Antolinos, María RosChumillas, Laura Navarro- Segura, Sonia Soto-Jover, Ginés Benito MartínezHernández, Antonio López-Gómez. 2019. Active cardboard box with a coating including essential oils entrapped within cyclodextrins and/or halloysite nanotubes. A case study for fresh tomato storage. Food Control 107, 106763. https://doi.org/10.1016/j.foodcont.2019.106763.

$>$ Factor de Impacto: 4,248. Posición: 11/135 
Además, se han presentado comunicaciones en los siguientes Congresos Internacionales:

- CYTEF 2018 - IX Congreso Ibérico, VII Congreso Iberoamericano de Ciencias y Técnicas del Frío. Valencia, España, 19-21 Junio, 2018.

Antonio López-Gómez, Sonia Soto-Jover, María Ros-Chumillas, María José Sánchez-Martínez, Laura Navarro-Segura, Laura Buendía-Moreno, Jesús Grande-Finch. Eficacia de un envase de cartón activo antimicrobiano en la conservación refrigerada de pimiento fresco a granel. CYTEF 2018:130.

- CYTEF 2018 - IX Congreso Ibérico, VII Congreso lberoamericano de Ciencias y Técnicas del Frío. Valencia, España, 19-21 Junio, 2018. Antonio López-Gómez, Sonia Soto-Jover, María Ros-Chumillas, María José Sánchez-Martínez, Laura Navarro-Segura, Laura Buendía-Moreno, Jesús Grande-Finch. Envase de cartón activo antimicrobiano para reducir la podredumbre del tomate fresco envasado a granel y conservado en refrigeración. CYTEF 2018:131. 
Universidad

Politécnica

de Cartagena

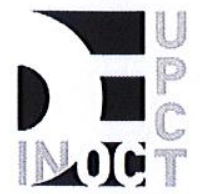

DT-16

\section{CONFORMIDAD DE SOLICITUD DEAUTORIZACIÓN DE DEPÓSITO DE}

\section{TESIS DOCTORAL POR LOS DIRECTORES DE LA TESIS}

D. Antonio López Gómez, Da ${ }^{\text {a }}$ María Ros Chumillas y Da. Sonia Soto Jover, Directores de la Tesis doctoral "ENVASE ACTIVO DE CARTÓN, QUE INCLUYE AGENTES NATURALES ENCAPSULADOS, PARA EL ENVASADO A GRANEL DE TOMATES Y PIMIENTOS FRESCOS”.

\section{INFORMAN:}

Que la referida Tesis Doctoral, ha sido realizada por Da ${ }^{\mathrm{a}}$. Laura Buendía Moreno, dentro del Programa de Doctorado Técnicas Avanzadas en Investigación y Desarrollo Agrario y Alimentario, dando nuestra conformidad para que sea presentada ante el Comité de Dirección de la Escuela Internacional de Doctorado para ser autorizado su depósito.

叉 Informe positivo sobre el plan de investigación y documento de actividades del doctorando/a emitido por el Director/ Tutor (RAPI).

La rama de conocimiento en la que esta tesis ha sido desarrollada es:

\footnotetext{
$\square$ Ciencias

$\square \quad$ Ciencias Sociales y Jurídicas

メ Ingeniería y Arquitectura
}

En Cartagena, a 06 de Noviembre de 2019

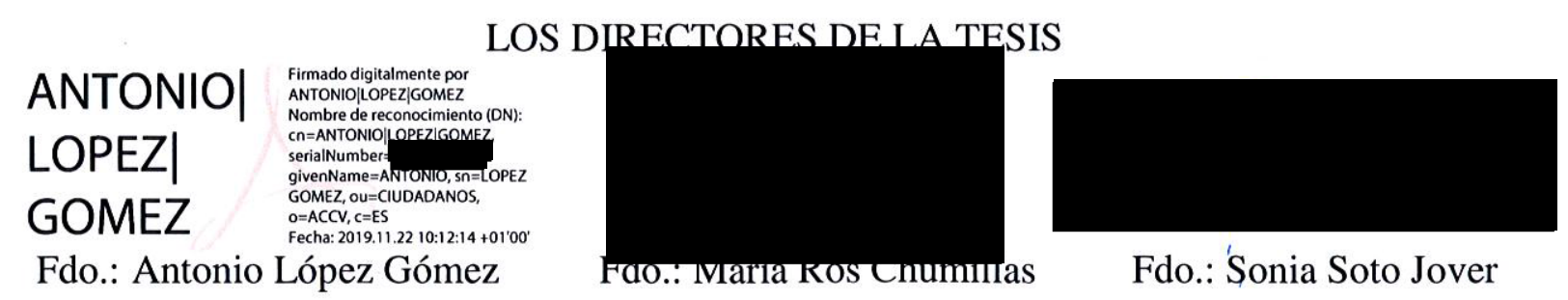




\section{Universidad \\ Politécnica \\ de Cartagena}

DT-17

\section{CONFORMIDAD DE DEPÓSITO DE TESIS DOCTORAL POR LA COMISIÓN ACADÉMICA DEL PROGRAMA}

D. Francisco Artés Hernández, Presidente de la Comisión Académica del Programa Técnicas Avanzadas en Investigación y Desarrollo Agrario y Alimentario.

\section{INFORMA:}

Que la Tesis Doctoral titulada, "ENVASE ACTIVO DE CARTÓN, QUE INCLUYE AGENTES NATURALES ENCAPSULADOS, PARA EL ENVASADO A GRANEL DE TOMATES Y PIMIENTOS FRESCOS", ha sido realizada, dentro del mencionado Programa de Doctorado, por $\mathrm{D}^{\mathrm{a}}$. Laura Buendía Moreno bajo la dirección y supervisión del Dr. Antonio López Gómez, Dra. María Ros Chumillas y Dra. Sonia Soto Jover.

En reunión de la Comisión Académica, visto que en la misma se acreditan los indicios de calidad correspondientes y la autorización de los Directores de la misma, se acordó dar la conformidad, con la finalidad de que sea autorizado su depósito por el Comité de Dirección de la Escuela Internacional de Doctorado.

X Evaluación positiva del plan de investigación y documento de actividades por el Presidente de la Comisión Académica del programa (RAPI).

La Rama de conocimiento por la que esta tesis ha sido desarrollada es:

Ciencias

Ciencias Sociales y Jurídicas

$X$ Ingeniería y Arquitectura

En Cartagena, a $\quad 7$ de noviembre de 2019

EL PRESIDENTE DE LA COMISIÓN ACADÉMICA

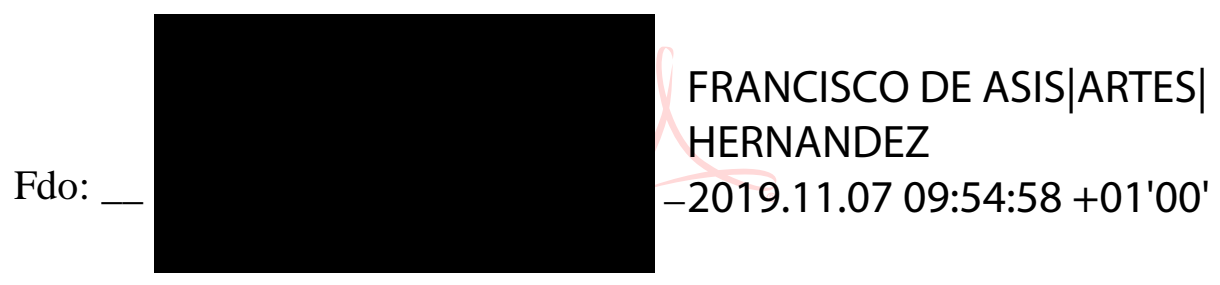



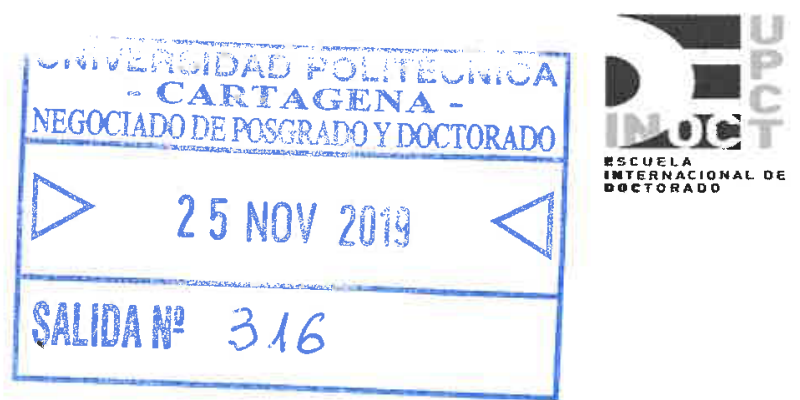

Sra. Dña. Laura Buendía Moreno

Visto el informe favorable del Director de Tesis y el $\mathrm{V}^{\mathbf{o}} \mathrm{B}^{\mathbf{o}}$ de la Comisión Académica del Programa de Doctorado "Técnicas Avanzadas en Investigación y Desarrollo Agrario y Alimentario" para la presentación de la Tesis Doctoral titulada: "Envase activo de cartón, que incluye agentes naturales encapsulados, para el envasado a granel de tomates y pimientos frescos" solicitada por DÑA. LAURA BUENDÍA MORENO, el Comité de Dirección de la Escuela Internacional de Doctorado de la Universidad Politécnica de Cartagena, en reunión celebrada el 25 de noviembre de 2019, considerando lo dispuesto en el artículo 23 del Reglamento de Estudios Oficiales de Doctorado de la UPCT, aprobado en Consejo de Gobierno el 17 de diciembre de 2015,

\section{ACUERDA}

Autorizar la presentación de la Tesis Doctoral a Dña. Laura Buendía Moreno en la modalidad de "compendio de publicaciones".

Contra el presente acuerdo, que no agota la vía administrativa, podrá formular recurso de alzada ante el Sr. Rector-Magnífico de la Universidad Politécnica de Cartagena, en el plazo de un mes a partir de la notificación de la presente.

Cartagena, 25 de noviembre de 2019

EL DIRECTOR DE LAESCUELA INTERNACIONAL DE DOCTORADO

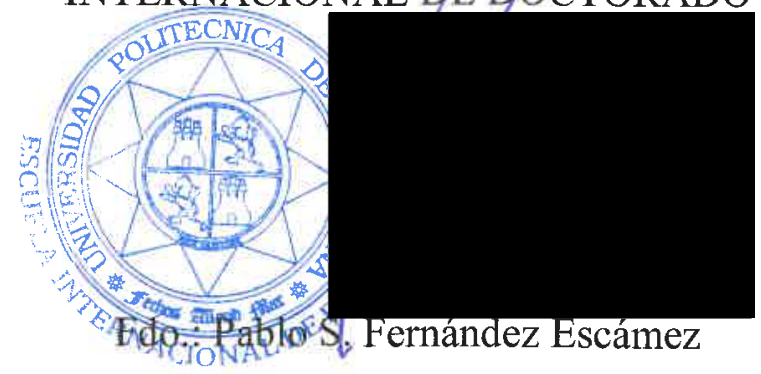




\section{AGRADECIMIENTOS}

Este trabajo de Tesis realizado en la Universidad Politécnica de Cartagena es un esfuerzo en el cual, directa e indirectamente, participaron distintas personas opinando, corrigiendo, dando ánimo, acompañándome en los momentos más cruciales y en los momentos de felicidad. Este trabajo me ha permitido aprender de otras personas, a ser crítica, a ser autosuficiente y por último, para mí la más importante, a ser una gran investigadora.

Mi director de Tesis, Dr. Antonio López Gómez, mi más amplio agradecimiento por haber confiado en mí para la realización de este trabajo. Su paciencia ante mi inconsistencia, su valiosa dirección y apoyo para seguir este camino, ha sido un aporte invaluable. Le agradezco, también, el haberme facilitado siempre los medios suficientes para llevar a cabo todas las actividades propuestas durante el desarrollo de esta Tesis.

Gracias de corazón a mis codirectoras, Dra. María Ros Chumillas y Dra. Sonia Soto Jover, por su paciencia, dedicación, motivación, criterio y aliento. Han hecho fácil lo difícil. Ha sido un privilegio poder contar con su guía y ayuda.

Gracias a Laura, Vera, Ginés Benito y María José, sin cuya colaboración este trabajo hubiera sido más largo, complicado y menos entretenido. Gracias por vuestra capacidad de esfuerzo, criterio y simpatía.

Gracias a las personas que, de una manera u otra, han sido claves en mi vida profesional, y por extensión, en la personal. Marta, mi mano derecha durante todo este tiempo. Te agradezco tu desinteresada ayuda cuando más la he necesitado, por aportar muchas cosas buenas y positivas a mi vida. Te doy las gracias no solo por la ayuda recibida, sino por los buenos momentos que hemos vivido fuera y dentro de la Universidad. Eres una gran persona, y me encanta tenerte a mi lado como una gran amiga. De nuevo, ¡Muchas gracias!

Vosotras, Sonia, Clara y Ana. Un pilar fundamental durante toda mi trayectoria universitaria, con vosotras empecé todo y con vosotras lo voy a terminar. Gracias por apoyarme cuando más lo he necesitado y por formar parte de mi pequeña gran familia.

Sin embargo, merecen reconocimiento especial mi madre y mi padre, quienes con su amor, paciencia y esfuerzo me han permitido llegar a cumplir hoy un sueño más. Gracias por inculcar en mí el ejemplo de esfuerzo, valentía, y de no temer a las adversidades. Han sido el apoyo, incondicional, a lo largo de toda mi carrera universitaria y a lo largo 
de mi vida. A ti, hermana. Tal vez seamos opuestos en ciertas cuestiones, pero eres y serás una de las personas más importantes de mi vida. Mil gracias por permanecer a mi lado todos estos años y por ayudarme en cada uno de mis proyectos. Te quiero mucho, y mientras tanto, iqué cese nuestro combate! Juanito, mi pequeño gran hombre. Sin parar de darnos lecciones de vida con tu lucha constante, todo esto va por ti y por tu valentía incansable. Muchos deberíamos aprender de ti.

Y para finalizar, tú. Tu ayuda ha sido fundamental, has estado conmigo en los momentos más turbulentos. Estuviste motivándome y ayudándome hasta donde tus alcances lo permitían. Millones de gracias por todo, por ser y por existir. 
"Una sociedad científica será una sociedad más libre"

Margarita Salas Falgueras (1938-2019) 


\section{ÍNDICE GENERAL}

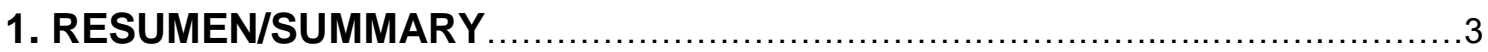

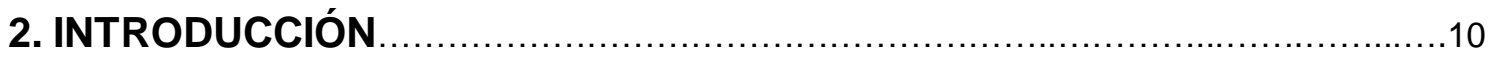

2.1. TOMATE FRESCO

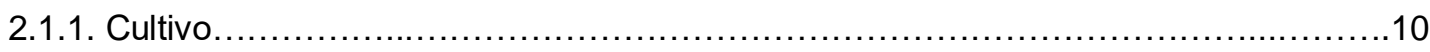

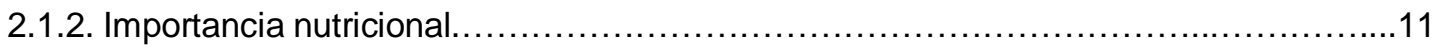

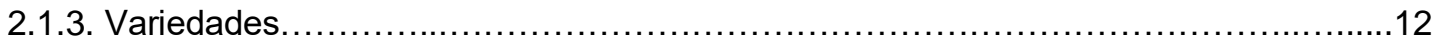

2.1.4. Problemas de conservación del tomate fresco a granel. $\ldots \ldots \ldots \ldots \ldots \ldots \ldots \ldots \ldots \ldots \ldots 14$

2.1.5. Importancia económica del tomate fresco en España y en la Región de Murcia.......17

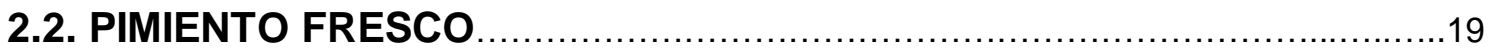

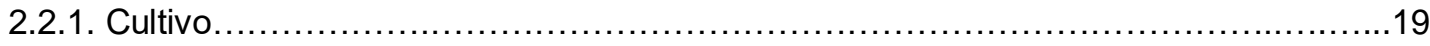

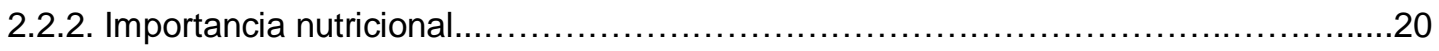

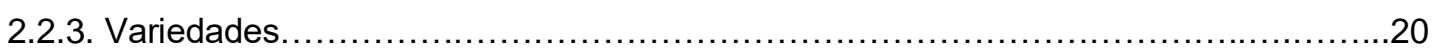

2.2.4. Problemas de conservación del pimiento dulce fresco a granel......................21

2.2.5. Importancia económica del pimiento dulce fresco en España y en la Región de Murcia.

\subsection{PROBLEMAS DE SEgURIDAD ALIMENTARIA EN PRODUCTOS}

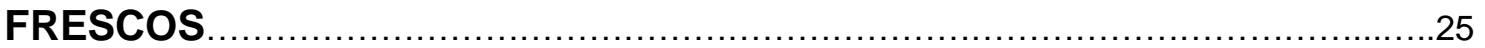

2.4. ENVASADO DE FRUTAS Y HORTALIZAS FRESCAS ENTERAS $\ldots \ldots \ldots \ldots 26$

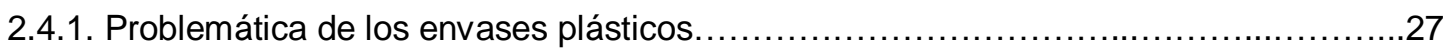

2.4.2. Envases plásticos biodegradables. Biopolímeros..............................28

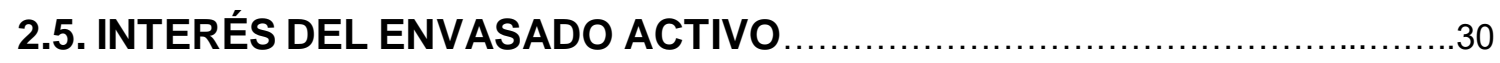

2.5.1. Agentes antimicrobianos y métodos de aplicación al envase activo..................31

2.5.2. Uso de los aceites esenciales como agentes antimicrobianos.......................34 
2.6.1. Posición del envase de cartón dentro de los envases sostenibles/biodegradables....37

2.6.2. Proceso de fabricación del cartón y limitaciones de desarrollo .39

\subsection{DESARROLLO DE UN ENVASE ACTIVO DE CARTÓN CON CARÁCTER ANTIMICROBIANO Y DE ADSORCIÓN DE ETILENO

2.7.1. Propuestas de envases activos de cartón .43

2.7.2. Encapsulación de los aceites esenciales usando ciclodextrinas y nanotubos de Halloysita, para el desarrollo del envase activo de cartón para el envasado a granel de tomates y pimientos frescos.

3. REFERENCIAS .55

4. JUSTIFICACIÓN Y OBJETIVOS. .72

5. RESULTADOS Y DISCUSIÓN .76

Capítulo I .79

Efectos de un envase activo de cartón que utiliza aceites esenciales nanoencapsulados sobre la vida útil del tomate. (Effects of an Active Cardboard Box Using Encapsulated Essential Oils on the Tomato Shelf Life).

Capítulo II. .92

Un envase de cartón activo e innovador para el envasado a granel de pimientos frescos, prolonga la vida útil de los mismos. (An Innovative Active Cardboard for Box Bulk Packaging of Fresh Bell Pepper Extends its Shelf Life).

Capítulo III. 142

Envase activo e innovador, de cartón, constituido por un revestimiento que incluye aceites esenciales encapsulados para extender la vida útil del tomate Cherry. (Innovative Cardboard Active Packaging with a Coating Including Encapsulated Essential Oils to Extend Cherry Tomato Shelf Life).

Capítulo IV

Envase de cartón activo formado por un revestimiento que incluye aceites esenciales encapsulados en ciclodextrinas y/o nanotubos de halloysita. Un caso de estudio para el almacenamiento de tomate fresco. (Active Cardboard Box with a Coating Including Essential Oils 
Entrapped within Cyclodextrins and/or Halloysite Nanotubes. A Case Study for Fresh Tomato Storage).

6. CONCLUSIONES. 


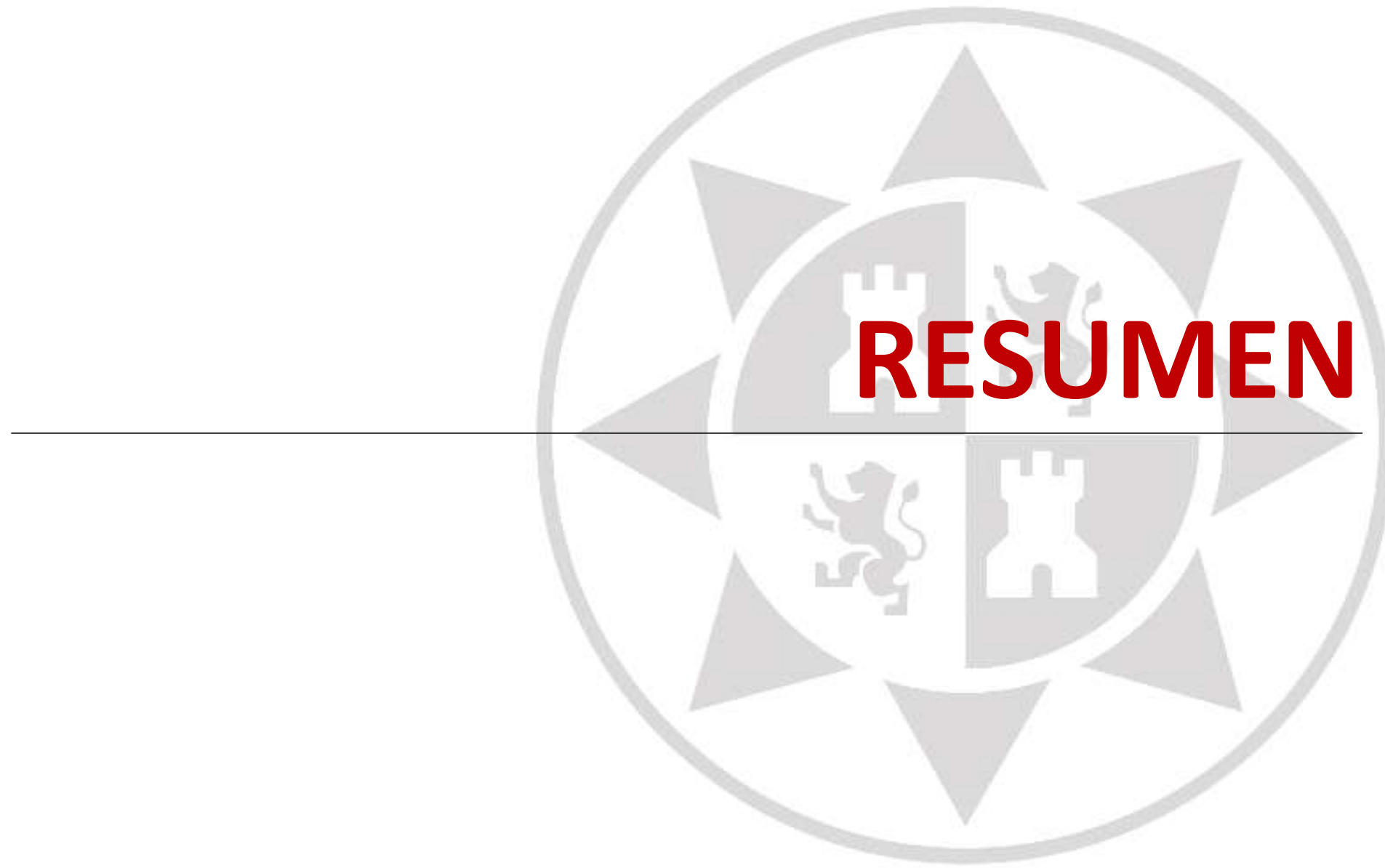




\section{RESUMEN}

España es uno de los principales países productores y exportadores de productos hortofrutícolas en la Unión Europea. Esto es en gran medida a la importancia que tiene este sector productivo en varias comunidades autónomas, donde tiene un puesto destacable la Región de Murcia. No obstante, este sector tiene que competir con otros países, sobre todo del arco Mediterráneo, donde pueden conseguir precios más bajos, aunque la calidad y seguridad de estos productos sea significativamente inferior. Por ello, es muy importante avanzar en la tecnología de envasado y conservación de frutas y hortalizas, para diferenciar todavía más la calidad y vida útil de estos productos frescos frente a la competencia, haciendo un especial hincapié en la mejora de su calidad microbiológica y organoléptica, y en su seguridad alimentaria.

Estos productos frescos son altamente perecederos, cuya calidad puede disminuir rápidamente a medida que pasan los días, debido principalmente al desarrollo de la actividad microbiológica de bacterias y hongos, y en algunos casos, por la liberación de etileno, una hormona que fomenta la maduración de los frutos. La incorrecta manipulación postcosecha, como la ruptura de la cadena de frío o el uso de envases inadecuados, pueden dar como resultado grandes pérdidas económicas postcosecha debidas, sobre todo, al desarrollo de la microbiología típica alterante de estos productos. Además, se pueden encontrar microorganismos patógenos en frutas y verduras frescas, debido a que son productos que se consumen prácticamente sin procesar o solamente lavados. Esta microbiología patógena y alterante puede aparecer durante las etapas de recolección, postcosecha y conservación.

Durante la manipulación postcosecha de las hortalizas frescas y antes del envasado, se lleva a cabo un tratamiento de descontaminación superficial utilizando agua clorada $u$ otros agentes desinfectantes. Esta es la única etapa donde se puede reducir el número de microorganismos patógenos y causantes del deterioro de estos productos. Este lavado de descontaminación superficial, normalmente reduce la carga microbiana solamente en una unidad logarítmica. Además, como no se trabaja en ambiente ultralimpio, suele producirse una recontaminación de los productos, normalmente por hongos procedentes del aire y de las superficies de los equipos de manipulación. Por tanto, es interesante considerar un sistema de envasado que controle la proliferación de la carga microbiana en estos productos.

Por ello tiene de gran interés el desarrollo de nuevas tecnologías de envasado activo 
antimicrobiano que satisfagan las demandas de los consumidores en cuanto al uso de agentes antimicrobianos naturales y que mejoren, a su vez, la seguridad alimentaria.

Los plásticos sintéticos son materiales muy empleados para la fabricación de envases para frutas y hortalizas, puesto que estos presentan buenas propiedades que contribuyen a la protección del alimento y permiten ver el mismo por su transparencia. Pero estos plásticos tienen el inconveniente de estar constituidos por polímeros no biodegradables derivados del petróleo. Esto implica que tienen una gran persistencia en la naturaleza, manteniendo sus características, durante varias décadas una vez que son vertidos, lo cual constituye un serio problema medioambiental. Como consecuencia de esta problemática medioambiental, el uso de envases de cartón corrugado se presenta como una alternativa importante al uso de plásticos, debido sobre todo a que tienen buenas propiedades mecánicas que se adaptan muy bien a los envases que se necesitan para la conservación y transporte de frutas y hortalizas frescas. Además, los envases de cartón son menos perjudiciales para el medio ambiente y más económicos que los plásticos.

Los procedimientos habituales de envasado de este tipo de productos en cajas de cartón sin carácter activo, aunque se mantenga una temperatura y humedad relativa (HR) adecuada de conservación del producto, no permiten extender mucho la vida útil ni asegurar la ausencia de podredumbres ni de microorganismos patógenos. Esta es la razón por la que se propone una solución tecnológica avanzada de envase activo de cartón con el objetivo de poder alargar la vida útil de frutas y hortalizas frescas, y de mejorar su seguridad alimentaria.

La solución que se propone consiste en el desarrollo de un envase activo de cartón que se caracteriza porque al menos una de sus caras internas posee un recubrimiento activo antimicrobiano que comprende una emulsión en base agua de un compuesto polimérico que incluye complejos de inclusión formados por ciclodextrinas (CDs) y aceites esenciales (AEs), y/o nanotubos de halloysita (HNT) con AEs, o componentes de éstos, o una mezcla de ambos. Las sustancias antimicrobianas que se proponen son AEs que pueden utilizarse solos, o mediante combinación de los mismos, los cuales se liberan por evaporación cuando el envase es almacenado en condiciones de elevada HR, ejerciendo su acción antimicrobiana sobre los microorganismos presentes en la superficie del producto envasado.

En esta tesis se ha desarrollado y validado, a escala de planta piloto y a nivel industrial, un prototipo de envase activo de cartón con actividad antimicrobiana y de control de etileno, que incluye agentes naturales encapsulados, para el envasado a granel de tomates y pimientos frescos, aumentando su vida útil, la calidad y seguridad alimentaria. 
Este tipo de envase desarrollado se ha evaluado como un sistema de envasado capaz de prolongar la vida útil de productos frescos, como son el tomate y el pimiento. La liberación controlada de los vapores de los AEs durante la conservación, a una determinada temperatura y $\mathrm{HR}$, permite el control de la pérdida de la calidad de estos productos frescos debido a que los AEs ejercen una acción antimicrobiana impidiendo el desarrollo de microorganismos alterantes que provocan podredumbres en los frutos, además de obtener una mejora en la calidad sensorial.

Durante la conservación de tomates y pimientos frescos se realizaron determinaciones microbiológicas, fisicoquímicas (sólidos solubles, $\mathrm{pH}$ y acidez titulable). También se estudió la firmeza de los frutos y su calidad sensorial, así como el porcentaje de frutos podridos y la determinación de residuos de AEs sobre la superficie del fruto, como en el envase.

Durante todo el estudio se observó que los frutos almacenados en envases de cartón activo presentaron un menor porcentaje de frutos podridos con respecto a los frutos almacenados en envases de cartón no activo, al final de su vida útil. Produciéndose una reducción de hasta el 14\% de frutos defectuosos envasados en cajas activas.

Por otro lado, en cuanto a la calidad sensorial, los frutos mejor evaluados fueron aquellos que se envasaron en sistema activo frente a los que se envasaron en sistema no activo. Sin embargo, ni la calidad microbiológica ni fisicoquímica, del fruto, se vieron afectadas independientemente del tipo de envase estudiado. 


\section{SUMMARY}

Spain is one of the main producers and exporters of fruit and vegetables in the world. In fact, this sector has a high importance in the Region of Murcia and other places of Spain. Nevertheless, many other countries produce such horticultural products with lower prices and quality. In order to consolidate, and even improve, the actual situation of this sector it is necessary to preserve the product quality using advanced technologies of packaging and preservation extending the shelf life of these fresh products. Such advances may allow to obtain a more competitive product against the other producer countries. Furthermore, it is crucial to ensure the food safety, while ensuring the highest microbiological and organoleptic quality.

Horticultural fresh products are highly perishable being their quality reduced during postharvest storage mostly due to microbial growth (mainly bacteria and fungi), and other physiological processes such related to senescence like the production and effects of ethylene, which is known as the ripening hormone. Nonadequate post-harvest techniques like inadequate refrigerated storage (e.g. not controlled relative humidity (HR), etc.) or inappropriate packaging, can result in high postharvest economic losses due to the microbial growth of spoilage microorganisms. Moreover, pathogenic microorganisms can be detected in fresh vegetables that are minimally processed. The origin of microbial crosscontamination may be originated during harvesting, post-harvesting or conservation periods.

During postharvest handling of fresh vegetables before packaging, surface decontamination treatment is carried out using chlorinated water or other sanitizing agents. This processing stage is crucial to minimize microbial loads of the product. Such surface decontamination using sanitizing washings normally reduces microbial loads less than one logarithmic unit. In addition, since horticultural products are not usually processed under an ultra-clean environment, they are usually decontaminated with fungi from the air and the 
surfaces of the handling equipment. Accordingly, it is of high interest to develop a packaging system that controls the microbial growth in these products.

In that sense, new active antimicrobial packaging technologies may control microbial growth of the contained product satisfying also the consumer demands since they are natural antimicrobial agents while ensuring the product food.

Synthetic films have been widely used as packaging materials for fruit and vegetables since they have excellent properties that contribute to the protection of the food while ensuring a good transparency. Nevertheless, these films are non-biodegradable polymers derived from petroleum. These petroleum-derived polymers have a great persistence in nature maintaining their characteristics for several decades once they are discharged, constituting a serious environmental problem. Due to this problematic situation, corrugated cardboard packages are an interesting alternative because they have good mechanical properties, which are crucial for a proper storage and transport of the packaged food. Moreover, cardboard packages are environment-friendly and economical compared with plastic materials.

Conventional cardboard boxes are not able to extend the shelf life of products as consequence of the control of microbial growth. Then, an emerging technology that allows the extension of the product shelf-life of fruit and vegetables using an active cardboard box coated with waterproof lacquers including nanoencapsulated antimicrobial compounds is here by studied. Essential oils (EOs), single or combined, have high antimicrobial properties. Encapsulation of EOs using cyclodextrins (CD) and/or nanotubes of halloysite (HNT) is incorporated in the lacquers of the active cardboard packages to extend the product shelf-life. Then, EOs are released from the CD by evaporation when the packaging is stored in conditions of high HR, exerting their antimicrobial activity on the microorganism present of the surface of the horticultural products packaged with this active packaging.

This Thesis has developed and optimized an active antimicrobial packaging at different scales (pilot plant and industrial) using a lacquer with the EOs-CD inclusion complex to preserve the quality of fresh tomatoes and peppers. This developed packaging type has been evaluated as a packaging system able to 
extend the shelf life of fresh horticultural products such as tomatoes and peppers. Controlled release of EOs vapours during storage at a specified temperature and HR allows the control of quality losses of these fresh products due to the antimicrobial activity of EOs reducing the growth of spoilage microorganisms, which are responsible of fruit rottenness. Overall, the product quality is better maintained with such proposed technology.

Microbiological and physicochemical determinations (soluble solids, $\mathrm{pH}$ and treatable acidity) were made during the storage of fresh tomatoes and peppers. Firmness was also studied together with sensory quality and the decay incidence. Furthermore, residues of EOs were also studied during storage in the fruit surface as well as the remaining EOs in the packaging material.

Throughout the study, products stored within the non-active cardboard packages showed a higher percentage of decay incidence compared to active cardboard packages during storage. On the other hand, samples packaged within the active system showed better sensory quality than those samples packaged with the non-active system. However, neither the microbiological quality nor the physicochemical quality of the products were affected regardless of the type of containers studied. 


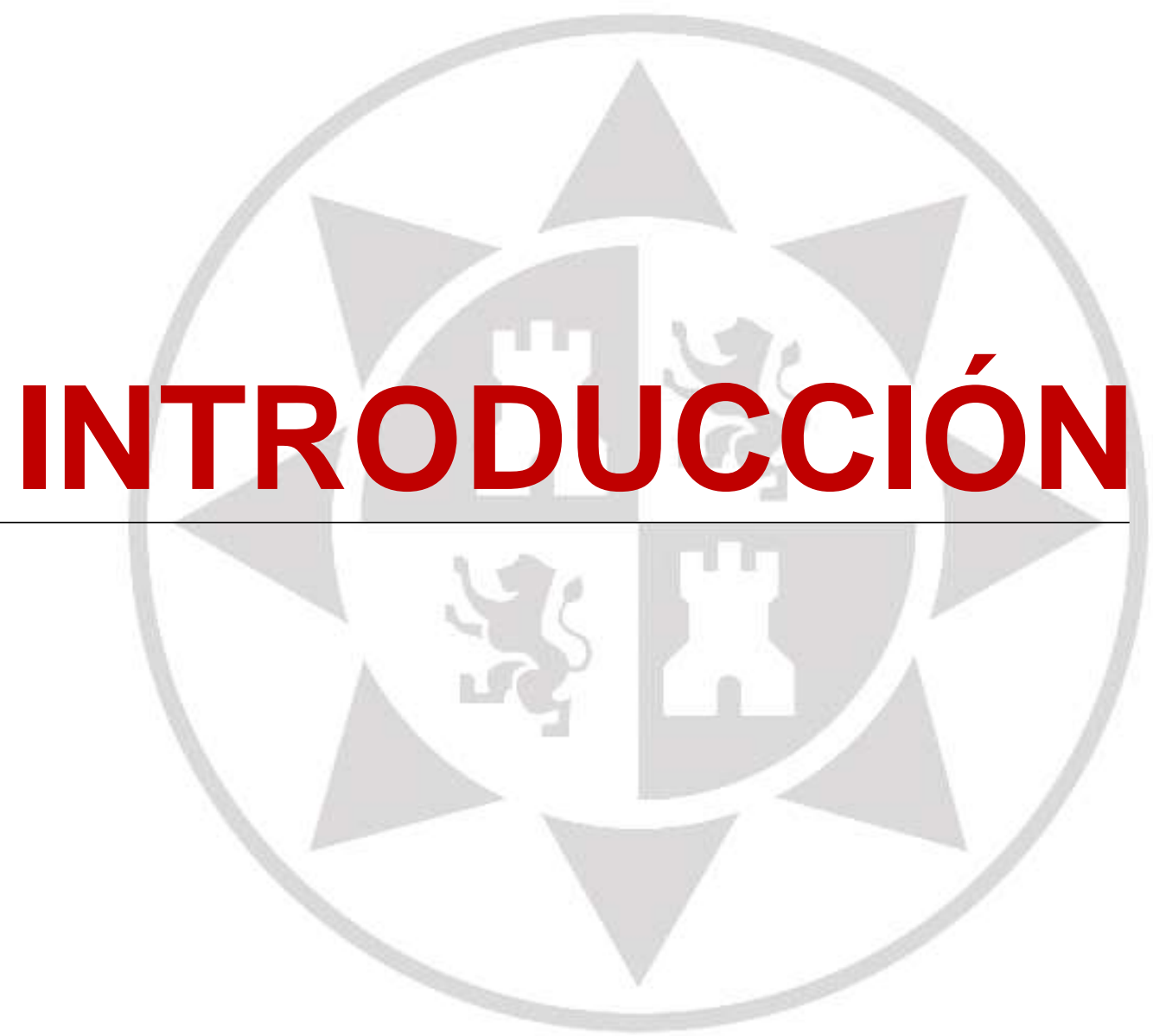




\section{INTRODUCCIÓN}

Las frutas y hortalizas frescas son productos altamente perecederos cuyo valor comercial puede disminuir rápidamente a medida que pasan los días. El deterioro de estos productos es causado, principalmente, por la actividad microbiológica de bacterias y hongos, y por la liberación de etileno, que es un regulador del crecimiento vegetal $u$ hormona vegetal que actúa en el control de gran cantidad de procesos fisiológicos, como la senescencia de los órganos vegetales (Martínez-Romero et al., 2007). Estos procesos biológicos no se pueden evitar, pero se pueden ralentizar a través de un sistema de envasado activo, con la incorporación de sustancias activas al envase, lo que permite mejorar la calidad y disminuir las pérdidas por podredumbre en el transporte y distribución de estos productos. En efecto, en los últimos años se ha producido un gran desarrollo tecnológico en el envasado de alimentos, y entre las innovaciones más interesantes se encuentra la técnica del envasado activo, que es un concepto relativamente amplio que implica distintas configuraciones (como los que emiten o adsorben compuestos activos) pero que tiene un objetivo principal: mejorar la calidad en el momento del consumo y aumentar la vida útil (Giraldo-Perdomo y Torres-Rubio, 2018).

\subsection{TOMATE FRESCO.}

\subsubsection{Cultivo.}

El tomate (Lycopersicon esculentum Mill. o Solanum lycopersicum L.), tomatera o jitomate, es una especie de planta herbácea del género Solanum de la familia Solanácea. El tomate tiene su origen en la zona oeste de América del Sur, entre el sur de Colombia y el norte de Chile, pero parece que fue en México donde se domesticó, ya que anteriormente parece que crecía como mala hierba en tierras de cultivo. En efecto, el tomate se introduce en la Unión Europea en el siglo XVI por el conquistador español Hernán Cortés (Infoagro, 2017; Rick y Fobes, 1976). Durante las décadas posteriores, el cultivo de las diferentes variedades de tomate se esparció por Francia, España e Italia, siendo muy rápida su aceptación como fruto comestible. Sin embargo pasó lo contrario en la zona este y norte de Europa, donde este fruto generaba gran desconfianza como producto de consumo, dado que se le creía venenoso. Este razonamiento era debido a diversas razones, como su relación con otras plantas de la 
misma familia (belladona y beleño), sus hojas punzantes y cierto grado de superstición de la población (Esquinas-Alcázar y Nuez, 1995).

Actualmente, es el producto hortícola de mayor importancia económica con más de 170 millones de toneladas $(\mathrm{t}$ ) producidas al año en todo el mundo. Además, es uno de los productos que más diversidad de usos presenta. A parte de consumirse crudo, puede servirse cocido, estofado, frito, encurtido, etc. (Costa y Heuvelink, 2018).

Es una planta dicotiledónea perteneciente a la familia de las Solanáceas de clima relativamente cálido donde su temperatura óptima dependerá de la etapa fisiológica en la que se encuentre, pero las temperaturas nocturnas deben estar entre $15 \stackrel{\circ}{ } \mathrm{C}$ y $17^{\circ} \mathrm{C}$, las temperaturas diurnas entre $20 \stackrel{\circ}{\circ}$ y $30 \stackrel{\circ}{ } \mathrm{C}$, siendo la temperatura ideal en la floración de $21^{\circ} \mathrm{C}$. Por ello el tomate es clasificado dentro de las hortalizas tolerantes al calor. La maduración del fruto está muy influenciada por la temperatura en lo referente tanto a la precocidad como a la coloración, de forma que valores cercanos a los $10 \stackrel{\circ}{ } \mathrm{C}$ así como superiores a los $30{ }^{\circ} \mathrm{C}$ originan tonalidades amarillentas (Rodríguez-Ortega et al., 2019).

\subsubsection{Importancia nutricional.}

En general, el tomate es un alimento cuyo componente mayoritario es el agua seguido de los hidratos de carbono. Es un alimento con escasa cantidad de calorías. Contiene azúcares simples que le confieren un ligero sabor dulce y algunos ácidos orgánicos que le otorgan el sabor ácido característico. El tomate es una fuente importante de ciertos minerales, como el sodio y el potasio. Es una fuente importante de vitaminas entre las que destacan la vitamina $C, E$, la provitamina $A$ (en forma de $\beta$-caroteno), vitaminas del grupo B (B1 y B3).

A pesar de que el tomate presenta una baja concentración de pigmentos, $20 \mathrm{mg} / \mathrm{kg}$ tomate fresco (Davies y Hobson, 1981), éstos le aportan un gran valor nutracético. Uno de los principales pigmentos, son los carotenoides. El 90-95 \% de los carotenoides presentes en el tomate maduro son carotenos, y dentro de este grupo se encuentra el licopeno, pigmento que da el color característico al tomate (Beecher, 1998; FEN, 2018). Tanto la vitamina $\mathrm{C}$ como el licopeno son compuestos antioxidantes con una importante función protectora del organismo humano. Además, el uso de tomate triturado o cocinado y su combinación con aceite, mejora la absorción del licopeno en nuestro organismo (Martínez-Hernández et al., 2016).

La prevención de diversas enfermedades causadas por la degeneración de tejidos debida al oxígeno reactivo, los radicales libres y los componentes tóxicos del medio, que causan daños en los vasos sanguíneos y en las células nerviosas, han llevado a la búsqueda e investigación de sustancias de alto potencial antioxidante como, por 
ejemplo, el licopeno, el cual se encuentra principalmente en tomates y es el principal componente responsable de su característico color rojo (Martínez-Hernández et al., 2016, 2019).

\subsubsection{Variedades.}

El desarrollo de variedades de tomate para conseguir nuevas formas, colores y gustos, además de frutos más resistentes a ciertas enfermedades, ha hecho que actualmente se conozcan más de 10.000 variedades. Es evidente que no todas llegan a nuestro mercado, pero sí es cierto que cada vez hay más variedades disponibles durante todo el año, a pesar de que se trata de un producto de verano, que es cuando este alimento está en su mejor época (Koening et al., 2013; eldiario, 2019).

Una de las maneras más habituales de consumir el tomate es en ensaladas, acompañado de lechuga y otros vegetales, como plato principal o como acompañamiento. Otras variedades son más idóneas para preparar rellenos, conservas, gazpachos o tomate frito. Si bien la lista de variedades de tomate es muy extensa, en la siguiente tabla se han seleccionado algunas de las variedades más consumidas en fresco en España (Tabla 1): 
Tabla 1. Variedades de tomate consumidas en fresco en España

(A partir de datos recogidos en la revista eldiario.es)

\begin{tabular}{|c|c|c|c|}
\hline VARIEDAD & CARACTERÍSTICAS & REFERENCIA & FOTO \\
\hline $\begin{array}{c}\text { TOMATE RAF } \\
\text { O } \\
\text { MUCHAMIEL }\end{array}$ & $\begin{array}{l}\text { Es una variedad resistente al ataque } \\
\text { de Fusarium. } \\
\text { Su tasa de producción de etileno, en } \\
\text { el momento de la cosecha, es de } 790 \\
\pm 41 \text { nmol/kg } \times \text { h. Mientras que su } \\
\text { tasa de respiración es de } 126 \pm 17 \\
\mu m o l / k g \text { x h. Ambas tasas son } \\
\text { ligeramente inferiores a otras } \\
\text { variedades dentro del tomate Raf, } \\
\text { como es la variedad Méndez. Sin } \\
\text { embargo, la concentración y } \\
\text { producción de etileno es mucho más } \\
\text { alta en esta variedad, que en tomates } \\
\text { en rama (Tasa producción de etileno: } \\
0,25 \text { nmol/kg } \times \text { s). } \\
\text { Una vez envasado en flow pack, en } \\
\text { film de PP macroperforado, la } \\
\text { concentración de etileno es mucho } \\
\text { mayor, del orden de } 70 \mu \mathrm{L} / \mathrm{L} \text {. } \\
\text { Según estudios, este fruto responde } \\
\text { bien a sistemas de adsorción de } \\
\text { etileno para alargar su vida útil. }\end{array}$ & $\begin{array}{l}\text { Bailén et al., 2013; } \\
\text { Domínguez et al., } 2016\end{array}$ & \\
\hline $\begin{array}{l}\text { TOMATE } \\
\text { CHERRY }\end{array}$ & $\begin{array}{l}\text { Por sus características } \\
\text { organolépticas esta variedad de } \\
\text { tomate se consume tanto en snack } \\
\text { como en ensalada. } \\
\text { Su tasa de producción de etileno es } \\
\text { del orden de } 0,13 \mu \mathrm{L} / \mathrm{kg} \times \mathrm{h} \text {, mientras } \\
\text { que su tasa de producción de } \mathrm{CO}_{2} \text { es } \\
\text { de } 11 \mu \mathrm{L} \text { de } \mathrm{CO}_{2} / \mathrm{g} \times \mathrm{h} \text {. } \\
\text { Esta variedad de tomate responde } \\
\text { bien a sistemas de envasado activo } \\
\text { de control de etileno, mediante la } \\
\text { fotodegradación o absorción del } \\
\text { etileno, para extender la vida útil. } \\
\end{array}$ & Kaewklin et al., 2018 & \\
\hline $\begin{array}{l}\text { TOMATE EN } \\
\text { RAMA }\end{array}$ & $\begin{array}{l}\text { La producción de etileno de esta } \\
\text { variedad es de } 0,03 \mathrm{nmol} / \mathrm{kg} \times \mathrm{s} \text { y su } \\
\text { tasa de respiración, del orden de } 12 \\
\mathrm{~mL} \mathrm{CO} / \mathrm{kg} \times \mathrm{h} \text {. }\end{array}$ & Domínguez et al., 2016 & \\
\hline $\begin{array}{l}\text { TOMATE } \\
\text { ROMA }\end{array}$ & $\begin{array}{l}\text { Es la variedad más usada para la } \\
\text { elaboración de ensaladas junto con } \\
\text { la variedad pera. } \\
\text { Su tasa de respiración es del orden } \\
\text { de } 24 \mathrm{~mL} \mathrm{CO}_{2} / \mathrm{kg} \times \mathrm{h} \text {. } \\
\text { Su tasa de producción de etileno es } \\
\text { de } 3 \mu \mathrm{L} / \mathrm{kg} \times \mathrm{h} \text {. }\end{array}$ & $\begin{array}{l}\text { Báez-Sañudo et al., } \\
2018\end{array}$ & \\
\hline $\begin{array}{c}\text { TOMATE } \\
\text { PERA }\end{array}$ & $\begin{array}{l}\text { Esta variedad tiene una actividad } \\
\text { respiratoria más elevada que } \\
\text { variedades como Cherry y tomate en } \\
\text { rama, que se manifiesta a través de } \\
\text { una mayor pérdida de peso durante } \\
\text { la conservación, incluso con la } \\
\text { incorporación de absorbedores de } \\
\text { etileno. }\end{array}$ & Kostekli et al., 2016 & \\
\hline
\end{tabular}




\subsubsection{Problemas de conservación del tomate fresco a granel.}

Normalmente la alteración de la calidad del tomate fresco se debe principalmente al ataque microbiano y al avance en el proceso de senescencia, que puede ir acompañado por un aumento de la tasa respiratoria y emisión de etileno, y que puede agravarse por cualquier daño mecánico sufrido por el fruto (Aguayo-Giménez, 2003).

Los factores que más influyen en la alteración del tomate, después de la cosecha, son los fisiológicos (relacionados con la madurez y la actividad respiratoria), los físicos (ligados a daños mecánicos) y los biológicos. Estos últimos se refieren a la presencia de una microbiología alterante sobre la superficie del producto, que prolifera con facilidad a elevadas temperaturas y $\mathrm{HR}$, por lo que se recomienda que, para combatirla, se reduzca cuanto sea posible la temperatura y se gestione bien la HR, evitando condensaciones (Arcentales et al., 2019). Los hongos alterantes de la calidad del tomate son principalmente: Alternaria sp., que es relativamente resistente a fungicidas, Rhizophus sp., frecuente sobre todo cuando se producen condensaciones de agua en la superficie del producto y Geotrichum sp., Phytophora infestans y Fusarium sp. Estas condensaciones se producen cuando se mantienen niveles altos de HR durante la conservación del tomate. Pero estas HR elevadas son necesarias si no se quiere que se deshidraten los tomates. También, aunque con mucha menor frecuencia, se encuentran hongos de herida de los géneros Cladosporium, Penicillium, Aspergillus, Colletotrichum y Sclerotinia. La podredumbre blanda bacteriana por Erwinia sp. aparece también ocasionalmente cuando no se aplica un adecuado lavado desinfectante superficial del fruto (Martínez-Ruiz, 2016).

Las condiciones óptimas de conservación del tomate deben controlar diferentes factores, como la tasa de respiración del producto, el calor de respiración, la tasa de producción de etileno, la temperatura y la Humedad Relativa (HR), y la concentración de los gases de respiración (Wilson et al., 1995).

El tomate experimenta una serie de cambios fisiológicos y morfológicos a medida que el fruto se va desarrollando. Estos cambios incluyen la aparición del color rojo (debido a la síntesis del licopeno y a la pérdida de clorofila), ablandamiento, pérdida de peso, aumento en la respiración del fruto y por tanto un aumento en la producción de etileno $\left(\mathrm{C}_{2} \mathrm{H}_{4}\right)$ (Radzevičius et al., 2009; Shewfelt et al., 1988; Tiejin, 2001; Valero y Serrano, 2010). En efecto, la respiración, la transpiración y la producción de $\mathrm{C}_{2} \mathrm{H}_{4}$ son tres factores principales que contribuyen al deterioro de la calidad de frutas y verduras después de la cosecha (Gonzalez-Aguilar, 2010; Bennett y Labavitch, 2010). 
El tomate es un fruto climatérico y, por tanto, su maduración se acompaña de un pico en la respiración y una elevada tasa de producción de $\mathrm{C}_{2} \mathrm{H}_{4}$. Existe una relación inversa entre la tasa de respiración y la vida útil de la fruta fresca, por lo que la respiración del fruto es importante para determinar su vida útil (Mangaraj y Goswami, 2011). El tomate puede sufrir diversos daños durante la cosecha, clasificación, envasado, transporte y almacenamiento que pueden conducir a cambios en la tasa de respiración y producción de $\mathrm{C}_{2} \mathrm{H}_{4}$. La respiración es un proceso metabólico muy importante en las células vivas y es la responsable de la producción de energía necesaria para el crecimiento y mantenimiento de la organización celular. La tasa de producción de $\mathrm{C}_{2} \mathrm{H}_{4}$ de frutas y verduras, es una actividad fisiológica importante en postcosecha y también afecta a la vida útil del producto durante su almacenamiento (Tiejin, 2001). En este sentido, el tomate produce cantidades moderadas de $\mathrm{C}_{2} \mathrm{H}_{4}$ que oscila entre $1 \mu \mathrm{L}$ y $10 \mu \mathrm{L} / \mathrm{kg} \times \mathrm{h}$ a $20 \stackrel{\circ}{-}$ y es muy sensible a la exposición del $\mathrm{C}_{2} \mathrm{H}_{4}$. Niveles de $\mathrm{C}_{2} \mathrm{H}_{4}$ por debajo de los 0,5 $\mu \mathrm{L} / \mathrm{L}$ son suficientes para desarrollar la maduración del fruto y otros procesos metabólicos asociados (Abeles et al., 1992). En la industria hortícola, para promover una maduración uniforme de tomates verdes se mantienen a $20-21{ }^{\circ} \mathrm{C}$ con un $90 \%$ de $\mathrm{HR}$ y $50 \mu \mathrm{L} / \mathrm{L}$ de $\mathrm{C}_{2} \mathrm{H}_{4}$ (Kubai, 2016).

La producción de $\mathrm{C}_{2} \mathrm{H}_{4}$ varía en función de la variedad, de la manipulación y procesado que sufra el fruto y de las condiciones de almacenamiento. Distintos autores han realizado estudios sobre la determinación de la tasa respiratoria en frutos enteros o en rodajas, comparando resultados y obteniendo conclusiones como que el producto procesado presenta mayor tasa de respiración que el producto intacto, tal como ponen de manifiesto Abdul-Baki et al. (1996) para el caso de judías verdes, pepinos, kiwis, plátanos, melocotón, lechugas y zanahorias. En tomate, las diferencias entre el producto entero y en rodajas empiezan a observarse a partir de los $5 \stackrel{\circ}{\circ}$, donde el tomate en rodajas presenta una mayor tasa de respiración en comparación con el tomate entero. Además, aquella aumenta conforme aumenta la temperatura, lo que hace que aumente el deterioro del producto (Tabla 2) (Aguayo-Giménez, 2003).

Tabla 2. Tasa respiratoria ( $\mathrm{mg} \mathrm{CO} / \mathrm{Kg} \times \mathrm{h}$ ) en tomates enteros y en rodajas almacenados a varias temperaturas (Adaptada de Aguayo-Martínez, 2003)

\begin{tabular}{|c|c|c|c|c|}
\hline Temperatura ( $\stackrel{-}{ } \mathbf{C})$ & 0 & 5 & 10 & 20 \\
\hline Tomate Entero & 1,6 & 2,3 & 4,7 & 20,2 \\
\hline Tomate Rodajas & 1,4 & 3 & 10 & 35 \\
\hline
\end{tabular}


Con la tasa de producción de $\mathrm{C}_{2} \mathrm{H}_{4}$ ocurre prácticamente lo mismo que para la tasa de respiración, ya que aumenta con la temperatura. Según Cantwell y Suslow (2012), la tasa de producción de $\mathrm{C}_{2} \mathrm{H}_{4}$ del tomate, conservado a dos temperaturas, es la siguiente (Tabla 3):

Tabla 3. Tasa producción de $\mathrm{C}_{2} \mathrm{H}_{4}(\mu \mathrm{L} / \mathrm{Kg} \times \mathrm{h})$ en tomates enteros almacenados a dos temperaturas (A partir de datos de Cantwell y Suslow, 2012)

\begin{tabular}{|c|c|c|}
\hline Temperatura $(\stackrel{\circ}{\circ})$ & 10 & 20 \\
\hline Producción de $\mathbf{C}_{2} \mathbf{H}_{4}$ & $1,2-1,5$ & $4,3-4,9$ \\
\hline
\end{tabular}

En efecto, el tomate es un producto hortícola muy sensible a los daños por frío, aunque depende del estado de madurez y la duración de la aplicación de una determinada temperatura. En general, estos daños ocurren cuando el tomate es expuesto a temperaturas menores de $10^{\circ} \mathrm{C}-13^{\circ} \mathrm{C}$, durante un tiempo prolongado, y se manifiestan con la aparición de un punteado sobre la superficie (Báez et al., 1998). La tolerancia y la sensibilidad de un fruto al daño por frío dependen de la variedad, especie y cultivar, del estado de desarrollo del producto (a mayor madurez, mayor daño por frío), de la temperatura a la cual el producto es almacenado (puesto que a menor temperatura, mayor es el daño por frío) y por último, el período de exposición a temperaturas de refrigeración (Hong y Gross, 2000).

De lo anterior se deduce el interés del envase activo antimicrobiano que controle el desarrollo de la microbiología superficial en el tomate, ya que es necesario utilizar HR elevadas en su conservación.

Para conseguir un aumento de la vida útil del tomate fresco se ha propuesto el uso del envasado en atmósfera modificada, así como el uso de recubrimientos comestibles a base de compuestos naturales que consiguen prolongar la vida del fruto y mantener su calidad. Además, la aplicación de estos recubrimientos tiene valor añadido ya que son portadores de ingredientes con propiedades activas como son los antioxidantes, antimicrobianos y nutracéticos (Báez-Sañudo et al., 2018; Guerrero, 2017). Barco et al. (2011) desarrollaron un recubrimiento comestible a base de almidón modificado de yuca a diferentes concentraciones para su evaluación en la conservación de frutos de tomate. Después de 20 días de almacenamiento se observó que, a medida que el porcentaje de almidón de yuca era mayor, la tasa de respiración disminuía, aumentando así la vida útil del fruto.

También se han desarrollado envases plásticos activos antimicrobianos, pero que no son de aplicación cuando el tomate fresco viene envasado a granel, en cajas de cartón 
por ejemplo, ya que estas soluciones de envasado activo incrementan demasiado los costes del producto. Además, el uso excesivo de plásticos provoca un impacto medioambiental muy severo (García-García et al., 2012; Choi et al., 2015; Otoni et al., 2016; Shemesh et al., 2016).

\subsubsection{Importancia económica del tomate fresco en España y en la Región de} Murcia.

España es uno de los países más importantes a nivel mundial en cuanto a producción y exportación hortofrutícola. Muestra de ello son las cifras que se comentan a continuación para tomate fresco.

La producción mundial de tomate ha batido su récord histórico al alcanzar la cifra de 170.750.000 t en 2017, según datos de la base estadística de la Organización de las Naciones Unidas para la Agricultura y la Alimentación (FAOSTAT, 2017). China sigue encabezando la lista de productores de esta hortaliza llegando, en 2017, a un volumen total de $59.514 .773 \mathrm{t}$, el $31,8 \%$ del total mundial. El segundo productor mundial es India con un volumen de 20.700 .000 t de tomate, le sigue Turquía con 12.750 .000 t y por último EEUU con 10.910.990 t (FAOSTAT, 2017). España ocupa la octava posición en este ranking, con un volumen de producción de 5.163.446 t, pero es la primera a nivel europeo y la tercera a nivel mundial en importancia económica de sus exportaciones (Tabla 4) (FAOSTAT, 2016).

Tabla 4. Mayores productores de tomate a nivel mundial en el año 2017

(A partir de datos de FAOSTAT, 2017)

\begin{tabular}{|c|c|c|c|}
\hline País & Posición & $\begin{array}{c}\text { Volumen Producción } \\
\text { (toneladas) }\end{array}$ & $\%$ \\
\hline China & 1 & 59.514 .773 & 31,8 \\
\hline India & 2 & 20.700 .000 & 11,4 \\
\hline Turquía & 3 & 12.750 .000 & 7,0 \\
\hline EE.UU & 4 & 10.910 .990 & 6,0 \\
\hline España & 8 & 5.163 .446 & 2,8 \\
\hline
\end{tabular}

La producción total de tomate en España en el año 2017 fue de 495,4 miles de t, de las cuales Andalucía y Extremadura son las CC.AA más significativas, con un volumen de producción de 2.302 y 2.075 miles de t respectivamente. Quedando Murcia en la tercera posición con un volumen de producción de 211,3 miles de t (Tabla 5). 
Tabla 5. Producción de tomate, expresada en miles de toneladas, en España por Comunidades Autónomas (CC.AA), en el año 2017 (A partir de datos de Statista, 2017)

\begin{tabular}{|c|c|c|}
\hline Comunidad Autónoma & Posición & Volumen Producción \\
\hline Andalucía & 1 & 2.302 \\
\hline Extremadura & 2 & 2.075 \\
\hline Murcia & 3 & 211,3 \\
\hline Navarra & 4 & 148 \\
\hline Galicia & 5 & 93,1 \\
\hline
\end{tabular}

En 2018, España ha exportado 812.570 t de tomate fresco, un 3,53\% más que en 2017. Alemania es el país que mejor ha pagado los tomates a España (1,285 €/kg de tomate), un $12,62 \%$ más que la media, por tanto Alemania ocupa la primera posición de este ranking.

Francia ha sido el segundo mayor comprador de tomate español, con un volumen de 127.284 t. Reino Unido ocupa la tercera posición entre los clientes del tomate español, con un volumen de $112.025 \mathrm{t}$; mientras que la cuarta posición la ocupa Holanda con $102.541 \mathrm{t}$ (Tabla 6) (Statista, 2018).

Tabla 6. Exportación española de tomate, expresada en toneladas, en el año 2018, a nivel mundial (A partir de datos de Statista, 2018)

\begin{tabular}{|c|c|c|}
\hline País & Posición & Volumen Exportación \\
\hline Alemania & 1 & 196.003 \\
\hline Francia & 2 & 127.284 \\
\hline Reino Unido & 3 & 112.025 \\
\hline Holanda & 4 & 102.541 \\
\hline
\end{tabular}

Se trata de un sector muy profesional y tecnificado que exporta en torno al $80 \%$ de su producción, principalmente a Europa. Almería ha sido la provincia española que más tomate ha vendido en la UE con un total de 537.600 t, un 59,23\% sobre el global. La segunda provincia ha sido Murcia con 98.370 t, en tercer lugar, figura Granada con 78.530 t, Las Palmas de Gran Canaria ocupa la cuarta posición con 48.680 t y en el quinto escalón se encuentra Alicante con un volumen de 38.750 t (Estacom, 2017) (Tabla 7). 
Tabla 7. Exportación española, expresada en toneladas, de tomate por provincias en el año 2017

(A partir de datos de Estacom, 2017)

\begin{tabular}{|c|c|c|}
\hline Provincias & Posición & Volumen Exportación \\
\hline Almería & 1 & 537.600 \\
\hline Murcia & 2 & 98.370 \\
\hline Granada & 3 & 78.530 \\
\hline Las Palmas & 4 & 48.680 \\
\hline Alicante & 8 & 38.750 \\
\hline
\end{tabular}

La Región de Murcia es una de las principales productoras de tomate en el ámbito nacional e internacional, debido a sus condiciones climáticas y de suelo. La cosecha de tomate en la Región de Murcia en 2018 fue de 260.084 t, lo que equivale a un aumento del 3,81\% respecto a la campaña anterior. La Región de Murcia exportó el pasado año un total de 98.370 t, siendo los principales destinatarios: Francia (25.000 t), Reino Unido $(23.300$ t) y Alemania (19.900 t) (EARM, 2017-2018).

Es interesante poner de manifiesto que la mayor parte de esta exportación de tomate se hace con envasado a granel, y principalmente en cajas de cartón de distintos formatos (por ejemplo, en cajas de $30 \times 40 \mathrm{~cm}$ o en cajas de $40 \times 60 \mathrm{~cm}$ ) (Almeida et al., 2014).

\subsection{PIMIENTO FRESCO.}

\subsubsection{Cultivo.}

El pimiento dulce (Capsicum annuum L.) es una especie de planta herbácea del género Capsicum, perteneciente a la familia Solanácea. La planta del pimiento es originaria de México, Bolivia y Perú, donde además del Capsicum annumm L., especie más importante, se cultivan otras cuatro especies del género Capsicum: C. frutescens, C. baccatum., C. chinenese y C. pubescens (Elibox et al., 2015).

Los pimientos llegaron a Europa en el primer viaje realizado por Colón en el año 1493 a América. Los indígenas americanos conocían el fruto por el nombre de chili, pero los españoles y portugueses lo bautizaron con los nombres de pimiento y pimiento de Brasil, respectivamente. La introducción del pimiento en Europa supuso un avance importante en las costumbres culinarias debido a que se empleaba como complemento de una especia muy popular, la pimienta negra. De hecho, llegó incluso a sustituirla. Su consumo en Europa data de hace varios siglos. Sin embargo las variedades de 
pimientos grandes, suaves y poco picantes que se consumen en la actualidad se consiguieron a principios del siglo XX gracias a los cultivos intensivos (Infoagro, 2017).

Se cultivan en todo tipo de terrenos con preferencia por las zonas húmedas, soportan muy bien las altas temperaturas $\left(30^{\circ} \mathrm{C}-40^{\circ} \mathrm{C}\right)$, pero son sensibles al frío. Por esta razón, su cultivo tiene lugar en el período que transcurre de verano a otoño, aunque gracias a la producción en invernadero están disponibles en el mercado durante todo el año (Infoagro, 2017).

El pimiento se cultiva en invernaderos en todo el mundo. En el Mediterráneo, constituye uno de los cultivos principales, que puede situarse inmediatamente después del tomate en la mayoría de los países, a excepción de Túnez, donde el pimiento dulce y la paprika ocupan el $55 \%$ de la superficie total de invernadero (FAO, 2002).

La mayoría de las especies de pimiento se podrían llevar al mercado aún verdes, porque adquieren la coloración amarilla o roja si se les deja en la planta hasta la maduración completa. Hay una gran diversidad de variedades de pimiento dulce que tienen distintos colores, formas y sabores, cualidades que son muy apreciadas en este producto fresco. El cierto picor de algunas variedades es debido a la presencia de la capsaicina (Finger y Pereira, 2016).

\subsubsection{Importancia nutricional.}

Los pimientos poseen propiedades beneficiosas para la salud debido a su composición. Son alimentos ricos en fibra, folatos, vitaminas y antioxidantes. El pimiento es una hortaliza con un valor energético muy bajo, que supone aproximadamente $27 \mathrm{Kcal} / 100$ g. Tiene unas características nutritivas muy importantes, ya que, aunque su contenido en lípidos, proteínas e hidratos de carbono no sea muy elevado, sí lo es el de minerales y vitaminas. Su contenido en agua ronda el $92 \%$ del peso total, seguido de los hidratos de carbono. Son una buena fuente de carotenos, como la capsantina, pigmento con propiedades antioxidantes que aporta el característico color rojo a algunos pimientos (FEN, 2016).

\subsubsection{Variedades.}

Los tipos de pimiento se clasifican por su tamaño y por su sabor: dulce o picante. Casi todas las variedades en Europa pertenecen a la especie de Capsicum annumm. Lo que resulta interesante es que la mayor parte de las variedades no se han perdido, ya que en mayor o menor medida se siguen cultivando en diferentes regiones de España. Las principales variedades de pimiento cultivadas en España se muestran en la Tabla 8 (eldiario, 2019). 
Tabla 8. Variedades de pimiento más consumidos en España (A partir de datos recogidos en la revista eldiario.es)

\begin{tabular}{|c|c|c|c|}
\hline VARIEDAD & CARACTERÍSTICAS & REFERENCIA & FОTо \\
\hline $\begin{array}{c}\text { PIMIENTO } \\
\text { CALIFORNIA }\end{array}$ & $\begin{array}{l}\text { Esta variedad de pimiento es la más rica } \\
\text { en vitamina } \mathrm{C} \text {, si se compara con los } \\
\text { pimientos Lamuyo e italiano. } \\
\text { Su actividad respiratoria es del orden de } \\
196,9 \pm 18,5 \mathrm{mg} / \mathrm{kg} \times \mathrm{h} \text { a temperatura } \\
\text { ambiente y después de la cosecha. Sin } \\
\text { embargo, la tasa de producción de etileno } \\
\text { es } 179 \pm 10,2 \mathrm{mg} / \mathrm{kg} \times \mathrm{h} \text {. } \\
\text { La actividad respiratoria de esta variedad } \\
\text { es menor que en la variedad Lamuyo. }\end{array}$ & $\begin{array}{l}\text { Guil-Guerrero et al., } \\
2006 . \\
\text { González-Saucedo et } \\
\text { al., } 2019\end{array}$ & \\
\hline $\begin{array}{l}\text { PIMIENTO } \\
\text { ITALIANO }\end{array}$ & $\begin{array}{l}\text { El contenido total de ascorbato es del } \\
\text { orden de } 1000-1200 \mathrm{\mu g} / \mathrm{g} \text { fruto, y es } \\
\text { relativamente estable durante los primeros } \\
\text { días de cosecha. Este contenido es similar } \\
\text { a las distintas variedades de pimiento } \\
\text { dulce (California, Lamuyo). Aunque } \\
\text { durante la conservación aumenta más en } \\
\text { los frutos rojos que en los verdes. }\end{array}$ & Palma et al., 2011 & \\
\hline $\begin{array}{l}\text { PIMIENTO } \\
\text { LAMUYO }\end{array}$ & $\begin{array}{l}\text { La actividad respiratoria en aire es de } 15- \\
22 \mathrm{mg} \mathrm{CO}_{2} / \mathrm{kg} \times \mathrm{h} \text { a } 8^{\circ} \mathrm{C} \text {. } \\
\mathrm{La} \text { emisión de etileno es inferior a } 0,05 \\
\mu \mathrm{L} / \mathrm{kg} \times \mathrm{h} \text {, al igual que en variedad } \\
\text { California. }\end{array}$ & $\begin{array}{c}\text { Escalona-Contreras et } \\
\text { al., } 2004\end{array}$ & \\
\hline
\end{tabular}

\subsubsection{Problemas de conservación del pimiento dulce fresco a granel.}

Los microorganismos más comunes que afectan al pimiento y limitan su conservación y vida útil son Botrytis cinerea, Alternaria alternata y podredumbres blandas de origen bacteriano y fúngico. Las podredumbres blandas se producen sobre todo cuando se ha llevado a cabo un lavado o un pre-enfriamiento mediante la técnica de hydrocooling, enfriamiento con agua fría, y no se ha realizado una desinfección adecuada con algún agente antimicrobiano (Rodoni et al., 2017). En efecto, durante el almacenamiento refrigerado del pimiento, del orden del $40 \%$ de las pérdidas pueden ser originadas por los hongos Alternaria alternata, Rhizophus stolonifer, y Botrytis cinerea, y las bacterias como Erwinia carotovora (León-Mendoza, 2017). 
Al contrario que el tomate, el pimiento tiene una tasa de respiración y de producción de $\mathrm{C}_{2} \mathrm{H}_{4}$ relativamente baja, y una vez recolectado sigue su proceso hasta su completa senescencia, respirando y sufriendo cambios en el color verde por disminución de la concentración de clorofila (Reche, 2010). El pimiento ha sido clasificado como fruto no climatérico por su patrón de producción de $\mathrm{CO}_{2}$ y $\mathrm{C}_{2} \mathrm{H}_{4}$. No obstante, este comportamiento no es el mismo en todas las variedades de Capsicum, ya que se han identificado algunas variedades que muestran un comportamiento similar al climatérico (Tan et al., 2012). El pimiento produce niveles muy bajos de $\mathrm{C}_{2} \mathrm{H}_{4}$, por lo que debe alcanzar el color deseado en la planta. Para acelerar la maduración o el cambio de color, lo más efectivo es mantener los pimientos con una coloración parcial a temperaturas tibias de $20 \stackrel{\circ}{\circ}-25 \stackrel{\circ}{\circ}$ y una HR elevada, superior al $95 \%$ (Tan et al., 2012).

La mayor producción de $\mathrm{C}_{2} \mathrm{H}_{4}$ se produce en los estadios más tempranos de maduración del fruto (cuando este está verde maduro) hasta que el fruto tiene aproximadamente el $30-40 \%$ de su superficie roja. A partir de ahí, la producción de $\mathrm{C}_{2} \mathrm{H}_{4}$ va disminuyendo conforme el fruto va alcanzando el estado más maduro de hasta casi el $100 \%$ de su superficie es roja. Por lo que la producción de $\mathrm{C}_{2} \mathrm{H}_{4}$ de este fruto está relacionada con la velocidad de maduración del mismo. Los frutos de las variedades que viran a rojo y maduran más rápidamente producen más $\mathrm{C}_{2} \mathrm{H}_{4}$ que las variedades que viran y maduran más lentamente (Villegas-Martínez, 2018).

La tasa de respiración máxima de los pimientos se observa inmediatamente después de la cosecha, con un valor entre 30-36 $\mathrm{mg} \mathrm{CO}_{2} / \mathrm{kg} \times \mathrm{h}$, y a partir de ahí los frutos disminuyen progresivamente su tasa de respiración durante la conservación postcosecha (20-25 mg CO $2 /$ kg x h) (Villegas-Martínez, 2018). En otras investigaciones también han llegado a la conclusión de que la producción de $\mathrm{CO}_{2}$ en frutos de pimiento cosechadas en estado verde maduro es más elevada que en otros estadios de maduración. Además, la producción de $\mathrm{CO}_{2}$ va disminuyendo a lo largo de la maduración postcosecha, alcanzando los valores más bajos cuando el fruto ha virado a color rojo (Villavicencio et al., 2001).

Debido a la gran diversidad del género Capsicum es difícil generalizar, pero las variaciones en la tasa de producción de $\mathrm{C}_{2} \mathrm{H}_{4}$ y en la tasa de respiración dependen mucho de las condiciones de manipulación, envasado y almacenado durante la postcosecha (Andrews, 1995; Villavicencio et al., 1999).

El pimiento dulce es altamente perecedero y necesita un apropiado manejo postcosecha para mantener la calidad y una adecuada vida útil. Este debe ser enfriado lo más rápidamente posible tras la recolección hasta temperaturas inferiores a $12 \stackrel{\circ}{\mathrm{C}}$, para 
reducir posibles pérdidas de agua. El uso de una HR elevada es un parámetro muy utilizado para extender la vida útil de los pimientos cuando se envasan en film de plástico. Pero, una excesiva HR origina condensaciones de agua en la superficie del pimiento pudiendo aumentar el riesgo de que el pimiento se deteriore por desarrollo microbiano (Pandey y Goswami, 2012; Singh et al., 2014). En efecto, la vida útil del pimiento dulce viene limitada sobre todo por un deterioro debido al desarrollo de microorganismos si la HR es elevada, o por el deterioro debido a la pérdida de agua durante el almacenamiento en condiciones de humedad demasiado bajas, y al hecho de que es susceptible de sufrir daños por frío (Rodoni et al., 2017). A temperaturas inferiores a $7 \stackrel{\circ}{\circ} \mathrm{C}$ los pimientos pueden sufrir daños por frío, mientras que las temperaturas superiores pueden dar lugar a pérdidas de peso, por deshidratación, y al crecimiento microbiano.

Para disminuir estos problemas de conservación se han propuesto distintas soluciones de envasado en atmósfera modificada, pero esta solución incrementa los costes y disminuye la competitividad en el mercado internacional que prefiere el simple envasado a granel en cajas de cartón. Además, el comportamiento del pimiento envasado en plástico en atmósfera modificada es desigual en función de los tipos de pimiento (Tipo Dulce Italiano, California o Lamuyo). Así, incluso el envasado en atmósfera modificada y con baja temperatura de $5{ }^{\circ} \mathrm{C}$ puede que no impida el desarrollo de podredumbres en el pimiento fresco (Granja-Carvajal, 2016).

Se han propuesto otras soluciones de envasado activo, como la que incorpora dentro del envase bolsitas con material adsorbente de la humedad, pero, aunque puede aumentar la vida útil de una manera significativa (7 días más que si se usa sólo atmósfera modificada), incrementa el coste del envase de modo prohibitivo. Además, el consumidor no suele querer que haya presencia de materiales extraños dentro del envase. También, se han propuesto recubrimientos comestibles con agentes antimicrobianos sobre el pimiento, pero este tratamiento también encarece el producto y debe ser declarado como aditivo, y esto es un inconveniente en el mercado de pimiento fresco a granel (Ali et al., 2015). Otros trabajos, como el de Glowacz et al. (2015) y Glowacz y Rees (2016), proponen la aplicación continua de ozono durante la conservación refrigerada pero tampoco ha dado resultados concluyentes que indiquen mejora de la vida útil del pimiento con este sistema de conservación.

Por todo lo anterior, se recomienda que la conservación refrigerada del pimiento se realice con temperaturas comprendidas entre $8{ }^{\circ} \mathrm{C}$ y $10 \stackrel{\circ}{ } \mathrm{C}$, y HR cercana al $90 \%$, para mantenerlos frescos y tersos durante aproximadamente 14 días, aunque en estas 
condiciones también se pueden producir alteraciones causadas por hongos y bacterias. Durante el transporte refrigerado en camión también se recomiendan esas condiciones de temperatura y HR. Si el transporte dura menos de 2 días, puede aguantar temperaturas alrededor de los $5 \stackrel{\circ}{\circ} \mathrm{C}$ con una HR del 85-95\%. Pero si el transporte es de mayor duración, a esa temperatura hay riesgo de daños por frío sobre todo en los pimientos de color verde que son más sensibles que los de color rojo (Rodoni et al., 2017).

\subsubsection{Importancia económica del pimiento dulce fresco en España y en la Región} de Murcia.

La producción mundial de pimiento ha superado por primera vez en la historia los 32.985.000 t, según los datos procedentes de FAOSTAT (2017). En concreto, en el año 2017 hubo una producción mundial de 34.496 .000 de t de pimiento, un 1,56\% más que el año anterior, y un $25,78 \%$ más que diez años atrás.

Entre los cinco mayores productores mundiales de pimiento (China, México, Turquía, Indonesia e India), se obtiene el $74 \%$ de la cosecha mundial de esta hortaliza. De entre ellos destaca China con un volumen de 18.109.346 t de la producción mundial, México produce 3.538.240 t, Turquía 2.624.527 t, Indonesia e India 2.359.411 t y 2.163.892 t respectivamente (Tabla 9) (FAOSTAT, 2017).

Tabla 9. Mayores productores de pimiento a nivel mundial en el año 2017.

(A partir de datos de FAOSTAT, 2017)

\begin{tabular}{|c|c|c|c|}
\hline País & Posición & $\begin{array}{c}\text { Volumen Producción } \\
\text { (toneladas) }\end{array}$ & $\%$ \\
\hline China & 1 & 18.109 .346 & 44,5 \\
\hline México & 2 & 3.538 .240 & 8,2 \\
\hline Turquía & 3 & 2.624 .527 & 6,4 \\
\hline Indonesia & 4 & 2.359 .411 & 5,8 \\
\hline India & 5 & 2.163 .892 & 5,3 \\
\hline España & 6 & 1.283 .546 & 3,2 \\
\hline
\end{tabular}

En cuanto a la producción de pimiento, España es el primer país productor de la Unión Europea, con un volumen de 1.274.200 t. Andalucía (Almería: 732.120 t) ocupa la primera posición, seguida de Murcia, Galicia, Extremadura, Comunidad Valenciana y Navarra (Tabla 10) (Statista, 2017). 
Tabla 10. Producción de pimiento, en toneladas, en España por Comunidades Autónomas (CC.AA), en el año 2017 (A partir de datos de Statista, 2017)

\begin{tabular}{|c|c|c|}
\hline Comunidad Autónoma & Posición & Volumen Producción \\
\hline Andalucía & 1 & 797.700 \\
\hline Murcia & 2 & 165.800 \\
\hline Galicia & 3 & 72.900 \\
\hline Extremadura & 4 & 6.100 \\
\hline Comunidad Valenciana & 5 & 5.900 \\
\hline Navarra & 6 & 4.320 \\
\hline
\end{tabular}

El volumen total de pimiento exportado en España, en 2016, fue de 715.574 t, un 93,57\% más que hace diez años, cuando la exportación española de pimiento fue de $379.050 \mathrm{t}$, siendo los principales países que importan pimiento: Alemania, Francia, Países Bajos, Reino Unido e Italia (FAOSTAT, 2018).

\subsection{PROBLEMAS DE SEGURIDAD ALIMENTARIA EN PRODUCTOS} FRESCOS.

En las verduras frescas, como los tomates y pimientos frescos, que se utilizan simplemente lavados en ensaladas sin cocinar previamente el producto, se pueden encontrar patógenos, debido a contaminaciones durante la recolección, operaciones postcosecha o durante las etapas de almacenamiento refrigerado y distribución (Mahmoud, 2010; Oliveira et al., 2010). Así, por ejemplo, la contaminación microbiana de tomates frescos enteros ha sido la causa de brotes de salmonelosis (Moreira et al., 2012; Niemira y Boyd, 2013). Salmonella typhimurium es un agente causal de la salmonelosis no tifoidea y se sabe que puede crecer en la superficie de los tomates a bajas temperaturas de conservación (Gurtler et al., 2012). Además, la mala manipulación postcosecha, así como la ruptura de la cadena de frío y el uso de envases inadecuados, pueden dar como resultado grandes pérdidas debido al desarrollo de la microbiología alterante. Por lo tanto, para poder satisfacer la demanda del mercado, en cuanto a mejora de la calidad microbiológica y aumento de la vida útil de los tomates y/o pimientos frescos, se debe controlar el crecimiento microbiano durante el envasado y almacenamiento refrigerado (Choi et al., 2015).

Durante la manipulación postcosecha de las hortalizas frescas previo al envasado, se lleva a cabo normalmente un tratamiento de descontaminación superficial con agua clorada. Esta es la única etapa donde se puede reducir el número de patógenos y 
microorganismos causantes de deterioro. Sin embargo, los compuestos clorados pueden reaccionar con la materia orgánica de los productos frescos y formar trihalometanos y ácidos haloacéticos, que son moléculas mutagénicas y carcinogénicas (São José y Vanetti, 2012; Choi et al., 2015).

Por todo lo anterior, en los últimos años, se ha trabajado en sistemas de descontaminación superficial de hortalizas que no utilicen agua clorada, y se han investigado sistemas de envasado activo antimicrobiano para reducir la microbiología alterante que provoca cuantiosas pérdidas económicas en la comercialización de frutas y hortalizas frescas, y para aumentar la seguridad alimentaria de estos productos, que en muchas ocasiones, se consumen sin lavar o con un lavado muy ligero con poca acción antimicrobiana (Van Long et al., 2016). Así, Shemesh et al. (2016) desarrollaron un tipo de plástico activo antimicrobiano que utiliza AEs nanoencapsulados en nanotubos de un aluminosilicato que es eficaz en el control de Alternaria alternata, Botrytis cinerea, Penicillium digitatum, Penicillium expansum y Aspergillus niger en distintas frutas y hortalizas, incluyendo el tomate.

\subsection{ENVASADO DE FRUTAS Y HORTALIZAS FRESCAS ENTERAS.}

Las frutas y verduras frescas deben satisfacer las demandas de los consumidores, al mismo tiempo que se debe garantizar la calidad y seguridad de las mismas (Brandwein et al., 2016). En la actualidad, el envasado es una parte esencial de la gestión y logística de los productos frescos puesto que su objetivo principal es el de contener y proteger estos productos, facilitando su manipulación durante las tareas de carga, descarga, transporte, almacenamiento y comercialización (Martínez-Tenorio y López-Malo, 2011)

La mayoría de los productos agrícolas frescos son comercializados en envases o cajas, a granel, con pesos comprendidos entre los $5 \mathrm{~kg}$ y $25 \mathrm{~kg}$ hasta el punto de venta final. Otros productos se transportan en sacos de $25 \mathrm{~kg}$ a $50 \mathrm{~kg}$ y para el caso de las verduras de hoja grande verde, como las acelgas, se comercializan en manojos en cajas. Otra forma de envasado, normalmente llevada a cabo en países desarrollados, consiste en seleccionar y envasar al mismo tiempo las hortalizas y frutas en el campo, ofreciendo así un producto más homogéneo, de buena calidad y con buena presentación para el mercado (FAO, 2004).

Los envases o cajas de productos frescos deben de cumplir una serie de requisitos:

- Presentar una resistencia mecánica lo suficientemente buena como para no deformarse con la carga y proteger el contenido durante su apilamiento y transporte.

- Adecuarse a la exigencia del mercado en cuanto a su forma, tamaño y peso. 
- El material con el que está formado el envase debe estar exento de productos químicos tóxicos que puedan transferirse al alimento.

- El envase debe de prevenir pérdidas por vertido o volcado.

- Resistir las condiciones térmicas a las que puede someterse durante su fabricación (altas temperaturas) y uso (bajas temperaturas).

El sistema de envasado para frutas y hortalizas, a granel, se puede realizar de forma manual eligiendo los productos homogéneos tanto en tamaño como en color y de buena calidad, pero es un sistema que requiere mucha mano de obra. Por ello, se realiza cada vez más el envasado de forma automatizada con sistemas automáticos de clasificación por tamaño y color (FAO, 2014).

\subsubsection{Problemática de los envases plásticos.}

Durante mucho tiempo los polímeros derivados del petróleo han sido la base para la elaboración de materiales de envasado debido a su gran versatilidad en propiedades físicas, bajo costo y transparencia. En envases plásticos alimentarios, las características más importantes a considerar de un polímero para ser seleccionado como material de envasado son: propiedades físico-mecánicas (resistencia a la punción, rasgado, tensión, impacto y elongación); propiedades barrera (permeabilidad a los gases: aromas, olores, dióxido de carbono, vapor de agua y oxígeno) y propiedades ópticas (transparencia y opacidad) (Klopffer et al., 2001).

Los materiales plásticos empleados para la fabricación de envases, en la mayoría de los casos, son plásticos sintéticos (derivados del petróleo) debido a que ofrecen una buena protección del alimento contra el deterioro del mismo, y tienen buena transparencia. Tienen adecuadas propiedades mecánicas y permiten obtener diferentes estructuras y diseños con costos bajos.

En función del tipo de producto a envasar, se pueden utilizar diferentes materiales que son ampliamente utilizados, como es el caso del cartón, el papel, las latas de aluminio y de hojalata, pero siguen utilizándose mucho los plásticos, como el polietileno (PE), el polipropileno (PP), el policloruro de vinilo (PVC), el polietileno de tereftalato (PET) y el poliestireno (PS) (Tharanathan, 2003). Uno de los puntos clave de un buen material de envasado es que no ceda al alimento componentes del mismo que comprometan la calidad y seguridad del alimento, pero tampoco debe permitir que el alimento pierda en exceso algún componente que sea importante para la calidad, como pueden ser los aromas en algún caso (Castro, 2016).

Las frutas y verduras son envasadas a granel en cajas de cartón y en envases de plástico para su distribución y consumo en supermercados y tiendas. Cuando estos 
productos se comercializan en pequeños envases, los más habituales son las bandejas de PP o PET termoformadas transparentes, aunque también se fabrican en cartoncillo o cartón microcorrugado (Tharanathan, 2003).

Los plásticos sintéticos, aunque sean reciclables, cuentan con el inconveniente de estar constituidos por polímeros derivados del petróleo que son muy estables frente a la biodegradación (son no biodegradables). Esto conlleva una gran persistencia en la naturaleza, durante varias décadas, una vez que son desechados, constituyendo un serio problema medioambiental (Cruz-Morfin, 2013). A pesar de lo anterior, la producción mundial de plásticos no para de crecer; en el año 2017 alcanzó los 348 millones de t, un 3,8 \% más que en el 2016 (PlasticsEurope, 2018). En efecto, si se analiza la producción total de plásticos a nivel mundial, China sigue siendo el principal productor con un 29 \% del total en 2016, seguido de Europa con un $19 \%$ y América del Norte con un $18 \%$. Debido a la elevada producción de plástico de China, en Asia se produce actualmente el $50 \%$ del plástico del mundo. Dentro de Europa, más de dos tercios de la demanda de plásticos se concentra en cinco países: Alemania (24,5\%), Italia (14,2\%), Francia (9,6 \%), España (7,7 \%) y Reino Unido (7,5\%) (Greenpeace, 2017).

Precisamente, uno de los principales sectores de aplicación que concentró la demanda de plásticos por parte de la industria transformadora europea en 2017 fue el del envasado (suponiendo el 39,7 \% del total) con diferencia frente a las industrias de la construcción (19,8 \%), la automoción (10,1\%), el sector electrónico y eléctrico (6,2%), el de deporte y ocio $(4,1 \%)$ y la agricultura $(3,4 \%)$. Los tipos de plásticos más demandados, en orden de mayor a menor, fueron el PP (19,3\%), el Polietileno de Baja Densidad (LDPE, 17,5 \%), Polietileno de alta densidad (HDPE, 12,3\%) y PVC (10,2\%) (PlasticsEurope, 2019).

\subsubsection{Envases plásticos biodegradables. Biopolímeros.}

Por todo lo anterior, desde hace años se están desarrollando materiales plásticos biodegradables, con las mismas o mejores propiedades que los plásticos convencionales, pero con origen renovable y con características biodegradables, siendo los Ilamados biopolímeros. Son materiales derivados de organismos biológicos, como los desarrollados en base a celulosas y almidones, que tienen características próximas a los plásticos tradicionales (Shimao, 2001). Su uso puede ayudar a reducir el impacto sobre el medio ambiente en comparación con los materiales plásticos convencionales, además de ofrecer nuevas oportunidades de negocio y ser económicamente viables (Shen et al., 2010). 
La formulación de un material de envase biodegradable debe hacerse para lograr una adecuada capacidad de formar una matriz o film con suficiente continuidad y cohesión para contener o envolver el producto. Además, es necesario que tenga adecuadas permeabilidades al oxígeno y al vapor de agua, y propiedades mecánicas como resistencia a la tensión y alargamiento antes de la ruptura. No obstante, la característica más importante e innovadora de los biopolímeros es que tenga la capacidad de servir de envase para la conservación de alimentos (Cruz-Morfin et al., 2013).

Los biopolímeros engloban a todos aquellos polímeros que han sido producidos a partir de fuentes renovables, ya sean de origen vegetal o animal. Estos biopolímeros, también conocidos como polímeros renovables, se clasifican tal como se muestra en la Figura 1.

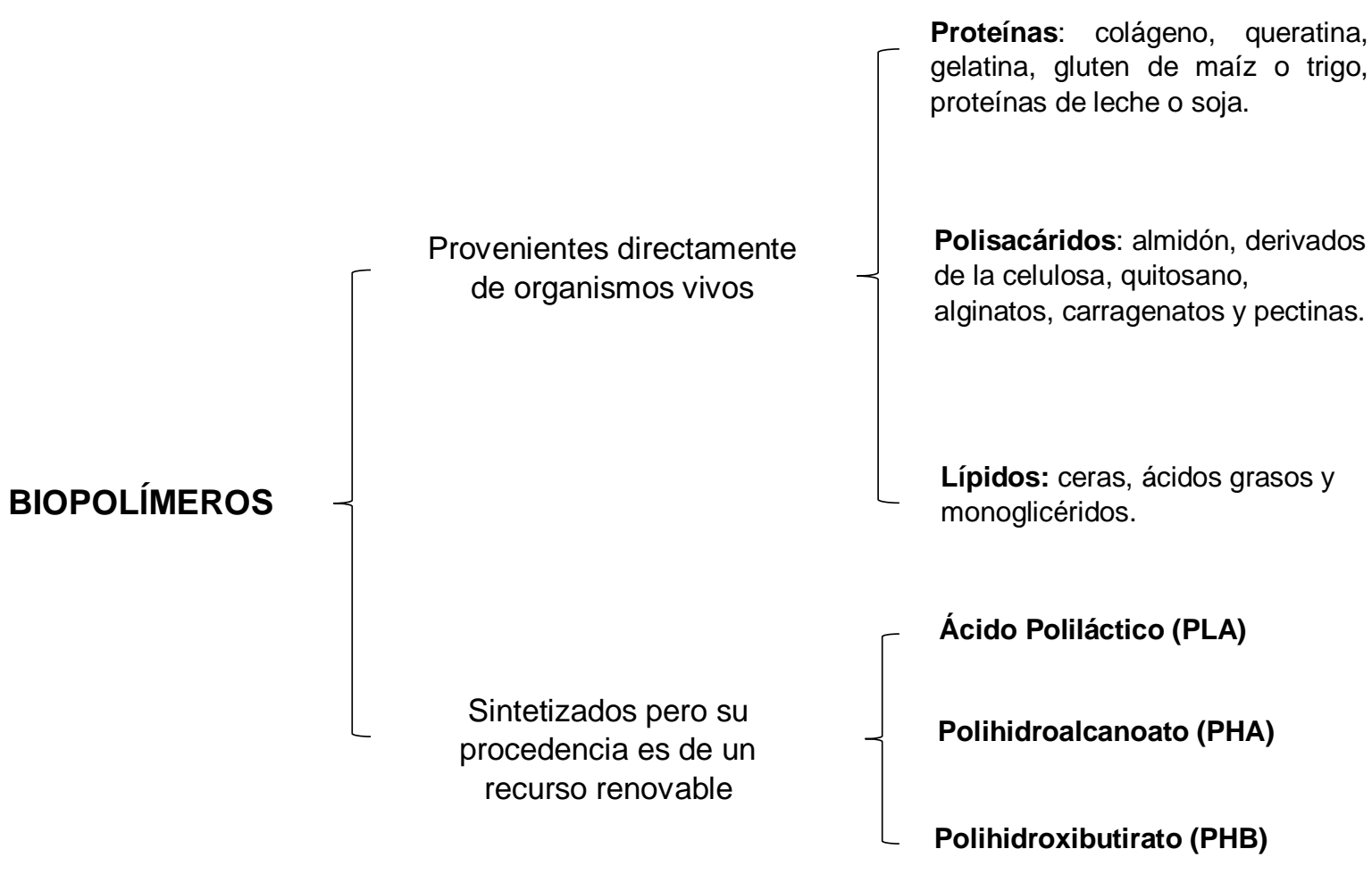

Figura 1. Clasificación de los biopolímeros según Tang et al., (2012)

Para conseguir reducir su coste, es necesario incrementar el uso y las aplicaciones de estos polímeros biodegradables. De esta forma se mejorará la acogida por parte del mercado, ya que no solo presentan el inconveniente del precio sino también, por problemas inherentes a su naturaleza, presentan ciertas deficiencias en cuanto a sus propiedades físicas, con respecto a los envases convencionales. 
El desarrollo de materiales de envasado basados en biopolímeros para uso en productos frescos ha creado un gran interés entre los investigadores. Actualmente se está trabajando mucho en la obtención de películas biodegradables a las que se incorporan aditivos que actúan contra la flora microbiana causante de podredumbres en productos hortofrutícolas. Se han desarrollado, también, películas a base de almidón que tienen propiedades físicas similares a las películas de polímeros sintéticos, puesto que son transparentes, no tienen olor ni sabor, son impermeables al dióxido de carbono y tienen cierta resistencia a la transmisión de oxígeno. Beltrán y Florez (2018) desarrollaron películas de almidón con glicerol como plastificante para el envasado de fresas frescas obteniendo buenos resultados de mejora de la vida útil, la cual se alargó de 14 a 21 días.

También, se han realizado estudios sobre el uso de films o películas plásticas a base de proteínas, que incluyen agentes antimicrobianos, para alargar la vida útil del producto, así como mejorar la seguridad y calidad del mismo. Así, Gutiérrez et al. (2009) desarrollaron un material de envasado biodegradable antimicrobiano que incluía una combinación de aceites esenciales junto con aromas comúnmente utilizados en la industria alimentaria (vainilla, plátano y fresa). Pudieron verificar que usando estos films con una concentración de antimicrobiano elevada (4\%) conseguían la inhibición de la mayoría de mohos y levaduras.

\subsection{INTERÉS DEL ENVASADO ACTIVO.}

En la actualidad, la mayor parte de los productos alimenticios se suministran a los consumidores envasados. Incluso aquellos que están envasados a granel, como las frutas y hortalizas frescas, se colocan en bolsas para su pesado y transporte al hogar en la última etapa de su distribución. Tanto los envases a granel como los envases primarios más pequeños pueden ser activos para desarrollar funciones de conservación del producto, y ser diseñados teniendo en cuenta que los consumidores demandan alimentos frescos sin conservantes de síntesis (Tang et al., 2012).

Los envases activos son capaces de tener una serie de interacciones con el producto, alargando la vida útil del mismo, manteniendo su calidad, y mejorando la seguridad y atributos sensoriales (Gutiérrez et al., 2009). Legalmente, el Reglamento (UE) oㅡ 1935/2004 Materiales y objetos destinados a entrar en contacto con alimentos, define los envases activos como: "materiales y objetos destinados a ampliar el tiempo de conservación, o a mantener o mejorar el estado de los alimentos envasados, y que están diseñados para incorporar deliberadamente componentes que transmitan sustancias a 
los alimentos envasados o al entorno de éstos o que adsorban sustancias de los alimentos envasados o del entorno de éstos" (EUR-lex, 2016). El objetivo de estos envases no es sólo incrementar la vida útil del producto, sino también obtener resultados beneficiosos en la logística y distribución de los productos. Por ejemplo, reducir las cantidades de desperdicio de alimentos, reducir los costes en el envasado del producto, mejorar el manejo y el etiquetado, etc. (Wilson-Charles, 2008).

Con esta definición se amplía el concepto de envase activo con respecto al envasado tradicional. Es decir, el envase pasa de ser un mero contenedor a desempeñar un papel activo en el mantenimiento o incluso mejora de la calidad del alimento envasado (Tian et al., 2010). Los envases activos pueden conseguirse por diversos medios, pero son dos básicamente los procedimientos de actuación: (i) la introducción del agente activo en el interior del envase junto con el producto envasado, y (ii) la inclusión del elemento activo en el material de envase (Catalá, 2001).

Con el envasado activo se pretende mantener el producto en condiciones óptimas, protegiéndolo de los agentes responsables de la alteración biológica, enzimática, química y física. El envasado convencional también tiene ese objetivo, pero mientras que con este se pretende minimizar los efectos de un número limitado de variables externas (luz, oxígeno, agua, calor, insectos, microorganismos, polvo, etc.), con el envasado activo se pretende mantener todas esas variables controladas en unos determinados niveles (Cruz et al., 2013).

Los envases activos se pueden clasificar en dos grandes grupos (Cruz et al., 2013):

a. Los envases adsorbedores o eliminadores, como aquellos que adsorben sustancias químicas del aire interior del envase. Esto implica una transferencia de masa desde el aire contenido en el envase al sistema activo del envase.

Son de destacar los adsorbedores de oxígeno, de etileno, de vapor de agua, y de componentes volátiles que originan olores y sabores desagradables en el alimento.

b. Los envases liberadores o emisores, como aquellos que liberan sustancias activas hacia el interior del envase. Esto implica una transferencia de masa desde el sistema o material activo al contenido del envase, como agentes antimicrobianos, antioxidantes, aromatizantes, saborizantes, colorantes, ingredientes alimentarios y extractos y aceites esenciales de plantas con acción antimicrobiana o antioxidante. 


\subsubsection{Agentes antimicrobianos y métodos de aplicación al envase activo.}

El uso de antimicrobianos como conservantes es muy común en la industria alimentaria. Durante muchos años se han utilizado antimicrobianos sintetizados químicamente, pero estos tienen un gran rechazo por parte de los consumidores, ya que su uso se asocia a intoxicaciones, cáncer y otras enfermedades degenerativas. Esto ha creado la necesidad de buscar alternativas a esos conservantes sintéticos, buscando que tengan como mínimo las mismas propiedades antimicrobianas y mejor compatibilidad con el alimento. Los antimicrobianos químicos más utilizados son los benzoatos, nitritos y nitratos, y anhídrido sulfuroso, entre otros (González et al., 2013), tal como se muestra en la Tabla 11.

Tabla 11. Compuestos químicos de acción antimicrobiana (Adaptada de Moreno, 2002)

\begin{tabular}{|c|c|}
\hline Antimicrobiano & Microorganismos sobre los que actúa \\
\hline Ácido propiónico y propionatos & Mohos \\
\hline Ácido sórbico y sorbatos & Mohos \\
\hline Ácido benzoico y benzoatos & Mohos y Levaduras \\
\hline Dióxido de azufre y sulfitos & Bacterias, Mohos y Levaduras \\
\hline Óxido de etileno y propileno & Mohos y Levaduras \\
\hline Diacetato de sodio & Mohos \\
\hline Nisina & Bacterias ácido lácticas, Clostridia \\
\hline Nitrito de sodio & Clostridia \\
\hline
\end{tabular}

La mayor parte de los antimicrobianos alimentarios solamente son bacteriostáticos 0 fungistáticos, en lugar de bactericidas o fungicidas, por lo que su efectividad sobre los alimentos es limitada. Por otra parte, debido a que algunos microorganismos pueden no verse inhibidos o destruidos por las dosis recomendadas individualmente, puede ser preferible utilizar una combinación de ellos (Moreno, 2002).

Los antimicrobianos naturales se obtienen de hierbas, especias y plantas principalmente. Su actividad es generalmente atribuida a los compuestos fenólicos presentes en sus extractos, y se ha observado que la grasa, concentración de sales, $\mathrm{pH}$, proteína y temperatura pueden afectar a la actividad antimicrobiana de estas sustancias (Cabrera, 2019).

Los envases con actividad antimicrobiana son un tipo de envase activo en el cual el producto, el envase y el ambiente interactúan entre sí para reducir o retardar el crecimiento microbiano con el fin de prolongar la vida útil del producto. Estos están 
específicamente diseñados para controlar el crecimiento de cualquier microorganismo que altere la estabilidad del alimento. Pero esos envases antimicrobianos no sustituyen a ningún otro sistema de calidad como las buenas prácticas de higiene y manufactura (Michelena et al., 2019).

Algunos de los envases antimicrobianos implican la incorporación de los agentes antimicrobianos en el mismo material de envase o como recubrimiento del mismo, normalmente aplicado en la cara en contacto con el alimento que se envasa. Así, se puede conseguir un efecto de liberación del agente activo, permitiendo su migración desde el envase hacia el alimento, consiguiendo una acción antimicrobiana en la superficie del alimento sólido. También, el agente activo puede quedar adsorbido (inmovilizado en el material de envase), y no se produce una liberación del agente antimicrobiano, sino que inhibe el crecimiento microbiano en la superficie del alimento en contacto con el envase. Este tipo de envase es menos efectivo en alimentos sólidos que en líquidos, ya que, en el caso del alimento sólido, no todo el alimento puede estar en contacto con el envase (Lee et al., 2008), a no ser que se tenga un envasado al vacío.

Otro método de aplicación del agente activo es mediante el uso de recubrimientos comestibles que incluyen el componente antimicrobiano. Estos recubrimientos están basados en una capa delgada que se forma directamente sobre la superficie de los productos vegetales como una envoltura protectora. Se elaboran a partir de una gran variedad de proteínas, polisacáridos y lípidos, aunque los más utilizados son los recubrimientos a base de polisacáridos (Fernández-Valdés et al., 2015). Algunos autores han desarrollado recubrimientos utilizando tres polisacáridos diferentes: almidón de maíz, goma guar y pectina de bajo metoxilo. Este recubrimiento fue aplicado sobre la superficie de productos hortícolas tales como pera, limón y aguacate, llegando a la conclusión de que estos polisacáridos mostraban mejora en la adherencia, viscosidad y flexibilidad del recubrimiento cuando era aplicado sobre la superficie de estos frutos (Ramos-García et al., 2018).

Varios autores atribuyen otros efectos a los recubrimientos, a base de polisacáridos, como es la mejora de los atributos de calidad del producto. Se realizó un estudio en el que se recubrieron coles de Bruselas (Brassica oleracea) con una mezcla de almidón de maíz, hidróxido de sodio y glicerol. Las muestras con este recubrimiento presentaron una mejora en la firmeza, color y menor deshidratación en comparación con las muestras control, sin recubrimiento (De Ancos et al., 2015). 
El desarrollo de estos recubrimientos comestibles ha ido evolucionando hasta incorporar en su matriz agentes antimicrobianos capaces de inhibir microorganismos. Un ejemplo de esto último es el uso de quitosano, que presenta actividad antifúngica, que inhibe el crecimiento de hongos causantes de la mayoría de las enfermedades postcosecha. Los recubrimientos con quitosano forman una cubierta en la superficie de los frutos que actúa como una barrera mecánica para proteger al fruto de infecciones causadas por mohos, ayudando así a disminuir pérdidas postcosecha durante el almacenamiento del producto (Mejía et al., 2018). Por ejemplo, el uso de recubrimientos de quitosano en una concentración de $15 \mathrm{mg} / \mathrm{mL}$ inhibió el crecimiento de Botrytis cinerea y Rhizopus stolonifer en fresa fresca. Los signos de desarrollo de estos hongos aparecieron 5 días después de ser almacenados a $13 \stackrel{\circ}{\circ}$, mientras que en el control se observó crecimiento de estos microorganismos a las 24 horas (Domini, 2018).

El mecanismo de acción de los antimicrobianos no está completamente establecido, pero se considera, en términos generales, que actúan generando en el microorganismo una inhibición de la biosíntesis de los ácidos nucleicos, un daño en la integridad de sus membranas, y también provocando una interferencia en los procesos metabólicos esenciales (Sánchez, 2016).

\subsubsection{Uso de los aceites esenciales (AEs) como agentes antimicrobianos.}

Dentro de los tipos de envases activos destacan los que presentan actividad antimicrobiana, capaces de reducir o retardar el crecimiento microbiano con el fin de prolongar la vida útil del producto (Lee et al., 2008). Estos agentes antimicrobianos se incorporan dentro de la estructura del envase liberándose al interior de este e interactuando con el alimento, con el fin de inhibir el crecimiento de cualquier tipo de microorganismo patógeno o alterante de su calidad. Numerosas investigaciones han puesto de manifiesto el efecto antimicrobiano que tienen los AEs extraídos de plantas aromáticas y especias (Espina et al., 2011; Ramos et al., 2012; Pino-Pérez et al., 2018). De este modo, el uso de los AEs para el control microbiano se ha convertido en una de las áreas de investigación más importantes con el objetivo de sustituir a los conservantes sintéticos. Muchas hierbas y especias contienen AEs que son antimicrobianos como los AEs de clavo, ajo, orégano, perejil, mostaza y vainilla, entre otros. Por su actividad antimicrobiana demostrada, también se puede utilizar uno o varios de sus componentes, principales o no, de estos AEs. Es decir, se pueden utilizar mezclas de los AEs puros, con o sin la adición de uno o más de sus componentes mayoritarios, dependiendo de cada aplicación y del tipo de microorganismo cuyo 
crecimiento se quiera inhibir (Espina et al., 2011; Ramos et al., 2012; Pino-Pérez et al., 2018).

Los AEs son las fracciones líquidas volátiles que contienen las sustancias responsables del aroma de las plantas y que son tan importantes en la industria cosmética, alimentaria y farmacéutica. Contienen distintas sustancias orgánicas volátiles que pueden ser monoterpenos, sesquiterpenos, y sus derivados oxigenados, como aldehídos, cetonas, ácidos y alcoholes (Espina et al., 2011). Son intensamente aromáticos, y son insolubles en agua y solubles en alcohol, grasas, ceras y aceites vegetales (Guerra-Alva y Pandura-Vele, 2012). La gran mayoría presenta olores agradables, aunque existen otros de olor desagradable como los AEs de ajo y cebolla, debido a que en su composición se encuentran compuestos azufrados. Los AEs pueden ser aceites puros de origen vegetal, procedentes de brotes o yemas, flores, hojas, tallos, ramas, semillas, frutos, raíces, o la madera o corteza, o una mezcla de los mismos (Pino-Pérez et al., 2018).

Estos AEs son sintetizados por las plantas como metabolitos secundarios, presentando un aroma distintivo de la planta de origen, y pueden ser extraídos mediante métodos físicos como puede ser la destilación a vapor, siendo ésta la más empleada, o mediante hidrodestilación o extracción mediante disolventes. Los AEs tienen un papel muy importante en la protección de las plantas, actuando como agentes antimicrobianos, antivirales, antifúngicos e insecticidas. Poseen una composición química muy compleja que consiste en una mezcla de sustancias orgánicas normalmente con peso molecular menor de $400 \mathrm{Da}$ y presión de vapor suficientemente alta para volatilizarse a temperatura ambiente (Ruiz et al., 2015).

El principal obstáculo para el uso de estos AEs como conservantes de alimentos es que tienen un olor y sabor muy fuerte si se aplican en dosis elevadas, y pueden generar un efecto sensorial negativo en el producto. Sin embargo, tienen la ventaja de que son fácilmente volatilizados y desaparecen de manera muy rápida, no dejando prácticamente residuos si se aplican superficialmente (Espina et al., 2011).

Los AEs se clasifican según diferentes criterios, como son: consistencia, origen y la naturaleza química de sus componentes mayoritarios (Figura 2). 


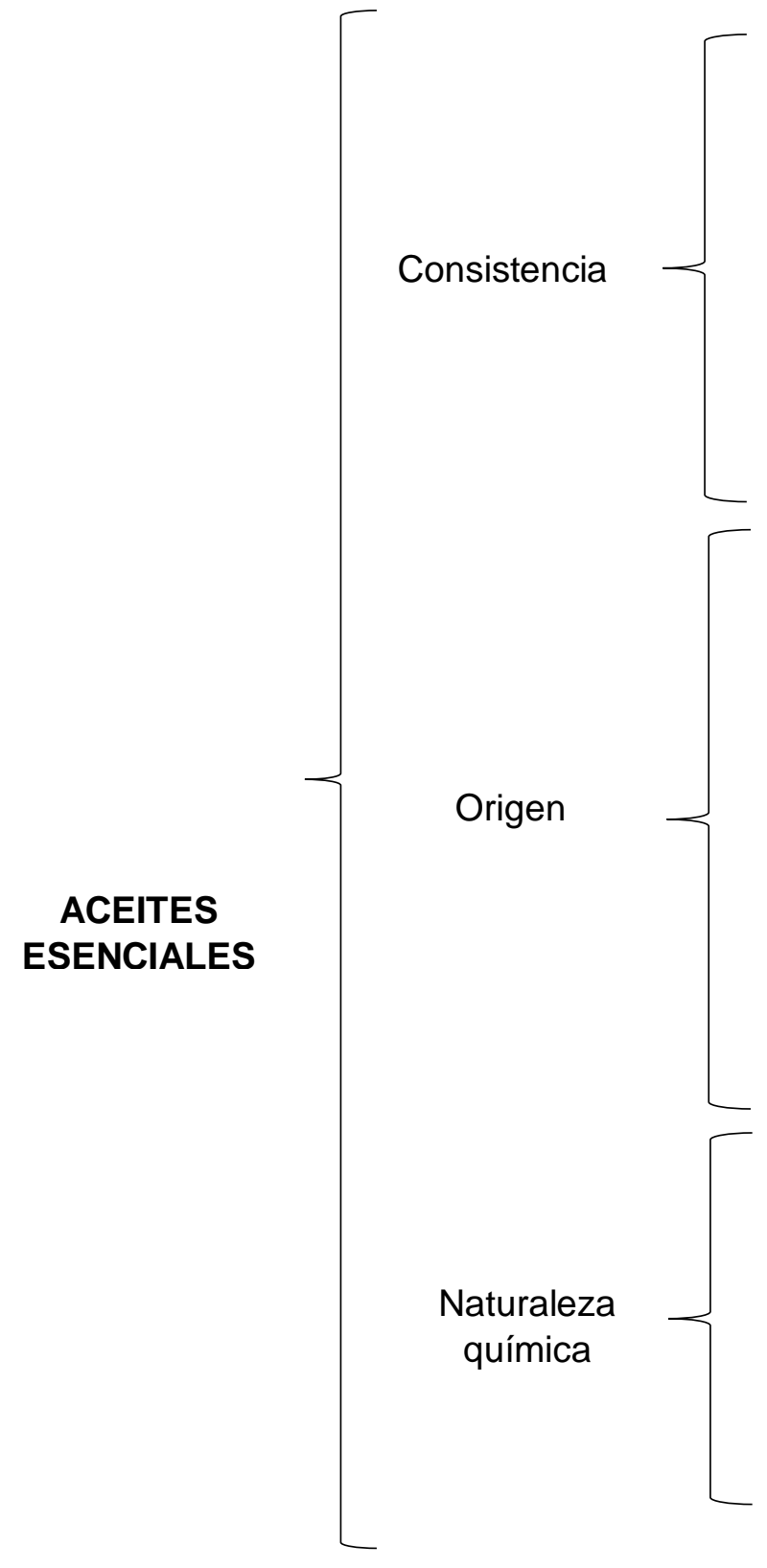

Esencias fluidas: líquidos volátiles a temperatura ambiente.

Bálsamos: de consistencia más espesa, son poco volátiles y propensos a sufrir reacciones de polimerización.

Oleorresinas: tiene el aroma de las plantas en forma concentrada y son típicamente líquidos muy viscosos 0 sustancias semisólidas.

Naturales: se obtienen directamente de la planta y no sufren modificaciones físicas ni auímicas bosteriores.

Artificiales: se obtienen a través de procesos de enriquecimiento de la misma esencia con uno 0 varios de sus componentes.

Sintéticos: productos obtenidos por la combinación de sus componentes los cuales, la mayoría, son producidos por procesos de síntesis química. Son los más económicos y utilizados como aromatizantes y saborizantes.

Monoterpenoides: ricos en monoterpenos (albahaca, salivia, etc.).

Sesquiterpenoides: ricos en sesquiterpenos (pino, junípero, copaiba, etc )

Fenilpropanoides: ricos en fenilpropanos (clavo, canela, anís, etc.).

Figura 2. Clasificación generalizada de los aceites esenciales (A partir de información recogida de Martínez, 2001)

Estos AEs tienen un efecto antimicrobiano debido a los compuestos fenólicos, terpénicos y otros compuestos volátiles que poseen. Estos compuestos tienen la capacidad de alterar las paredes de las células microbianas, aunque sus mecanismos precisos de acción no han sido del todo dilucidados. Es importante tener en cuenta que la actividad antimicrobiana de los AEs depende principalmente de su carácter hidrófobo o lipofílico, y del contenido de determinados compuestos químicos. Pero también, la actividad antimicrobiana depende del tipo de microorganismo que se desea inhibir 
(López et al., 2005). También, muchas investigaciones han puesto de manifiesto que el uso de vapores de estas sustancias tiene mayor efecto antimicrobiano que cuando se aplican de forma líquida. Esto puede ser especialmente interesante en la inhibición del crecimiento de mohos en frutas y hortalizas frescas, ya que debido a su crecimiento superficial pueden ser más sensibles a los vapores de los AEs (Edris y Farrag, 2003). En efecto, un estudio realizado por Kloucek et al. (2012) verificó el efecto antimicrobiano en fase de vapor de 69 AEs, demostrando que 39 de ellos tuvieron una actividad antimicrobiana, siendo los mohos más sensibles a los vapores de AEs que las bacterias. Otros autores estudiaron el efecto de los AEs sobre la actividad antibacteriana y antifúngica empleando $3 \mathrm{AEs}$ de canela, tomillo y orégano. El estudio se realizó sobre ciertos microorganismos y mohos, y demostró que estos aceites tienen mayor efecto antifúngico que antibacteriano (Caballero et al., 2016). Otro estudio evaluó el efecto de los AEs a diferentes concentraciones sobre la acción antifúngica, in vitro, y se obtuvo un efecto significativo de estos AEs (Montero-Recalde et al., 2017, 2018).

A pesar de haberse realizado numerosos estudios que han investigado sobre la actividad antimicrobiana de los AEs en alimentos, se ha comprobado que la eficacia de los AEs es frecuentemente mayor in vitro que in vivo, cuando son aplicados en los alimentos en condiciones reales de conservación (Van Long et al., 2016).

\subsection{ENVASE ACTIVO DE CARTÓN.}

\subsubsection{Posición del envase de cartón dentro de los envases sostenibles/biodegradables.}

Los materiales empleados para la fabricación de envases, como ya se ha comentado anteriormente, suelen ser plásticos sintéticos por sus numerosas ventajas, aun sabiendo el grave problema medioambiental que estos presentan al no ser biodegradables. Todo esto genera una percepción negativa por parte de la sociedad, por lo que existe cierta presión por usar envases de cartón. Numerosas investigaciones proponen el uso de materiales fáciles de reciclar y sostenibles, como la utilización de envases de cartón en todas sus formas (Mercado et al., 2019).

Este es uno de los motivos del uso creciente del envase de cartón corrugado o microcorrugado. Además, el cartón corrugado, que puede ser de los tipos doble-cara, doble-doble cara, y triple ondulado, y con onda grande, onda mediana, onda pequeña y microcanal (Figura 3) (que se denomina también como cartón microcorrugado), tiene unas propiedades mecánicas que se adaptan muy bien a los envases que se necesitan en el envasado de frutas y hortalizas frescas (AFCO, 2018). 
Las cajas de cartón se utilizan para el envasado a granel de estos productos frescos, usando cajas de distintos tipos y diseños, como por ejemplo los tipos de formatos comprendidos dentro de la Norma UNE 137005:2005. Esta norma especifica las dimensiones exteriores y la designación de los envases y embalajes de cartón ondulado interapilables para frutas y hortalizas de bases modulares, como las de dimensiones $600 \mathrm{~mm}$ x 400mm x 300mm apilables entre sí (Norma UNE 137005:2005).

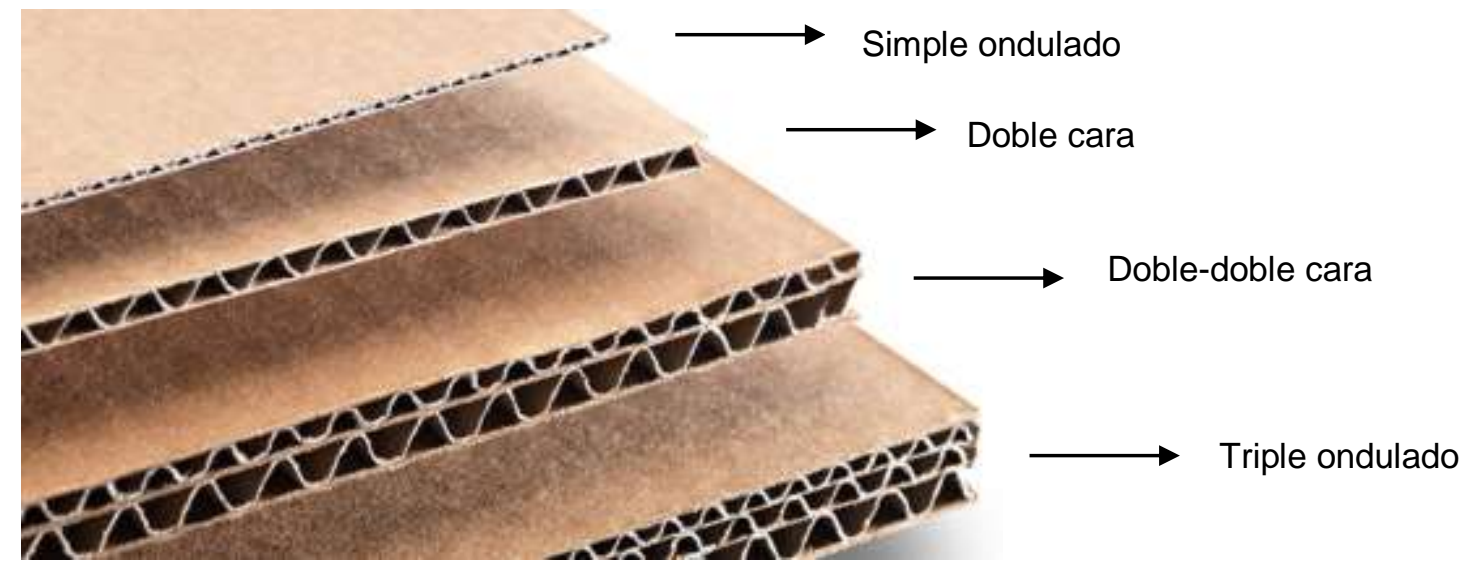

Figura 3. Diferentes tipos de cartón ondulado (Fuente: Kartox.com)

Para el envasado de pequeñas cantidades, normalmente menos de $1 \mathrm{~kg}$, de frutas y hortalizas las cajas o bandejas de cartón pueden ser de cartón microcorrugado o de otro tipo. En estas aplicaciones, las cajas de cartón o barquetas pueden ir envueltas totalmente o parcialmente con una lámina de material polimérico, aplicada según el conocido sistema de flow-pack o simplemente como un cubre. En el formato con envoltura total flow-pack se utilizan normalmente cajitas o barquetas de cartón microcorrugado y son aplicadas al envasado de pequeñas cantidades de frutas y hortalizas (López-Gómez, 2016).

Desde hace ya una década, España se mantiene entre los países europeos que mayor volumen de cartón ondulado produce, concretamente ocupando la cuarta posición por detrás de Alemania, Italia y Francia. En 2017, nuestro país produjo 5.201 millones de metros cuadrados $\left(\mathrm{m}^{2}\right)$ de este material, un 5,02 \% más que en el año 2016. En 2018 según el informe sectorial de la industria del cartón ondulado, España se mantuvo como cuarto productor europeo en volumen, con 5.286 millones de $\mathrm{m}^{2}$ (Figura 4) (AFCO, 2018).

La industria del cartón ondulado supone una fuente de riqueza para España, ayudando de manera significativa al crecimiento económico del país, creando puestos de trabajo 
locales y apostando siempre por el desarrollo sostenible. El principal consumidor de cartón ondulado en España correspondió al sector de productos agrícolas, con un $23,3 \%$. Por detrás del sector de la agricultura, se sitúa el sector alimenticio con un $16,4 \%$ y el sector de las bebidas con un 15\%. Esta industria se ha visto fortalecida por unas cifras que demuestran la preferencia del consumidor por un material respetuoso con el medio ambiente, más higiénico, que alarga la vida del producto fresco, y que optimiza el almacenaje, la logística y el transporte (Fruittoday, 2017).

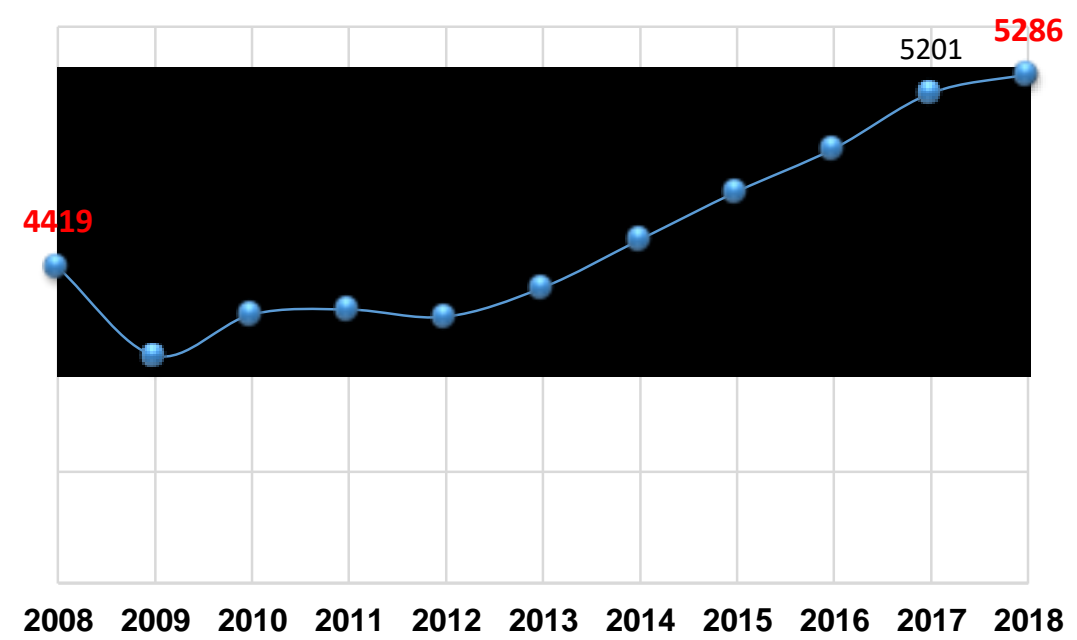

Figura 4. Producción de cartón, en millones de $\mathrm{m}^{2}$, en España desde el año 2008 hasta el año 2018 (Fuente: AFCO)

Un reciente estudio elaborado por la Asociación Española de Fabricantes de envases y embalajes de cartón ondulado (AFCO) y Estrategia e Investigación Sociológica, ha situado al cartón ondulado como el envase que goza de una mayor reputación y aceptación medioambiental entre los españoles. En comparación con otros materiales, el cartón se encuentra en la cima con un $41,7 \%$ de aceptación, frente al vidrio con un $28,4 \%$, madera con un $13,9 \%$ seguido del plástico con un $5,7 \%$ y el aluminio con un $2,3 \%$ (AFCO, 2018).

\subsubsection{Proceso de fabricación del cartón y limitaciones de desarrollo.}

El cartón es un material construido por varias capas de papel intercaladas, elaboradas a base de fibra virgen o de papel reciclado. El grosor y el volumen son aspectos importantes en el proceso de elaboración del cartón corrugado, ya que deberá soportar cargas de relativamente elevado peso, además de realizar otras funciones mecánicas, sin alterarse su forma. El uso de este tipo de cartón constituye un sistema de envasado versátil, ligero, económico, reciclable y muy práctico, además de ser un material eficiente para la distribución, transporte y almacenamiento de productos, especialmente frutas y hortalizas frescas a granel o envasadas en envases primarios (Mendoza-Robledo, 2018). 
El cartón corrugado se fabrica en un sistema de procesado de alta precisión formado por una combinación de varias máquinas, conocido como onduladora o corrugadora. En el proceso de fabricación del cartón se diferencian dos partes: la parte húmeda y la parte seca. Todo comienza en el área de diseño gráfico que crea un prototipo de caja de cartón mediante un software específico, teniendo en cuenta las propiedades estructurales (cumpliendo con unas especificaciones de dimensiones del producto y tamaño de la caja, peso del producto, y las condiciones ambientales a las cuales estará sometida la caja durante el almacenamiento con el producto envasado). A continuación, se organiza la fabricación del cartón en planchas. Para ello, el papel en bobinas pasa por la línea de la onduladora que incluye una serie de rodillos pesados. Estos rodillos tienen dos funciones principales: precalentar y ondular la capa interior de papel del cartón ondulado. La lámina de papel interior o tripa, previamente calentada, pasa por unos rodillos con estrías o rebordes que ondulan (o acanalan) el papel para después pegarlo con adhesivos a una lámina inferior primero, y otra superior, después, hasta obtener la plancha de cartón ondulado o corrugado (Figura 5) (Allansson y Suärd, 2001). La lámina inferior es la que se recubre con una emulsión en base agua de ceras o compuestos poliméricos acrílicos para conseguir la impermeabilidad del cartón para envasar productos hortofrutícolas frescos (Nowacka et al, 2018).

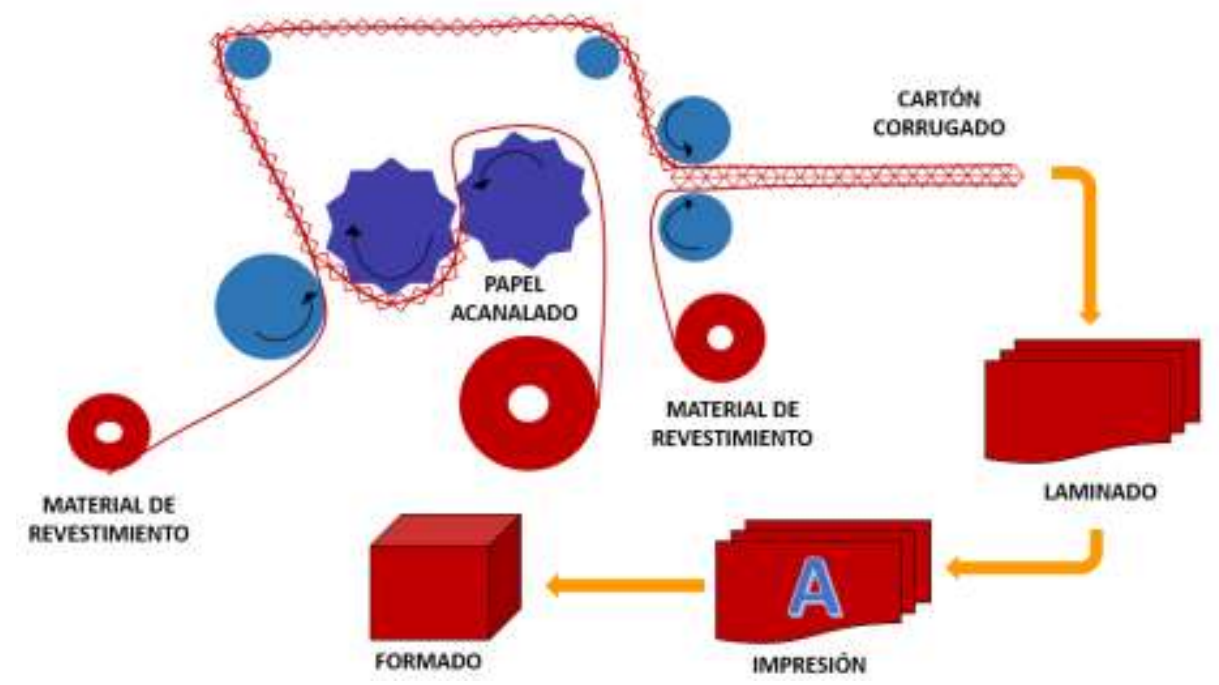

Figura 5. Proceso de fabricación del cartón corrugado (adaptada de Allansson y Suärd, 2001)

Un apartado importante es controlar la calidad de los papeles kraft, del papel corrugado o tripa, del encolado y que el acabado de la plancha de cartón esté perfecto, así como también la impresión, el troquelado, y el formado final de las cajas de cartón, para 
cumplir con las garantías de calidad del fabricante y con las expectativas del cliente final (Allansson y Süard, 2001).

Las cajas de cartón corrugado están formadas normalmente por múltiples capas de cartón ondulado (Figura 3) con la funcionalidad de mejorar la resistencia mecánica, acolchar y proteger mejor a los alimentos de golpes, y así evitar pérdidas por podredumbres. En este sentido, es importante controlar la calidad de las fibras de celulosa, las propiedades mecánicas y de impermeabilización de los revestimientos, así como las propiedades estructurales del envase obtenido para poder garantizar resistencia a fuerzas de compresión, impactos, vibraciones o una combinación de las tres (Frank, 2014).

Por otro lado, el envase de cartón destinado al transporte de productos hortofrutícolas frescos debe tener un adecuado sistema de ventilación para evitar la acumulación de calor y dióxido de carbono, por lo que posee ventanas laterales y orificios -en el fondo de la caja y en los laterales- que mejoran el flujo de aire alrededor del producto envasado (para conseguir un mejor enfriamiento durante la refrigeración y una adecuada ventilación del producto). Al mismo tiempo, tal como se ha indicado anteriormente, el envase de cartón corrugado deber de ser capaz de resistir altas fuerzas de compresión (por apilamiento de cajas en pallets) durante todo el tiempo de almacenamiento y transporte. En este sentido, Jinkarn et al. (2006) observaron una correlación entre el tamaño de las aberturas del sistema de ventilación y la resistencia mecánica del envase de cartón. Esta es la razón de que, para reducir la pérdida de resistencia mecánica, se incorporen refuerzos en las paredes del envase de cartón Biancolini y Brutti, 2003).

Durante el proceso de fabricación del cartón corrugado se pueden presentar algunos problemas conocidos como "Warp" y "Washboarding", que son debidos al desequilibrio o diferencias de contenido de humedad entre las capas de papel dentro del cartón corrugado, y que dan lugar a la deformación del envase. Esto se produce por la naturaleza hidrofílica de la celulosa. En efecto, los cartones son propensos a adsorber vapor de agua del aire que le rodea, especialmente cuando se utilizan como material de envasado de productos hortofrutícolas frescos. La adsorción de humedad puede reducir la resistencia mecánica de los cartones, causando su deterioro y la pérdida de la funcionalidad principal del envase como es la de contener. Esta es la razón de que normalmente, para el envasado de frutas y verduras frescas, se traten los cartones con un recubrimiento que consiste en una emulsión de cera o parafina. Estos recubrimientos 
pueden ser biodegradables, siendo totalmente compatibles con el reciclado del cartón (Frank, 2014; Nowacka et al, 2018).

Además del uso de parafina, se ha propuesto como recubrimiento el uso de láminas de ácido poliláctico (PLA), un biopolímero producido a partir de la fermentación de la glucosa obtenida a partir de almidones de distintas fuentes como el trigo, maíz y melazas. Este film de polímero biodegradable permite mejorar la impermeabilidad del cartón cuando se aplica como recubrimiento del mismo (García-García et al., 2012). Una investigación realizada por Rhim et al. (2007) estudió el uso del PLA como recubrimiento del cartón para mejorar su resistencia al agua. Estos autores pusieron de manifiesto que las características de barrera frente al vapor de agua fueron mejoradas en el cartón con recubrimiento de film de PLA, obteniendo los mejores resultados cuando el recubrimiento se hacía con una solución de PLA al $3 \%$ p/v.

Por otro lado, los procedimientos habituales de envasado de las frutas y hortalizas frescas, que implican el uso de estas cajas de cartón, sin carácter activo, en sus diferentes formatos, en combinación con la conservación refrigerada, a temperaturas por encima de $1^{\circ} \mathrm{C}$, pueden dar lugar a problemas de seguridad alimentaria por la presencia de microorganismos sobre los productos, teniendo también problemas de vida útil del producto que puede ser relativamente reducida (López-Gómez, 2016).

Una patente española ha desarrollado un envase activo de cartón recubierto con PLA que se caracteriza por tener propiedades absorbentes de etileno y de vapor de agua, por lo que interacciona con la atmósfera reinante en el interior del envase lleno de producto fresco (eliminando parte del etileno y del vapor de agua), y de esta manera consigue una mejor conservación del producto hortofrutícola que contiene, alargando de forma importante su vida útil comercial (García-García et al., 2012). Además, este envase puede tener actividad antimicrobiana cuando la lámina de PLA incorpora AEs, permitiendo el control de la proliferación de microorganismos patógenos y de deterioro del producto hortofrutícola que se envasa. La película de PLA con agentes antimicrobianos se puede fabricar mediante extrusión de la mezcla, según procedimientos industriales ya establecidos. Las planchas de cartón microcorrugado se recubren después con este film de PLA para su posterior troquelado y formado (GarcíaGarcía et al., 2012). Este envase activo se ha validado en conservación de tomate. Se ha podido comprobar que este recubrimiento de film de PLA se van liberando los vapores de AEs que permiten mantener el control del desarrollo microbiano y así evitar el deterioro del tomate fresco. El envase activo patentado es una bandeja, que a su vez, está envuelta con una lámina de LDPE que permite la evacuación de parte del vapor de 
agua que se genera en el interior del envase, y la evacuación de parte del etileno que se va generando, obteniendo unas condiciones adecuadas para la conservación del fruto (García-García et al., 2012). Otras soluciones de envases utilizan envolturas (envasado en flow-pack con el producto en tarrina o cesta) con determinados films plásticos con distinto grado de permeabilidad a los gases y vapor de agua, permitiendo así controlar la composición gaseosa en la atmósfera del interior del envase de productos hortofrutícolas frescos. Pero estas soluciones puede que no sean adecuadas para ciertas hortalizas que producen ciertas cantidades de etileno y vapor de agua (Peron y Razeti, 2008; Wilson, 2008). Esta es la razón por la que actualmente se utilizan mucho los envases con envolturas macroperforadas (flow-pack con envoltura de film macroperforado) para dejar salir el etileno que es producido por los productos hortofrutícolas. Aunque, con esta solución no se controla la composición de $\mathrm{O}_{2}$ y $\mathrm{CO}_{2}$, y tampoco la humedad, ya que el envase está relativamente abierto al exterior.

\subsection{DESARROLLO DE UN ENVASE ACTIVO DE CARTÓN CON CARÁCTER ANTIMICROBIANO Y DE ABSORCIÓN DE ETILENO.}

\subsubsection{Propuestas de envases activos de cartón.}

Se han propuesto diferentes soluciones de envasado activo para frutas y hortalizas frescas. Algunas de ellas se recogen en patentes como las que se describen a continuación.

La patente de Wood et al. (2011), de número EP 2512232 A1 y de título "Maturation or ripening inhibitor release from polymer, fiber, film, sheet or packaging", se refiere a composiciones de poliolefinas termoplásticas, polímeros, fibras, tejidos, películas, cierres, y laminados que incluyen un polímero y compuesto de ciclodextrina (CD) con un inhibidor de la maduración que es volátil. El inhibidor (el 1-MCP) se introduce en esos materiales de envasado y se libera bajo condiciones controladas de humedad. Con esta solución de envasado se podría controlar el proceso de deterioro de las frutas y hortalizas envasadas. Pero esta propuesta no se refiere a envases de cartón, y lo que propone es un material de envase que libera sustancias inhibidoras de etileno, pero no sustancias antimicrobianas, como el envase propuesto por Alarcón-García et al. (2015), que desarrollaron un envase activo que incorpora AEs de cítricos (limón, pomelo y naranja) para controlar el hongo Botrytis cinerea en fresa. Estos autores realizaron pruebas in vitro empleando tres concentraciones diferentes de estos antimicrobianos por separado y empleando combinaciones entre ellos, para determinar si la mezcla de éstos podría aumentar la inhibición del hongo. Una vez obtenidos los resultados in vitro, 
fabricaron el envase con la combinación de AEs seleccionada por su mayor inhibición del crecimiento micelial del hongo. Estos autores concluyeron que la concentración más elevada de AE de limón inhibe en torno al $24-28 \%$ de los micelios del hongo Botrytis cinerea a los 10 días de incubación.

Otra patente es la de García-García et al. (2012), de número ES 2393388 B1, y de título "Envase activo para conservación de productos vegetales frescos", que se refiere a un envase activo para conservación de productos vegetales frescos que se caracteriza por aportar propiedades de absorción de etileno, control de vapor de agua y actividad antimicrobiana. Este envase activo consta de un recipiente de material biodegradable como el cartón, recubierto en su superficie interna de una lámina de un biopolímero con capacidad de absorción de etileno y vapor de agua, tal como el PLA, en la que se incorporan AEs naturales con acción antimicrobiana, pero no encapsulados en ciclodextrinas (CDs). Con esta solución de adición de los AEs al PLA ocurre que éstos se liberan continuamente desde esta capa de PLA y el envase huele y pierde sus propiedades antes de que se utilice con el producto a envasar.

También es interesante destacar la patente de Nerín de la Puerta et al. (2008), de número ES 2289930 B1 y de título "Envase activo inhibidor de patógenos alimentarios". Esta propuesta consiste en un envase activo antimicrobiano que comprende un soporte de papel, cartón, corcho, aluminio, o madera, y un recubrimiento activo del mismo. $Y$ dicho recubrimiento consiste en una formulación de parafina y extractos de plantas naturales, pero no encapsulados en ciclodextrinas.

En estas dos últimas patentes, las sustancias antimicrobianas que utilizan se liberan continuamente desde que se fabrica el envase, y no de forma modulada desde el momento en que el producto fresco es envasado. Además, las condiciones de fabricación del material del envase de cartón (que implica su sometimiento a temperaturas superiores a $100^{\circ} \mathrm{C}$ ), pueden hacer que se pierdan por evaporación una parte importante de estas sustancias antimicrobianas volátiles añadidas en el recubrimiento del cartón. Por otro lado, la mayoría de las patentes actuales sobre envases de cartón se refieren a envases activos que tienen solamente una actividad, a excepción de la patente García-García et al. (2012) de número 2393388 B1.

Por último, la patente de Rodler y Fleischmann (2010), de número US 20100092634 A1 y titulada "Method for increasing the shelf life of agricultural products which produce ethylene, during transport, sale, presentation and/or storage", se refiere a un recubrimiento o material que se aplica al cartón, o a algunas de sus capas de papel, que tiene actividad de absorción de etileno. De esta manera, según los autores de la patente, 
los productos envasados en cajas de cartón abiertas que incluyen este material absorbente de etileno, pueden conseguir una vida útil más larga. El problema de este envase activo es que tiene solo actividad de absorción de etileno pero no actividad antimicrobiana.

Por todo lo anterior, López-Gómez (2016) propuso la solución tecnológica avanzada de envase activo que se basa en el uso de AEs encapsulados en $\beta$-ciclodextrinas ( $\beta$-CDs) aplicados junto con el recubrimiento en el cartón en combinación con la citada emulsión en base agua que se aplica para aumentar la impermeabilidad al vapor de agua. Este envase tiene la particularidad de que se mantiene estable durante su tiempo de almacenamiento antes de su uso en el envasado del producto, y comienza a actuar como envase activo antimicrobiano justo cuando el producto se carga y es almacenado a HR elevada y baja temperatura. Este envase de cartón se caracteriza porque posee, al menos en una de las caras interiores del envase, un recubrimiento activo antimicrobiano que comprende un compuesto polimérico (que puede ser una cera o parafina) y complejos de inclusión de $\beta$-CDs con AEs, o de componentes de estos aceites o mezcla de ambos.

Estos AEs muestran excelentes propiedades antimicrobianas in vitro en una amplia diversidad de microorganismos patógenos y de deterioro de los alimentos, tal y como se ha visto en apartados anteriores (Pastrana-Puche et al., 2017). Sin embargo, la actividad antimicrobiana in vivo de los AEs puede ser reducida, debido principalmente a su rápida evaporación y a otras reacciones de oxidación. Por eso es necesario la aplicación de concentraciones elevadas de AEs que pueden desencadenar problemas relacionados con modificaciones de las características organolépticas del producto. Esta evaporación de los AEs se puede evitar a través de su encapsulación en diferentes moléculas hospedadoras capaces de albergar en su interior este tipo de sustancias, como son las ciclodextrinas (CDs) o los nanotubos de halloysita (HNT, Halloysite nanotubes, en inglés) (Wen et al., 2016; Matiacevich y Sáez, 2018).

\subsubsection{Encapsulación de los AEs usando CDs y HNT en el desarrollo de un envase} activo de cartón para el envasado a granel de tomates y pimientos frescos.

Los primeros métodos de encapsulación se desarrollaron entre los años 1930 y 1940 de la mano de la National Cash Register, cuya evolución ha llevado al desarrollo de numerosos métodos de encapsulación entre los que se encuentran procesos como el secado por atomización, secado en lecho fluidizado, atrapamiento en liposomas, coacervación, polimerización artificial y la encapsulación molecular que usa CDs para la 
encapsulación de estos AEs formando los denominados complejos de inclusión (Marques, 2010).

En esta Tesis se trata de validar la tecnología de envases activo de cartón propuesta por López-Gómez (2016) en su aplicación al envasado a granel de pimientos y tomates frescos. Además, se analiza el interés de que los AEs sean encapsulados tanto en CDs como en HNT, para conseguir una mayor estabilidad térmica de los AEs y evitar su rápida evaporación, desde la pared del envase de cartón, durante su fabricación. Los HNT se han estudiado también en esta Tesis por sus propiedades de absorción de $\mathrm{C}_{2} \mathrm{H}_{4}$, interesante para el envasado de frutos sensibles al etileno como es el caso del tomate fresco. Así, los AEs encapsulados se liberarán gradualmente del complejo de inclusión o cápsula que los engloba o atrapa, manifestando su actividad antimicrobiana para conservar mejor los tomates y pimientos frescos. El complejo de inclusión protege también a los AEs frente a reacciones de oxidación debido a la luz o al oxígeno (Tas et al., 2017; Makaremi et al., 2017).

Las CDs son oligosacáridos cíclicos naturales que se obtienen a partir de la degradación enzimática de uno de los polisacáridos más importantes de la naturaleza, el almidón o sus derivados, por medio del enzima glicosiltransferasa, produciendo CDs de diversa índole. Las CDs son compuestos con estructura molecular tronco-cónica, en cuyo interior existe una cavidad estable de naturaleza hidrofóbica que puede atrapar o encapsular otras moléculas (Radu et al., 2016). El uso de las CDs está ampliamente extendido en la industria farmacéutica, alimentaria, química, etc. En la industria farmacéutica, las CDs y sus derivados se han utilizado para la complejación de fármacos con el fin de mejorar las propiedades físico-químicas del medicamento, o aumentar su solubilidad y biodisponibilidad (Singh et al., 2002). En la industria química, las CDs se utilizan también como catalizadores para mejorar la cinética de determinadas reacciones, así como para la purificación y separación de productos industriales (LucasAbellán et al., 2008). No obstante, el $90 \%$ de las CDs producidas se emplean en la industria alimentaria para estabilizar aromas, eliminar sabores no deseados, evitar contaminaciones por microorganismos, etc. (Singh et al., 2002).

Aunque se conocen desde el siglo XIX, las CDs comenzaron su auge en la década de los años 80 del siglo pasado con las primeras aplicaciones en la industria farmacéutica y alimentaria. Su expansión fue posible gracias a la producción a escala industrial de las tres CDs conocidas como nativas, $\alpha-, \beta-$ y $\gamma$-CDs (Rajendiran y Jenita, 2015), que están formadas por 6,7 y 8 unidades de glucosa, respectivamente, unidas entre sí por enlaces 
glucosídicos $\alpha(1,4)$. Las principales propiedades fisicoquímicas de las CDs se recogen en la siguiente Tabla 12 (Martín del Valle, 2004).

Tabla 12. Propiedades físico-químicas de las ciclodextrinas (alfa-ciclodextrinas, beta-ciclodextrinas y gamma-ciclodextrinas, denominadas como $\alpha-C D, \beta-C D$ y $\gamma-C D$, respectivamente) (Martín del Valle, 2004).

\begin{tabular}{|c|c|c|c|}
\hline Características & $\alpha-C D$ & $\beta-C D$ & Y-CD \\
\hline № unidades de glucosa (glucopiranosas) & 6 & 7 & 8 \\
\hline Peso molecular ( $\mathrm{g} / \mathrm{mol})$ & 972 & 1135 & 1297 \\
\hline № moléculas de agua en la cavidad & 6 & 11 & 17 \\
\hline Solubilidad en agua $\left(25^{\circ} \mathrm{C}\right)$ & 14,5 & 1,85 & 23,2 \\
\hline Diámetro de la cavidad central (Á) & $4,7-5,3$ & $6,0-6,5$ & $7,5-8,3$ \\
\hline Diámetro exterior $(\AA \hat{)})$ & 14,6 & 15,4 & 17,5 \\
\hline Altura del toroide $(\AA \hat{)})$ & 7,9 & 7,9 & 7,9 \\
\hline
\end{tabular}

La regulación sobre el uso de las CDs depende del país en el que se estén utilizando. Por ejemplo, en Estados Unidos están incluidas dentro de la lista de aditivos GRAS (Generalmente Reconocidos como Seguros). En Japón, están consideradas como productos naturales y su comercialización en el sector alimentario está restringidas por consideraciones de pureza. En Australia y Nueva Zelanda están consideradas como nuevos alimentos desde el año 2004 (Cravotto et al., 2006) y en Europa están consideradas como ingredientes alimentarios, o aditivos, y han sido incluidas en las listas europeas de aditivos autorizados para su uso alimentario con los números E-457, E-459 y E-458 para las $\alpha-C D, \beta-C D$ y $Y-C D$, respectivamente (EFSA, 2011).

Tal como se ha indicado antes, los productos frescos como las frutas y las verduras generalmente se degradan rápidamente después de la cosecha, especialmente debido

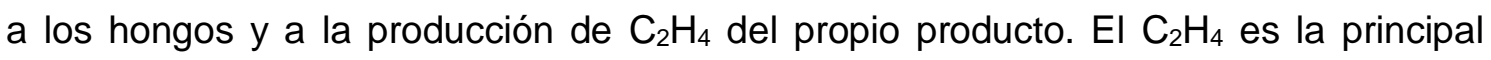
fitohormona relacionada con los procesos de maduración y senescencia en las frutas y hortalizas climatéricas. Con el objetivo de reducir las pérdidas de los productos hortofrutícolas en postcosecha, se utiliza el frío con otras tecnologías que ayudan a alargar el período de conservación y a mantener la calidad de las frutas y hortalizas frescas, como es el uso de los absorbedores de $\mathrm{C}_{2} \mathrm{H}_{4}$. Estos absorbedores, que generalmente son de permanganato potásico, se instalan en las cámaras de conservación o se incorporan al envase en forma de almohadillas o bandejas, eliminando el $\mathrm{C}_{2} \mathrm{H}_{4}$ del ambiente (Guerra y Casquero, 2005). Estos absorbedores de $\mathrm{C}_{2} \mathrm{H}_{4}$ utilizados en envases son sustancias químicas que interactúan con el alimento y 
con el aire ambiente dentro del envase, pero crean cierto rechazo por parte del consumidor que, cada vez más, demanda alimentos más naturales sin la presencia de elementos extraños o químicos en el envase. Por ello, en esta Tesis se propone el uso de agentes absorbedores de $\mathrm{C}_{2} \mathrm{H}_{4}$ naturales, como son los nanotubos de halloysita (HNT). En este mismo sentido, se propone también el uso de los nanotubos de HNT como otro tipo alternativo de carrier o agente de encapsulación para alojamiento de los AEs (Tas et al., 2017), como alternativa a las CDs.

Los HNT fueron descritos por primera vez por Berthier en el año 1826 como un mineral arcilloso dioctaédrico del grupo caolín, y nombrada en honor al geólogo belga Omalius d`Halloy. Los HNT se encuentran ampliamente en las rocas y suelos, y su formación se debe a la alteración de una amplia variedad de rocas ígneas y no-ígneas (Churchman, 2000). Sin embargo, los HNT a menudo forman un componente importante de los suelos derivados de materiales volcánicos de las regiones tropicales y subtropicales húmedas (Chadwick et al., 2003; Ziegler et al., 2003; Joussein et al., 2007; Gorrasi et al., 2018).

La estructura y composición química de los HNT es similar a la de la caolinita, dickite o nacrite. Se diferencian de la caolinita porque tienen láminas curvadas que son capaces de ubicar moléculas de agua en el espacio interlaminar, dando una fórmula general de $\mathrm{Al}_{2} \mathrm{Si}_{2} \mathrm{O}_{5}(\mathrm{OH})_{4} \times 2 \mathrm{H}_{2} \mathrm{O}$ (Cholewa y Kuzahiewicz, 2012; Hofmann et al., 1934; Churchman et al., 1972). Por tanto, químicamente son un aluminosilicato hidroxilado constituido principalmente por aluminio, silicio e hidrógeno. Este mineral se encuentra en abundancia en países como Australia, Nueva Zelanda, Estados Unidos y China, y se forman generalmente por la alteración hidrotermal de minerales alumino-silicatos, pudiéndose encontrar mezclado o asociado con dickita, caolinita, montmorillonita y otros minerales arcillosos. Las propiedades físicas de los HNT se recogen en la Tabla 13 (UCM, 2010).

Tabla 13. Propiedades físicas de los HNT (Fuente: UCM, 2010).

\begin{tabular}{|c|c|}
\hline Color & Blanco con tonalidades variadas \\
\hline Raya & Blanca \\
\hline Lustre & Terroso \\
\hline Transparencia & Translúcido a opaco \\
\hline Sistema Cristalino & Monoclínico \\
\hline Fractura & Terrosa \\
\hline Dureza & 2 (Mohs) \\
\hline Densidad & 2,59 \\
\hline
\end{tabular}


La utilización de nanotubos de carbono, nanofluidos, nanopartículas, nanoemulsiones etc., en el ámbito de la nanotecnología, puede crear una percepción negativa por parte de la industria y del consumidor porque se puede pensar que no seguros para el ser humano y medio ambiente. En esta Tesis se recurre a la utilización de nanotubos de HNT porque es una sustancia natural y generalmente reconocida como segura (GRAS) por la Food and Drug Administration (FDA) (Kamble et al., 2012; Tsagkaris et al., 2018). Además, los HNTs son sustancias ecológicas, biocompatibles y solubles en agua incluso a elevadas concentraciones (Vergaro et al., 2010). Además, los HNT presentan la particularidad de que son absorbedores de $\mathrm{C}_{2} \mathrm{H}_{4}$, por lo que presentan un gran interés en su aplicación en envases activos para productos hortícolas sensibles al $\mathrm{C}_{2} \mathrm{H}_{4}$ (Kasmire y Suslow, 2002; Tas et al., 2017).

Así pues, las CDs y los HNT pueden considerarse como cápsulas vacías de un cierto tamaño molecular o nanoscópico que pueden incluir en su interior una gran variedad de moléculas, formando lo que se denomina complejos de inclusión o nanocápsulas. Los complejos de inclusión se forman entre dos moléculas, la molécula llamada "anfitrión" y la que se incluye, parcial o totalmente en su interior, que se denomina molécula "huésped". Por su parte, los HNT presentan una estructura tubular debido a las moléculas de agua que se encuentran entre sus capas. Suelen tener una superficie con apariencia muy rugosa a causa de la conformación similar a "fibras amontonadas" que son consecuencia de la posible agrupación de los nanotubos de halloysita. Las dimensiones de los nanotubos varían, aunque todas presentan una relación típica de menos de $3 \mu \mathrm{m}$ de largo por 0,3 $\mu \mathrm{m}$ de diámetro exterior. No obstante, en algunas muestras se pueden encontrar túbulos de hasta $20 \mu \mathrm{m}$ de largo (Lvov y Abdullayev, 2013; Carrillo et al., 2014), tal como se muestra en la Figura 6. 

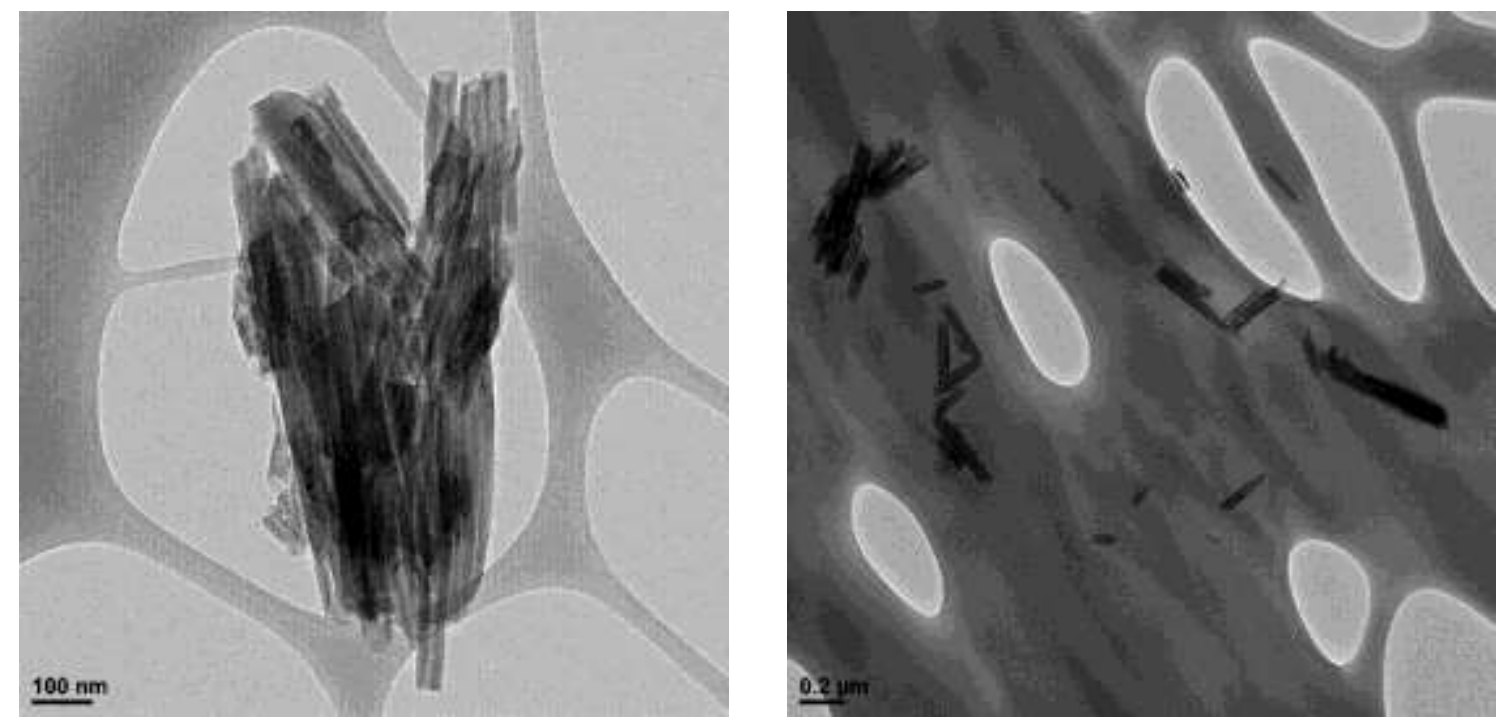

Figura 6. Estructura de los HNTs por Microscopía Electrónica de Transmisión (TEM) (Elaboración propia)

Numerosas investigaciones han estudiado el uso de los HNT como absorbedores de $\mathrm{C}_{2} \mathrm{H}_{4}$ en el envasado de diferentes productos, siendo utilizados incluso embebidos en la matriz polimérica del envase plástico de conservación del producto. Tas et al. (2017) estudiaron estas películas poliméricas con HNT para el envasado de bananas, tomates y fresas, demostrando que el uso de los HNT retrasa el envejecimiento y el ablandamiento en el caso de la banana, y mantiene la firmeza de los tomates debido a las propiedades de absorción de $\mathrm{C}_{2} \mathrm{H}_{4}$ por parte de los $\mathrm{HNT}$. Además, estas películas también redujeron la pérdida de peso de las fresas, así como la proliferación microbiana en todas las muestras estudiadas, con respecto a las muestras envasadas en film de PE.

En esta Tesis, las moléculas "huésped" elegidas para llevar a cabo el proceso de encapsulación han sido los AEs, mientras que las moléculas empleadas como "anfitrión" han sido las CDs y los HNT. La estereoquímica, y posiblemente, la polaridad de las moléculas, tanto del anfitrión como del huésped, determinan si se puede producir este complejo de inclusión. La principal causa de unión entre estas moléculas y el huésped es el ajuste geométrico entre las moléculas, por lo que la formación de complejos de inclusión con las CDs y con los HNT se produce de forma estereoespecífica (Marques, 2010).

La propiedad más importante de las CDs es la formación de complejos de inclusión mediante el acoplamiento de una molécula huésped en la cavidad hidrofóbica interior de las CDs, mediante la formación de enlaces no covalentes, cumpliendo un equilibrio dinámico gobernado por una constante de complejación (Kc) (Figura 7). 

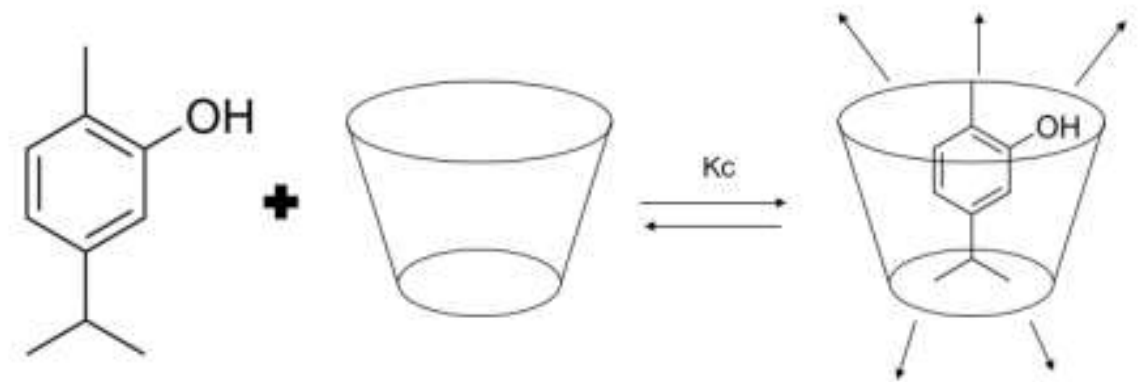

Figura 7. Formación de complejos de inclusión entre la CD y la molécula huésped (AE) (Elaboración propia)

La estabilidad de estos complejos de inclusión, y por tanto la magnitud de su constante de complejación, depende del grado de acoplamiento entre la molécula huésped y la CD. A mayor Kc mayor estabilidad del complejo. La inclusión de una molécula en el interior de la cavidad de las CDs, consiste en la sustitución de las moléculas de agua, que se encuentran en el interior de esta sustancia, por la molécula de menor polaridad, en este caso la molécula de AE, tal como se muestra en la Figura 8.

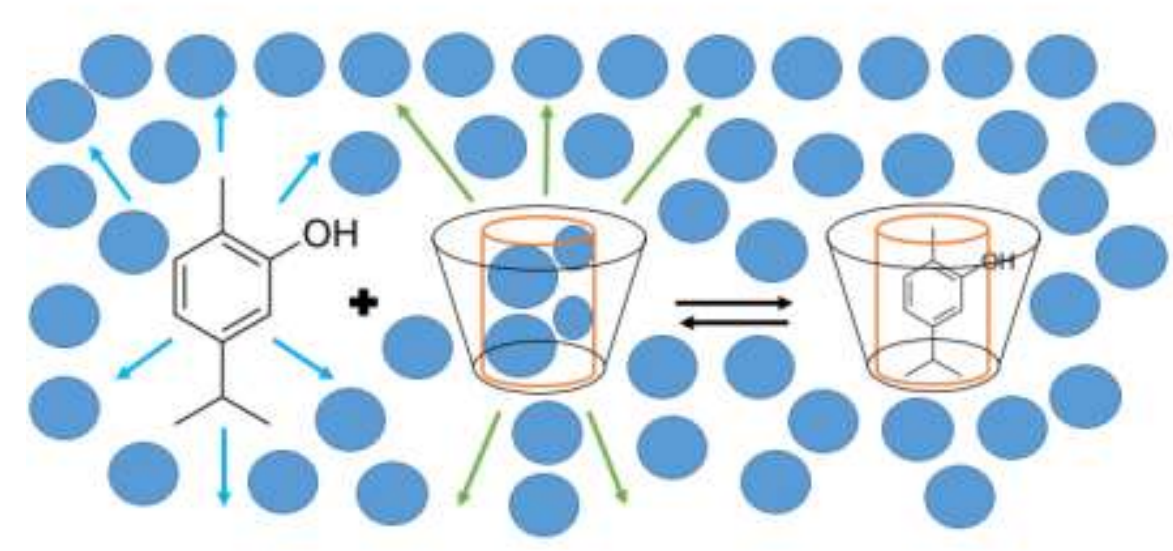

Figura 8. Formación de complejos de inclusión entre la CD y la molécula huésped (AE) Los círculos azules representan moléculas de agua (Fuente: adaptada de Astray et al., 2009)

La encapsulación o preparación del complejo de inclusión entre el AE y las/los CDs/HNT se puede realizar mediante cualquiera de los métodos siguientes: amasado, coprecipitación, método de calentamiento en un envase o recipiente sellado, interacción gas-líquido, liofilización, atomización, o usando tecnologías de fluidos supercríticos (Marques, 2010). La cavidad de las $\beta-C D$ es la que tiene mayor versatilidad para el atrapamiento molecular entre las CDs nativas, formando complejos de inclusión estables con mono y sesquiterpenos (Szejtli et al., 1998).

Debido a que la cavidad interior de las CDs es hidrófoba, estas moléculas son capaces de albergar moléculas hidrófobas más pequeñas como las moléculas de los distintos 
componentes de los AEs, para formar complejos "anfitrión-huésped", donde la molécula huésped queda encapsulada por la CD. De esta forma, moléculas insolubles en agua pueden llegar a ser completamente hidrosolubles cuando forman complejos de inclusión con la $C D$, sin que se produzca modificación química alguna en la molécula huésped, ya que no se origina ningún enlace covalente durante la interacción entre la CD y la molécula insoluble en agua (Martínez y Gómez, 2007). Sin embargo, una vez formados estos complejos, la presencia de agua puede llegar a desestabilizarlos y provocar, así, su descomposición. Esto es lo que ocurre cuando estos complejos de inclusión se ponen en contacto con aire a elevada $\mathrm{HR}$, superior al $85 \%$, tal como lo ponen de manifiesto los estudios de Cevallos et al. (2010). En estas condiciones de HR superior al 85 \%, las moléculas de agua provocan que se liberen las moléculas de AEs que estaban encapsuladas en las CDs.

Otro de los elementos esenciales en el desarrollo de este envase activo de cartón es el compuesto polimérico que se aplica en el recubrimiento, en forma de emulsión en base agua, mezclado con el complejo de inclusión entre CDs y AEs, o HNT con o sin AEs, sobre la cara interna del envase. Este compuesto polimérico genera una película con propiedades hidrófobas, además de constituir cierta barrera frente a la grasa, el aceite y el vapor de agua en la superficie del cartón. El uso de estos compuestos acrílicos (denominado UKAPHOB 530), o de ceras vegetales, está aprobado por el Reglamento Europeo (CE) № 1935/2004 del Parlamento Europeo y del Consejo sobre materiales y artículos destinados a entrar en contacto con alimentos.

La estabilidad de los AEs es mayor cuando se forman complejos de inclusión con las CDs, pero estos se descomponen a determinados niveles de temperatura. Esto se puede apreciar en estudios de calorimetría mediante la técnica DSC (Calorimetría Diferencial de Barrido), tal y como se muestra en el trabajo de Cevallos et al. (2010). Un estudio realizado por López-Gómez (2016) pone de manifiesto que la temperatura de fusión de las $\beta-C D$, aproximadamente de $157 \stackrel{\circ}{\circ}$ (pico endotérmico de la curva $B$, de la Figura 9), se incrementa cuando se forma un complejo de inclusión entre las $\beta-C D$ y los AEs, pasando a aproximadamente $162 \stackrel{\circ}{\circ}$ (pico endotérmico de la curva $\mathrm{C}$ ). Cuando este complejo de inclusión se combina con el polímero acrílico (que denominamos laca) para ser aplicado en el cartón se consigue incrementar aún más la temperatura de fusión, llegando a $178 \stackrel{\circ}{\circ}$, siendo en la laca sola de $145 \stackrel{\circ}{\circ}$ aproximadamente (pico endotérmico de la curva D) (Figura 9). 


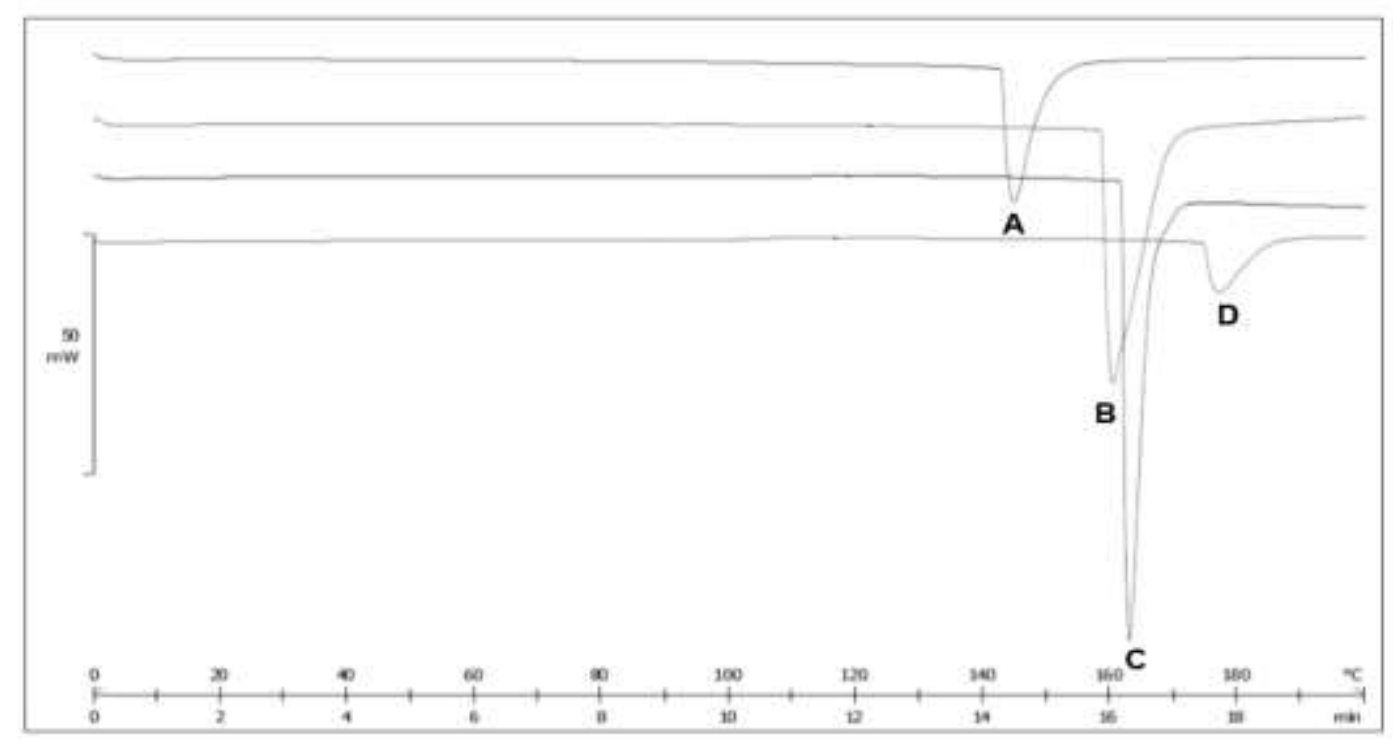

Figura 9. Curvas obtenidas mediante un análisis de DSC para: una muestra seca de copolímero acrílico (curva indicada como A); una muestra de $\beta-C D$ sin formar complejos de inclusión (curva indicada como B); muestra del complejo de inclusión formado por $A E$ (curva indicada como $C$ ) y una muestra de un copolímero acrílico más un complejo de inclusión formado por el $A E$ y $\beta-C D$ (curva indicada como D) (López-Gómez, 2016)

En efecto, cuando se fabrica el cartón ondulado, el citado recubrimiento que se aplica sobre una de las láminas de papel kraft se debe secar, y para ello se calienta a temperaturas que son del orden de $150 \stackrel{\circ}{\circ}$. Estos niveles de temperatura son aguantados por el complejo de inclusión con las CDs, de forma que se impide la pérdida por evaporación del AE utilizado en este envase activo. Esta pérdida de AEs puede ser un problema grave porque los aceites esenciales consiguen su eficacia si se tiene una adecuada cantidad de miligramos de AEs por $\mathrm{m}^{2}$ de cartón. Si hay una evaporación severa, se puede perder más del $50 \%$ de los AEs aplicados simplemente mezclados con la emulsión en base agua. Además, los AEs suelen tener un coste elevado, y estas pérdidas por evaporación pueden hacer que no sea viable económicamente el uso de AEs como antimicrobianos aplicados en el recubrimiento del cartón. De aquí el gran interés de la encapsulación de los AEs para ser aplicados en el recubrimiento del envase activo de cartón. 


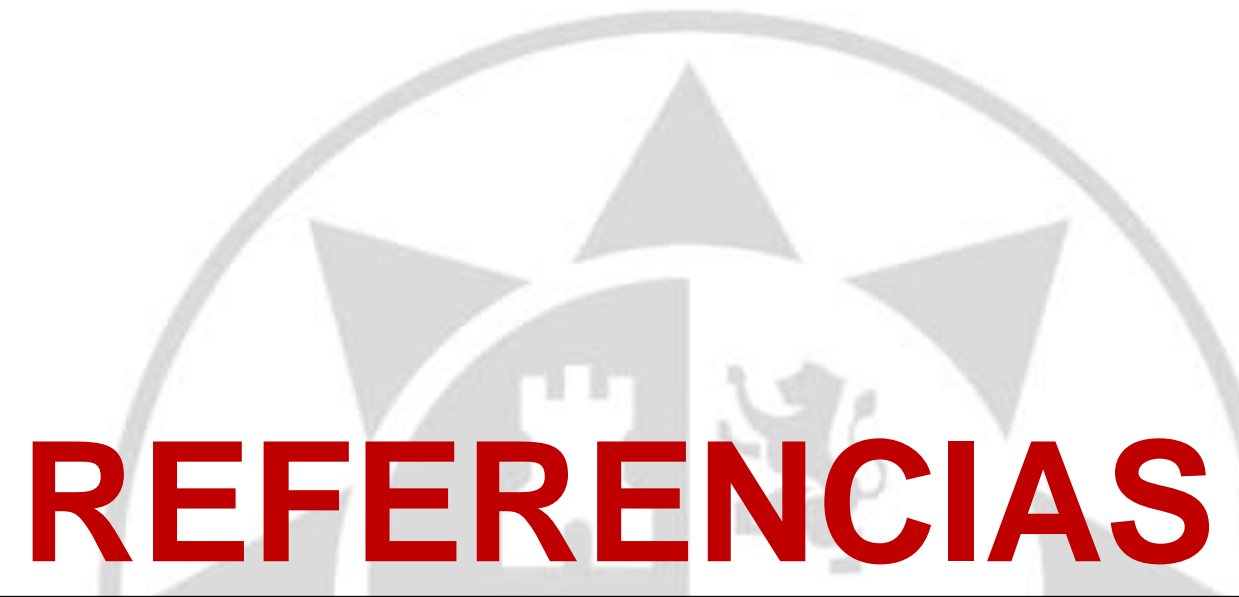




\section{REFERENCIAS}

Abdul-Baki AA, Stommel JR, Watada AE, Teasdale JR, Morse RD (1996) Hairy vetch mulch favorably impacts yield of processing tomatoes. Horticultural Science, 31(3), 338340.

Abeles FB, Morgan PW, Saltveit ME (1992) Ethylene in Plant Biology. Academic Press, New York, USA. ISBN: 0-12-041451-1.

AFCO (2018) Asociación Española de Fabricantes de Envases y Embalajes de Cartón Ondulado. http://www.afco.es/. Accedido 13 agosto 2019.

Aguayo-Giménez E (2003) Innovaciones tecnológicas en la conservación de melón y tomate. Procesado en fresco. Tesis Doctoral, Departamento de Ingeniería de Alimentos y el Equipamiento Agrícola, 1-421.

Alarcón-García Y, Trejo-Márquez MA, Corrales-Salinas A, Pascual-Bustamente S (2015) Desarrollo de un envase activo adicionado con aceites esenciales de cítricos para el control de la podredumbre en fresa. Revista Iberoamericana de Tecnología Postcosecha, 16(2), 222-227.

Ali A, Noh NM, Mustafa MA (2015) Antimicrobial activity of chitosan enriched with lemongrass oil against anthracnose of bell pepper. Food packaging and Shelf Life, 3, 56-61.

Allansson A, Svärd B (2001) Stability and collapse of corrugated board; numerical and experimental analysis. Master`s Thesis. Sweden: Division of Structural Mechanics, LTH, Lund University, 1-74.

Almeida J, Achten WM, Verbist B, Heuts RF, Schrevens E, Muys B (2014) Carbon and water footprints and energy use of greenhouse tomato production in Northern Italy. Journal of industrial ecology, 18(6), 898-908.

Andrews J (1995) Peppers: The domesticated Capsicums. Univ. Texas Press, Austin, 1-122.

Arcentales-Oña B, Padilla-Torres C, Guijarro-Fuertes M, Andrade-Cuvi MJ (2018) Calidad fisicoquímica y microbiológica de Tomate de Árbol (Solanum betaceum) mínimamente procesado tratado con radiación UV-C y ozono gaseoso. Revista Iberoamericana de Tecnología Postcosecha, 19(1), 1-10. 
Astray G, González-Barreiro C, Mejuto JC, Rial-Otero R, Simal-Gándara J (2009) A review on the use of cyclodextrins in foods. Food Hydrocolloids, 23, 1631-1640.

Báez R, Ojeda CJ, Mercado RJN, Mendoza WAM, Bringas-Taddei E (1998) Manejo de postcosecha del tomate (Lycopersicon esculentum Mill.). Manejo Postcosecha de Frutas y Verduras en Iberoamérica. Editorial, CYTED, 15,104-109.

Báez-Sañudo R, Mercado-Ruiz JN, García-Robles JM, Valle-Sotelo EG, FalcónVerdugo LP, Martínez-Gárate AA, Anaya-Dyck JM (2018) Ácido Acetilsalicílico y cubiertas comestibles para la conservación de frutos: Tomate como modelo. Revista Iberoamericana de Tecnología Postcosecha, 19(1), 76-87.

Bailén G, Guillén F, Castillo S, Zapata PJ, Serrano M, Valero D, Martínez-Romero D (2013) Use of a palladium catalyst to improve the capacity of activated carbon to absorb ethylene, and its effect on tomato ripening. Spanish Journal of Agricultural Research, $5(4), 579-586$.

Barco PA, Burbano S, Mosquera H, Villada, Navia D (2011) Efecto del recubrimiento a base de almidón de yuca modificado sobre la maduración del tomate. Revista Lasallista de Investigación, 8, 96-103.

Beecher GR (1998) Nutrient content of tomatoes and tomato products. Proceedings of the Society for Experimental Biology and Medicine, 218, 98-100.

Beltran CAU, Florez IF (2018) Elaboración de bioempaques a partir de almidones nativos y aceites esenciales prolongando vida útil en fresas. Revista Colombiana de Investigaciones Agroindustriales, 5(1), 71-86.

Bennett AB, JM Labavitch (2008) Ethylene and ripening-regulated expression and functional of fruit cell wall modifying proteins. Plant Science, 175, 130-136.

Biancolini ME, Brutti C (2003) Numerical and experimental investigation of the strength of corrugated board packages. Packaging Technology and Science, 16(2), 47-60.

Brandwein M, Al-Quntar A, Goldberg H, Mosheyev G, Goffer M, Marín-Iniesta F, LópezGómez A, Steinberg D (2016) Mitigation of biofilm formation on corrugated cardboard fresh produce packaging surfaces using a novel thiazolidinedione derivative integrated in acrylic emulsion polymers. Frontiers in microbiology, 7, 1-9.

Caballero CA, Villacorta LM, Vásquez CP (2016) Efecto del aceite esencial de clavo de olor (Syzygium aromaticum), canela (Cinnamomum zeylanicum) y su combinación sobre la acción antifúngica en Aspergillus flavus en agar chicha de maíz (Zea mays L.), variedad morado. Pueblo continente, 22(1), 123-132. 
Cabrera CE (2019) Actividad antimicrobiana de un sistema a base de un extracto vegetal y tres aceites esenciales. Ciencia e Investigación, 22(1), 21-25.

Cantwell M, Suslow T (2002) Lettuce, Crisphead: Recommendations for Maintaining Postharvest Quality. http://postharvest.ucdavis.edu/Commodity_Resources/Fact_Sheet s/Datastores/Vegetables_Spanish/index.cfm?uid=30\&ds=803.

Carrillo AM, Urruchurto CM, Carriazo JG, Moreno S, Molina RA (2014) Caracterización estructural y textural de una haloisita colombiana. Revista Méxicana de Ingeniería Química, 13(2), 563-571.

Castro A (2016) Envases alimentarios o alimentos envasados. Arxiu d'Etnografia de Catalunya, (7), 138-149.

Catalá R, Gavara R (2001) Nuevos envases. De la protección pasiva a la defensa activa de los alimentos envasados. Arbor, 168(661), 109-127.

Cevallos PAP, Buera MP, Yelizalde BE (2010) Encapsulation of cinnamon and thyme essential oils components (cinnamaldehyde and thymol) in betacyclodextrin: effect of interaction with water on complex stability. Journal of Food Engineering, 99, 70-75.

Chadwick OA, Gavenda RT, Kelly EF, Ziegler K, Olson CG, Elliot WC, Hendricks DM (2003) The impact of climate on the biogeochemical functioning of volcanic soils. Chemical Geology, 202, 195-223.

Choi DS, Park SH, Choi SR, Kim JS, Chun HH (2015) The combined effects of ultraviolet$\mathrm{C}$ irradiation and modified atmosphere packaging for inactivating Salmonella enterica serovar Typhimurium and extending the shelf life of cherry tomatoes during cold storage. Food Packaging and Shelf Life, 3, 19-30.

Cholewa M, Kozakiewicz L (2012) The properties of moulding sand with halloysite. Archives Foundry Engineering, 12(2), 205-210.

Churchuman GJ, Aldridge LP, Carr RM (1972) The relationship between the hydrated and dehydrated states of a halloysite. Clays and Clay Minerals, 20, 241-246.

Churchman GJ, Sumner ME (2000) The alteration and formation of soil minerals by weathering. Handbook of Soil Science, 3-76.

Costa JM, Heuvelink E (2018) The global tomato industry, in Tomatoes, $2^{\text {nd }}$ Editor Heuvelink E (Oxfordshire, UK: CAB International). 1-26.

Cravotto G, Binello A, Baranelli E, Carraro P, Trotta F (2006) Cyclodextrins as food additives and in food processing. Current Nutrition and Food Science, 2, 343-350. 
Cruz R, Martínez Y, López V (2013) Biopolímeros y su integración con polímeros convencionales como alternativa de empaque de alimentos. Temas selectos de Ingeniería de Alimentos, 7(2), 42-52.

Cruz Morfin RM (2013) Biopolímeros y su integración con polímeros convencionales como alternativa de empaque de alimentos. Temas selectos de Ingeniería de alimentos, 42-52.

Cruz-Morfin R, Martínez-Tenorio Y, López-Malo A (2013) Biopolímeros y su integración con polímeros convencionales como alternativa de empaque de alimentos. Temas de Selección de Ingeniería de Alimentos, 7(2), 42-52.

Davies JN, Hobson GE (1981) The constituents of tomato fruit. The influence of environment, nutrition and genotype. Critical Reviews in Food Science and Nutrition, 15, 205-280.

De-Ancos B, González-Peña D, Colina-Coca C, Sánchez-Moreno C (2015) Uso de películas/recubrimientos comestibles en los productos de IV y $\mathrm{V}$ gama. Revista Iberoamericana de Tecnología Postcosecha, 16(1), 8-17.

Domínguez I, Lafuente MT, Hernández-Muñoz P, Gavara R (2016) Influence of modified atmosphere and ethylene levels on quality attributes of fresh tomatoes (Lycopersicon esculentum Mill.). Food chemistry, 209, 211-219.

Domini AK (2018) Potencialidades del quitosano para la fresa. Usos en la mejora y conservación de los frutos. Cultivos Tropicales, 39(1), 134-142.

EARM (2018) Estadística Agraria de la Región de Murcia CARM. https://www.carm.es/web/pagina?IDCONTENIDO=2589\&IDTIPO=100\&RASTRO=c80 $\$$ m22721,22746,1174, Accedido 25 julio 2019.

Edris A, Farrag E (2003) Antifungal activity of peppermint and sweet basil essential oils and their major aroma constituents on some plant pathogenic fungi from the vapor phase. Nahrunh, 47, 117-121.

EFSA (2011) European Food Safety Authority. Reglamento (UE) № 1129/2011 de la Comisión de 11 de noviembre de 2011 por el que se modifica el anexo II del Reglamento (CE) n¹333/2008 del Parlamento Europeo y del Consejo para establecer una lista de aditivos alimentarios de la Unión. https://eur-lex.europa.eu/legalcontent/ES/TXT/PDF/?uri=CELEX:32011R1129\&from=es. Accedido 6 julio de 2019. 
Eldiario (2019) Estas son las 12 variedades de tomates más consumidas en España. https://www.eldiario.es/consumoclaro/comer/variedades-tomates-consumidas-

Espana_0_871763158.html. Accedido 13 octubre 2019.

Eldiario (2019) Estas son las 12 variedades de pimiento más consumidas en España. https://www.eldiario.es/consumoclaro/comer/variedades-pimiento-consumidas-

Espana_0_871763158.html. Accedido 13 octubre 2019.

Elibox W, Meynard CP, Umaharan P (2015) Morphological changes associated with postharvest fruit deterioration and physical parameters for early determination of shelf life in Capsicum chinense Jacq. Horticultural Science, 50(10), 1537-1541.

Escalona-Contreras VH, Aguayo-Giménez EP, Artés-Calero F (2004) Envasado en atmósfera modificada de pimiento de carne gruesa. Alimentaria, 352, 89-95.

Esquinas-Alcazar, J, Nuez F (1995) Situación taxonómica, domesticación y difusión del tomate. In: F. Nuez (Editor), El Cultivo del Tomate. Ediciones Mundi Prensa, Madrid, pp. 14-42.

Espina L, Somolinos M, Lorán S, Conchello P, García D, Pagán R (2011). Chemical composition of commercial citrus fruit essential oils and evaluation of their antimicrobial activity acting alone or in combined processes. Food control, 22(6), 896-902.

ESTACOM (2017) Estadísticas españolas de comercio exterior. Accedido 31 Julio 2019.

FAO (2014) Organización de las Naciones Unidas para la Alimentación y la Agricultura. http://www.fao.org/3/s8270s/S8270S01.htm. Accedido 14 octubre 2019.

FAOSTAT (2017) Estadísticas de la Organización de las Naciones Unidas para la Alimentación y la Agricultura. http://www.fao.org/faostat/es/. Accedido 29 julio 2019.

FAOSTAT (2017) Estadísticas de la Organización de las Naciones Unidas para la Alimentación y la Agricultura. https://blogagricultura.com/etiqueta/faostat/. Accedido 3 agosto 2019.

Fernández-Valdés D, Bautista-Baños $S$, Fernández-Valdés $D$, Ocampo-Ramírez $A$, García-Pereira A, Falcón-Rodríguez A (2015) Películas y recubrimientos comestibles: una alternativa favorable en la conservación postcosecha de frutas y hortalizas. Revista Ciencias Técnicas Agropecuarias, 24(3), 52-57.

Finger FL, Pereira GM (2016) Physiology and postharvest of pepper fruits. In: Production and Breeding of Chili Peppers (Capsicum spp.). Springer, Cham, 27-40. 
Frank CA, Nelson RG, Simonne EH, Behe BK, Simonne AH (2001) Consumer preferences for color, price, and vitamin C content of bell peppers. HortScience, 36(4), 795-800.

Fruittoday (2017) España supera los 5.000 millones de $\mathrm{m}^{2}$ de producción de cartón ondulado en 2017. Autor: anónimo. https://fruittoday.com/espana-supera-los-5.000millones-de-metros-cuadrados-de-produccion-de-carton-ondulado-en-2017/. Accedido 2 octubre de 2019 .

FEN. Fundación Española de Nutrición http://fen.org.es/mercadoFen/pdfs/tomate.pdf. Accedido 13 octubre 2019.

FEN. Fundación Española de Nutrición

https://www.fen.org.es/index.php/articulo/el-pimiento. Accedido 6 octubre 2019.

García-García IJ, Taboada-Rodríguez A, Marín-Iniesta F, López-Gómez A (2012) Envase activo para conservación de productos vegetales frescos. Spanish Patent ES 2 393388 B1.

Giraldo-Perdomo YF, Torres-Rubio JE (2018) Evaluación técnica de la cadena de frío en la producción de frutas y verduras en Colombia, para Acaire (Bachelor's thesis, Fundación Universidad de América).

Glowacz M, Colgan R, Rees D (2015) Influence of continuous exposure to gaseous ozone on the quality of red bell peppers, cucumbers and zucchini. Postharvest Biology and Technology, 99, 1-8.

Glowacz M, Rees D (2016) Exposure to ozone reduces postharvest quality loss in red and green chilli peppers. Food chemistry, 210, 305-310.

González G, Tiznado M (1993) Postharvest physiology of bell peppers stored in lowdensity polyethylene bags. LWT Food Science and Technology, 26(5), 450-455.

Gonzalez-Aguilar GA, Ayala-Zavala JF, De la Rosa LA, Alvarez-Parrilla E (2010) Phytochemical Changes in the Postharvest and Minimal Processing of Fresh Fruits and Vegetables. In: Fruit and Vegetable Phytochemicals: Chemistry, Nutritional Value and Stability (Eds.). Wiley-Blackwell, Ames, USA, ISBN: 9780-8138-0320-3, 309-340.

González-Saucedo A, Barrera-Necha LL, Ventura-Aguilar RI, Correa-Pacheco ZN, Bautista-Baños S, Hernández-López M (2019) Extension of the postharvest quality of bell pepper by applying nanostructured coatings of chitosan with Byrsonima crassifolia extract (L.) Kunth. Postharvest Biology and Technology, 149, 74-82. 
Gorrasi, G., Bugatti, V., \& Sorrentino, A. (2018). Nanohybrid Active Fillers in Food Contact Bio-based Materials. In Bionanocomposites for Packaging Applications, Springer, Cham, 71-94.

Guerra M, Casquero PA (2005) Evolución de la madurez de variedades de manzana y pera en almacenamiento frigorífico conjunto con absorbedor de etileno. Información tecnológica, 16(4), 11-16.

Granja-Carvajal EJ (2016) Estudio de la aplicación de radiación gamma para extender la vida útil de pimiento (Capsicum annuum) entero y el efecto sobre sus compuestos bioactivos (Bachelor's thesis, Quito, 2016.).

Greenpeace

https://es.greenpeace.org/es/trabajamosen/consumismo/plasticos/datos-sobre-la-produccion-de-plasticos/. Accedido 15 septiembre 2019.

Guerra-Alva D, Pandura-Vela DH (2012) Aceites esenciales. Universidad nacional de la Amazonía Peruana. Tesis Doctoral, Facultad de Ingeniería Química (Perú).

Guerrero K (2017) Evaluación de recubrimientos de quitosano con diferentes ácidos orgánicos para el control de la podredumbre gris causada por Botrytis sp. En la postcosecha de Mora de Castilla (Rubus glaucus). Tesis profesional. Escuela Politécnica Nacional, Quito, Ecuador.

Guil-Guerrero JL, Martínez-Guirado C, del Mar Rebolloso-Fuentes M, Carrique-Pérez A (2006) Nutrient composition and antioxidant activity of 10 pepper (Capsicum annuum) varieties. European Food Research and Technology, 224(1), 1-9.

Gurtler JB, Smelser AM, Niemira BA, Jin TZ, Yan X, Geveke DJ (2012) Inactivation of Salmonella enterica on tomato stem scars by antimicrobial solutions and vacuum perfusion. International Journal of Food Microbiology, 159, 84-92.

Gutiérrez L, Escudero A, Batlle R, Nerín C (2009) Effect of Mixed Antimicrobial Agents and Flavors in Active Packaging Films. Journal of Agricultural and Food Chemistry, 57, 8564-8571.

Hofmann U, Endell K, Wilm D (1934) Röntgenographise und kolloidchemische Untersuchungen über ton. Angewandte Chemie, 47, 539-547.

Hong JH y Gross KC (2000) Involvement of ethylene in development of chilling injury in fresh-cut tomato slices during cold storage. Journal of the America Society for Horticultural Science, 125, 736-741. 
Hortoinfo (2017) http://www.hortoinfo.es/index.php/informes/cultivos/5897-inf-tomate2017. Accedido 6 agosto 2019.

Hortoinfo (2018) http://www.hortoinfo.es/index.php/6601-prod-mund-pim-100118. Accedido 8 agosto 2019.

Infoagro (2017) El cultivo del tomate (1 ${ }^{a}$ parte). http://infoagro.com/hortalizas/tomate. Accedido 13 octubre de 2019.

Infoagro (2017) El cultivo del pimiento (1 ${ }^{\text {a }}$ parte) https://www.infoagro.com/hortalizas/pimiento.htm. Accedido 11 octubre 2019.

Jinkarn T, Boonchu P, Bao-Ban S (2006) Effect of carrying slots on the compressive strength of corrugated board panels. Kasetsart Journal: Natural Science, 40 (6), 154161.

Joussein E, Petit S, Churchman J, Theng B, Righi D y Delvaux B (2005) Halloysite clay minerals: a review. Clay Minerals 40, 383-426.

Kaewklin P, Siripatrawan U, Suwanagul A, Lee YS (2018) Active packaging from chitosan-titanium dioxide nanocomposite film for prolonging storage life of tomato fruit. International journal of biological macromolecules, 112, 523-529.

Kamble R, Ghag M, Gaikaward S, Panda BK (2012) Halloysite nanotubles and applications: A review. Journal of Advance Scientific Research, 3(2), 25-29.

Kartox, https://kartox.com/blog/las-diferentes-tipos-de-carton-ondulado/. Accedido 15 octubre 2019.

Kasmire RF, Cantwell MI (1992) Postharvest handling systems: Fruit vegetables. In Kader, AA (Ed.), Postharvest quality of horticultural crops. University of California Publications, Oakland, CA, USA, 15-20.

Klopffer MH, Flaconneche B (2001) Transport properdines of gases in polymers: bibliographic review. Oil \& Gas Science and Technology, 56(3), 223-244.

Kloucek P, Smid J, Frankova A, Kokoska L, Valterova I, Pavel R (2011) Fast screening method for assessment of antimicrobial activity of essential oils in vapor phase. Food Research International, 47, 1-5.

Koenig D, Jiménez-Gómez JM, Kimura S, Fulop D, Chitwood DH, Headland LR, Tohge T (2013) Comparative transcriptomics reveals patterns of selection in domesticated and wild tomato. Proceedings of the National Academy of Sciences, 110(28), 2655-2662. 
Köstekli M, Özdzikicierlev O, Cortes C, Zulueta-Albelda A, Esteve-Más MJ, FrígolaCánoves A (2016) Role of potassium permanganate ethylene on physicochemical properties, during storage of five different tomato cultivars. MOJ food processing \& technology, 3(2), 1-9.

Kubai RM (2017) Nutritional and postharvest quality attributes of commercial tomato varieties. Doctoral dissertation, Faculty of Agriculture, JKUAT, 1-94.

Lee DS, Yam KL, Piergiovanni L, Yam KL (2008) Food packaging polymers, Chapter 6, Food Packaging Science and Technology. Boca Raton, Florida. CRC Press.

León-Mendoza C (2017) Determinación de la acción antifúngica de los aceites esenciales de pimienta negra (piper nigrum), romero (rosmarinus officinalis) y orégano (origanum vulgare) sobre hongos post cosecha en aji paprika (capsicum annuum L.). Tesis Doctoral, Facultad de Biología, Lima, Perú, 10-63.

López-Gómez A (2016) Envase de cartón para envasado activo de frutas y hortalizas frescas, y procedimiento de fabricación del mismo. Spanish Patent ES 2588261 A1.

López P, Sánchez C, Batle R, Nerín C (2005) Solid-and vapor-phase antimicrobial activities of six essential oils: susceptibility of selected foodborne bacterial and fungal strains. Journal of Agricultural and Food Chemistry, 53, 6939-6946.

Lucas-Abellán C, Gabaldón-Hernández JA, Penalva J, Fortea MI, Núñez-Delicado E (2008) Preparation and Characterization of the inclusion complex of chlorpyrifos in cyclodextrins to improve insecticide formulations. Journal Agricultural Food Chemistry. $56,8081-8085$.

Lvov Y, Abdullayev E (2013) Funtional polymer-clay nanotube composites with sustained release of chemical agents. Progress in Polymer Science, 38, 1690-1719.

Mahmoud BSM (2010) Effects of X-ray radiation on Escherichia coli O157:H7, Listeria monocytogenes, Salmonella enterica and Shigella flexneri inoculated on whole Roma tomatoes. Food Microbiology, 27, 1057-1063.

Makaremi M, Pasbakhsh P, Cavallaro G, Lazzara G, Aw YK, Lee SM, Milioto S (2017) Effect of morphology and size of halloysite nanotubes on functional pectin bionanocomposites for food packaging applications. ACS applied materials \& interfaces, 9(20), 17476-17488.

Mangaraj S, Goswami TK (2011) Modeling of respiration rate of Litchi fruit under aerobic conditions. Journal Food Biology Technology, 4, 272-281. 
Marques HMC (2010) A review on cyclodextrin encapsulation of essential oils and volátiles. Flavour and Fragance Journal, 25(5), 313-326.

Martin del Valle EM (2004) Cyclodextrins and their uses: A review. Process Biochemistry, 39, 1033-1046.

Martínez A (2001) Aceites esenciales. Universidad de Antioquia. Medellín, Colombia, 4-17.

Martínez G, Gómez MA (2007) Ciclodextrinas: complejos de inclusión con polímeros. Revista Iberoamericana de Polímeros, 8, 300-312.

Martínez-Hernández GB, Boluda-Aguilar M, Taboada-Rodríguez A, Soto-Jover S, Marín-Iniesta F, López-Gómez A (2016) Processing, packaging, and storage of tomato products: influence on the lycopene content. Food Engineering Reviews, 8(1), 52-75.

Martínez-Hernández GB, Castillejo N, Artés-Hernández F (2019) Effect of fresh-cut apples fortification with lycopene microspheres, revalorized from tomato by-products, during shelf life. Postharvest Biology and Technology, 156, 110925.

Martínez-Romero D, Bailén G, Serrano M, Guillén F, Valverde JM, Zapata P, Castillo S, Valero D (2007) Tools to maintain postharvest fruit and vegetable quality through the inhibition of ethylene action: a review. Critical reviews in food science and nutrition, 47(6), 543-560.

Martínez-Ruiz FE, Cervantes-Díaz L, Aíl-Catzím CE, Hernández-Montiel LG, Sánchez CLDT, Rueda-Puente EO (2016) Hongos fitopatógenos asociados al tomate (Solanum Lycopersicum L.) en la zona árida del noroeste de México: la importancia de su diagnóstico. European Scientific Journal, 12(18), 232-256.

Martinez-Tenorio Y, Lopez-Malo V (2011) Envases activos con agentes antimicrobianos y su aplicación en los alimentos. Temas selectos de Ingenieria de alimentos, 5(2), 1-12.

Matiacevich S, Sáez C (2018) Encapsulación de aceite esencial de lemongrass en el desarrollo de ingredientes naturales en polvo para preservación de alimentos: Una revisión. Contribuciones Científicas y Tecnológicas, 42(2), 23-31.

Mejía RJ, Martínez MTA, Lara PDL (2018) Quitosano: actividad antimicrobiana y mecanismos de acción. e-CUCBA, 9, 17-23.

Mendoza-Robledo J (2018) Empaques, envases y embalajes: el producto y su recipiente. Editorial Javeriano-Pontificia Universidad Javeriana, Cali. Colombia. ISBN: 978-958-5453-07-4. 
Mercado FR, Bugueño JB, Torres A, Galotto MJ, Moraga AG (2019) Envases de alimentos y medio ambiente: desafíos para avanzar por una sociedad eco-amigable. Revista Contribuciones científicas y tecnológicas. Universidad de Santiago de Chile, 43, 29-37.

Michelena SP, Herrera RR, Gallegos ACF, González MLC, Ramos-González R, Ceniceros EPS, llina A (2019) Alternativas para el control de bacterias transmitidas por alimentos. CienciAcierta 57, 1-10.

Montero-Recalde M, Revelo J, Avilés-Esquivel D, Valle E, Guevara-Freire D (2017) Efecto antimicrobiano del aceite esencial de canela (Cinnamomum zeylanicum) sobre cepas de Salmonella. Revista de Investigaciones Veterinarias del Perú, 28(4), 987-993.

Montero-Recalde M, Mira JC, Avilés-Esquivel D, Pazmiño-Miranda P, \& Erazo-Gutiérrez R (2018) Eficacia antimicrobiana del aceite esencial de tomillo (Thymus vulgaris) sobre una cepa de Staphylococcus aureus. Revista de Investigaciones Veterinarias del Perú, 29(2), 588-593.

Moreira RG, Puerta-Gómez AF, Kim J, Castell-Pérez ME (2012) Factors affecting radiation D-values (D10) of an Escherichia coli cocktail and Salmonella Typhimurium LT2 inoculated in fresh produce. Journal of Food Science, 77, 104-111.

Moreno PM (2002) Inhibición de Aspergillus flavus y Penicillium digitatum utilizando agentes antimicrobianos naturales y/o sintéticos. Tesis de Licenciatura. Universidad de las Américas, Puebla, México.

Nerín de la Puerta C, Astudillo-Campillo M, Covián-Sánchez I, Mujika-García R (2008) Envase activo inhibidor de patógenos alimentarios. Spanish Patent ES 2289930 B1.

Niemira BA, Boyd G (2013) Influence of modified atmosphere and varying time in storage on the irradiation sensitivity of Salmonella on sliced roma tomatoes. Radiation Physics and Chemistry, 90, 120-124.

Norma UNE 137005:2005. Envases y embalajes de cartón ondulado. Envases y embalajes interapilables para frutas y hortalizas. https://www.une.org/encuentra-tunorma/busca-tu-norma/norma?c=N0033212. Accedido 15 octubre de 2019.

Nowacka M, Rybak K, Wiktor A, Mika A, Boruszewski P, Woch J, Witrowa-Rajchert D (2018) The quality and safety of food contact materials-paper and cardboard coated with paraffin emulsion. Food control, 93, 183-190. 
Oliveira M, Usall J, Solsona C, Alegre I, Vinas I, Abadias M (2010) Effects of packaging type and storage temperature on the growth of foodborne pathogens on shredded 'Romaine' lettuce. Food Microbiology, 27, 375-380.

Otoni CG, Espitia PJ, Avena-Bustillos RJ, Mchugh TH (2016) Trends in antimicrobial food packaging systems: Emitting sachets and absorbent pads. Food Research International, 83, 60-73.

Palma JM, Jiménez A, Corpas FJ, Mateos RM, Martí MC, Sevilla F, del Río LA (2011) Role of ascorbate on the fruit physiology of pepper (Capsicum annumm L.). Functional Plant Science and Biotechnology, 5, 56-61.

Pandey SK, Goswami TK (2012) An Engineering Approach to Design Perforated and Non Perforated Modified Atmospheric Packaging unit for Capsicum. Journal of Food Processing and Technology, 3(11), 1-4.

Pastrana-Puche Y, Durango-Villadiego A, Cevedo-Correa D (2017) Efecto antimicrobiano del clavo y la canela sobre patógenos. Biotecnología en el sector agropecuario y agroindustrial, 15(1), 56-65.

Peron E, Razeti M (2008) Envase particularmente para el empaquetado de productos alimenticios. ES2297087T3.

Pino-Pérez O, Rojas-Fernández MM, Sánchez-Pérez Y, Espinosa-Castaño I (2018) Actividad antibacteriana de aceites esenciales obtenidos de plantas de origen cubano sobre Streptococcus suis. Revista de Salud Animal, 40(3), 1-5.

PlasticsEurope https://www.plasticseurope.org/application /files/6315/4510/9658/Plastics_the_facts_2018_AF_web.pdf. Accedido 8 octubre 2019. PlasticsEurope (2019) https://www.plasticseurope.org/es/about-plastics/what-areplastics/large-family. Accedido 8 octubre 2019.

Radu CD, Parteni O, Ochiuz L (2016) Applications of cyclodextrins in medical textilesreview. Journal of Controlled Release, 224, 146-157.

Radzevičius A, Karklelienè R, Viškelis $P$, Bobinas $C$, Bobinaitè $T$, Sakalauskienè $S$ (2009) Tomato (Lycopersicon esculentum Mill.) fruit quality and physiological parameters at different ripening stages of Lithuanian cultivars. Lithuanian Institute of Horticulture, Agronomy Research, 7(2), 712-718. 
Rajendiran N, Jenita MJ (2015) Encapsulation of 4-hydroxy-3-methoxy benzoic acid and 4-hydroxy-3, 5-dimethoxy benzoic acid with native and modified cyclodextrins. Spectrochimica Acta Molecular and Biomolecular Spectroscopy, 136, 1349-1357.

Ramos M, Jiménez A, Peltzer M, Carrigós MC (2012) Characterization and antimicrobial activity studies of polypropylene films with carvacrol and thymol for active packaging. Journal of Food Engineering, 109, 513-519.

Ramos M, Romero C, Bautista S (2018) Almidón modificado: Propiedades y usos como recubrimientos comestibles para la conservación de frutas y hortalizas frescas. Revista Iberoamericana de Tecnología y Postcosecha, 19, 30-44.

Reche J (2010) Cultivo del pimiento dulce en invernadero. Junta de Andalucía, Consejería de Agricultura y Pesca. Servicio de Publicaciones y Divulgación, Sevilla.

Reglamento (UE) № 1935/2004 (2004) Materiales y objetos destinados a entrar en contacto con alimentos. Parlamento europeo, Consejo de la Unión Europea. https://eurlex.europa.eu/search.html?qid=1572022328125\&text=1935/2004\%20Materiales\%20y \%20objetos\%20destinados\%20a\%20entrar\%20en\%20contacto\%20con\%20alimentos $\&$ scope $=E U R L E X \&$ type $=$ quick $\&$ lang $=e s$

Rhim JW, Lee JH, Hong SI (2007) Increase in water resistance of paperboard by coating with poly (lactide). Packaging Technology and Science, 20, 393-402.

Rick CM, Fobes JF (1976) Peroxidase complex with concomitant anodal and cathodal variation in red-fruited tomato species. Proceedings of the National Academy of Sciences, 73(3), 900-904.

Rodler N, Fleischmann V (2010) Method for increasing the self-life or agricultural products which produce ethylene, during transport, sale, presentation and/or storage. United State Patent US 20100092634 A1.

Rodoni LM, Massolo JF, Vicente AR (2017) Evaluación de diferentes tratamientos físicos en pimiento Capsicum annuum L. verde y rojo mínimamente procesado. Enfoque UTE, 8(2), 33-43.

Rodríguez-Ortega WM, Martínez V, Nieves M, Simón I. Lidón V, Fernandez-Zapata JC, García-Sánchez F (2019) Agricultural and physiological Responses of tomato plants Grown in Different Soilless Culture systems with saline Water under Greenhouse Conditions. Scientific reports, 9, 1-13.

Ruiz C, Díaz C, Rojas R (2015) Composición química de aceites esenciales de 10 plantas aromáticas peruanas. Revista de la Sociedad Química de Perú, 81, 81- 94. 
São José JFB, Vanetti MCD (2012) Effect of ultrasound and commercial sanitizers in removing natural contaminants and Salmonella enterica Typhimurium on cherry tomatoes. Food Control, 24(1), 95-99.

Sánchez ML (2016) Mecanismos de acción de péptidos antimicrobianos y mecanismos de resistencia de los patógenos. Revista de la Asociación de Bioquímica Argentina, 80 (1), 36-43.

Shemesh R, Krepker M, Nitzan N, Vaxman A, Segal E (2016) Active packaging containing encapsulated carvacrol for control of postharvest decay. Postharvest Biology and Technology, 118, 175-182.

Shen L, Worrell E, Patel M (2010) Present and future development in plastics from biomass. Biofuels Bioproducts and Biorefining, 4, 25-40.

Shewfelt RL, Thai CN, Davies JW (1988) Prediction of changes in color of tomatoes during ripening at different constant temperatures. Journal Food Science, 53, 14331437.

Shimao M (2001) Biodegradation of plastics. Current Opinion in Biotechnology, 12, 242247.

Singh M, Sharma R, Banerjee UC (2002) Biotechnological applications of cyclodextrins. Biotechnology Advances, 20, 341-359.

Singh R, Giri SK, Kotwaliwale N (2014) Shelf-life enhancement of green bell pepper (Capsicum annuum L.) under active modified atmosphere storage. Food Packaging and Shelf Life, 1(2), 101-112.

Statista. Investigación de mercados y estadística. https://es.statista.com/. Accedido 25 Julio 2019.

Szejtli J (1998) Introduction and general overview of cyclodextrin chemistry, Chemical Reviews, 98, 1743-1753.

Tang XX, Kumar P, Alavi S, Sande KP (2012) Recent advances in biopolymers and biopolymer-based nanocomposites for food packaging materials. Critical Reviews in Food Science and Nutrition, 52, 426-442.

Tas CE, Hendessi S, Baysal M, Unal S, Cebeci FC, Menceloglu YZ, Unal H (2017) Halloysite nanotubes/polyethylene nanocomposites for active food packaging materials with ethylene scavenging and gas barrier properties. Food Bioprocess Technology, 10, 789-798. 
Tharanathan RN (2003) Biodegradable films and composite coatings: past, present and future. Trends in Food Science and Technology 14, 71-78.

Tian H, Wang Y, Zhang L, Quan C, Zhang X (2010) Improved flexibility and water resistance of soy protein thermoplastics containing waterborne polyurethane. Industrial Crops and Products, 32, 13-20.

Tsagkaris, A. S., Tzegkas, S. G., \& Danezis, G. P. (2018). Nanomaterials in food packaging: state of the art and analysis. Journal of food science and technology, 55(8), 2862-2870.

UCM (2010) Universidad Complutense de Madrid. https://www.ucm.es/data/cont/media/www/pag-15563/Filo\%201.pdf. Accedido 10 agosto 2019.

Valero D, Serrano M (2010) Postharvest Biology and Technology for Preserving Fruit Quality. CRC Press, Boca Raton, Florida, USA, 1-61.

Van Long NN, Joly C, Dantigny P (2016) Active packaging with antifungal activities. International Journal of Food Microbiology, 220, 73-90.

Vergaro V, Abdullayev E, Lvov YM, Zeitoun A, Cingolani R, Rinaldi E, Leporatti S (2010) Cytocompatibility and uptake of halloysite clay nanotubes. Biomacromolecules, 11, 820826.

Villavicencio L, Blankenship SM, Sanders DC, Swallow WH (1999) Ethylene and carbon dioxide production in detached fruit of selected pepper cultivars. Journal of the American Society for Horticultural Science, 124(4), 402-406.

Villavicencio L, Blankenship SM, Sanders DC, Swallow WH (2001) Ethylene and carbon dioxide concentrations in attached fruits of pepper cultivars during ripening. Scientia Horticulturae, 91, 17-24.

Villegas-Martínez M (2018) Papel del Etileno en el Comportamiento Diferencial de la Maduración del Fruto en Cuatro Variedades de Pimiento. Máster en Biotecnología Industrial y Agroalimentaria, Universidad de Almería, 1-39.

Wen P, Zhu DH, Wu H, Zong MH, Jing YR, Han SY (2016) Encapsulation of cinnamon essential oil in electrosporum nanofibrous film for active food packaging. Food Control, 59, 366-376.

Wilson-Charles I (2008) Packaging system for preserving perishable ítems. United State Patent US 7387205 B1. 
Wilson LG, Boyette MD, Estes EA (1995) Postharvest handling and cooling of fruits, vegetables and flowers for small farms, part 1: quality maintenance. Wilson LG, Boyette MD, Estes EA, (Eds.), N. C. Coop. Extension Service Horticultural Information, Leaf No. $800,4$.

Wood WE, Beaverson NJ, Kuduk WJ (2011) Maturation or ripening inhibitor release from polymer, fiber, film, sheet or packaging. European Patent EP 2512232 A1.

Ziegler K, Hsieh JCC, Chadwick OA, Kelly EF, Hendricks DM, Savin SM (2003) Halloysite as a kinetically controlled end product of arid-zone basalt weathering. Chemical Geology, 202, 461-478. 


\section{JUSTIFICACIÓN}

OBJETIVOS 


\section{JUSTIFICACIÓN Y OBJETIVOS}

España es uno de los países más importantes a nivel mundial en cuanto a producción y exportación hortofrutícola, lo cual se corresponde también con la gran importancia de este sector en la Región de Murcia y provincias colindantes, siendo el tomate y el pimiento las hortalizas de mayor producción y exportación. Es importante destacar también que más del $50 \%$ de estos productos frescos son comercializados a granel y en cajas de cartón. Sin embargo, antes del desarrollo de esta Tesis no existían en el mercado soluciones viables de envasado activo a granel en cajas de cartón para estos productos frescos. Esto motivó el comienzo de una línea de investigación enfocada al desarrollo de este tipo de envase activo para productos hortofrutícolas frescos comercializados a granel, dentro del Grupo de Investigación en Ingeniería del Frío y Seguridad Alimentaria de la UPCT, en colaboración con la empresa Sociedad Anónima Española de Cartón Ondulado (SAECO).

Por otro lado, existe una tendencia muy fuerte en los últimos años a utilizar envases biodegradables para así conseguir un menor impacto medioambiental. Este es uno de los motivos del uso creciente del envase de cartón corrugado o microcorrugado. Otros motivos del uso de este envase reciclable y sostenible es que tiene unas propiedades mecánicas que se adaptan muy bien a los envases que se necesitan en el envasado de frutas y hortalizas frescas. Pero, los procedimientos habituales de envasado en este tipo de envase de cartón, sin carácter activo, pueden dar lugar a problemas de pérdidas importantes de producto por podredumbres y a problemas de seguridad alimentaria, porque no se pueden combatir con este envase convencional los microorganismos patógenos que puedan estar presentes en la superficie de estos productos frescos.

Por todo lo anterior, se propone llevar a cabo esta Tesis centrada en el desarrollo de un envase de cartón activo antimicrobiano para el envasado a granel de tomates y pimientos frescos, que sea competitivo y no suponga un incremento significativo de los costes del producto, y que controle la proliferación de la microbiología alterante de estos productos. De esta manera se quiere conseguir el alargamiento de la vida útil del producto, que se mantenga fresco con toda su calidad más tiempo cuando sean almacenados en condiciones recomendadas de conservación a temperaturas adecuadamente bajas y HR elevadas, para que no se produzcan daños por frío ni se tengan pérdidas de peso y calidad por deshidratación. 
De esta manera, con esta Tesis se pretenden conseguir los siguientes objetivos generales:

- Mejorar la calidad y vida útil de tomates y pimientos frescos comercializados a granel mediante el desarrollo de un envase activo de cartón, que incluye agentes antimicrobianos encapsulados, que permitan conservar la frescura y la calidad y disminuir las pérdidas de estos productos por podredumbre en el transporte y distribución.

- Mejorar la seguridad alimentaria de estos productos envasados a granel que, a menudo, se consumen en fresco sin lavar o con un ligero lavado. Se trata de desarrollar un envase de cartón activo antimicrobiano que tenga acción tanto sobre los microorganismos alterantes como sobre patógenos (Salmonella, Listeria y Escherichia coli) que pueden llegar a desarrollarse en este tipo de productos frescos.

\section{Objetivos específicos}

- Desarrollo de un envase activo de cartón con carácter antimicrobiano que incluya agentes antimicrobianos naturales encapsulados, para el envasado a granel de tomates y pimientos frescos, y así aumentar la vida útil, calidad y seguridad alimentaria percibida por el consumidor en el momento de su consumo. Para ello se estudiará la combinación y dosis más apropiada de AEs que serán encapsulados en $\beta-C D$, y aplicados en combinación con una laca polimérica en base agua como recubrimiento del cartón.

- Validación a escala de planta piloto e industrial del prototipo de envase de cartón activo antimicrobiano desarrollado, para el envasado de tomates y pimientos frescos.

- Evaluar la calidad fisicoquímica, microbiológica, sensorial, porcentaje de podridos, firmeza y color de tomates frescos envasados a granel en envase activo antimicrobiano recubierto por una laca impermeabilizante que incluye el complejo de inclusión $(A E+\beta-C D)$, durante su conservación a $8 \stackrel{\circ}{\circ}$ y $25^{\circ} \mathrm{C}$.

- Evaluar el efecto de los envases activos antimicrobianos recubierto con AEs encapsulados en $\beta-C D$ constituyendo un complejo de inclusión, sobre la microbiología, sobre los análisis fisicoquímicos y análisis sensorial de pimientos frescos envasados y almacenados a $8 \stackrel{\circ}{\circ}$ y un $90 \%$ de HR.

- Analizar el efecto de este envase activo antimicrobiano, recubierto con AEs encapsulados en $\beta-C D$, sobre la calidad microbiológica, fisicoquímica y sensorial de tomates Cherry envasados y almacenados a $8 \stackrel{\circ}{\circ}$ y un $90 \%$ de HR. 
- Evaluar la efectividad de adicionar AEs encapsulados en distintos tipos de nanocápsulas $(A E+\beta-C D / H N T)$ en la laca impermeabilizante del cartón. Se estudiará la calidad de tomates frescos durante su conservación a $8{ }^{\circ} \mathrm{C}$ durante 6 días (simulando el transporte refrigerado) y después a temperatura ambiente durante 5 días (simulando el período de comercialización).

- $\quad$ Caracterizar mediante Termogravimetría (TG), Análisis Térmico Diferencial (DTA), Espectroscopía de absorción infrarroja (FTIR) y Microscopía Electrónica de Barrido (SEM), los AEs, $\beta$-CD y el complejo de inclusión AEs + $\beta-C D$.

- Determinar las propiedades mecánicas e hidrofóbicas del envase activo de cartón que incluye el complejo de inclusión $(A E+\beta-C D)$, comparándolas con las del envase control sin el complejo de inclusión.

- Determinar la migración de AEs desde el envase activo de cartón hacia los frutos de tomate y pimiento frescos durante su conservación en este tipo de envase activo. 


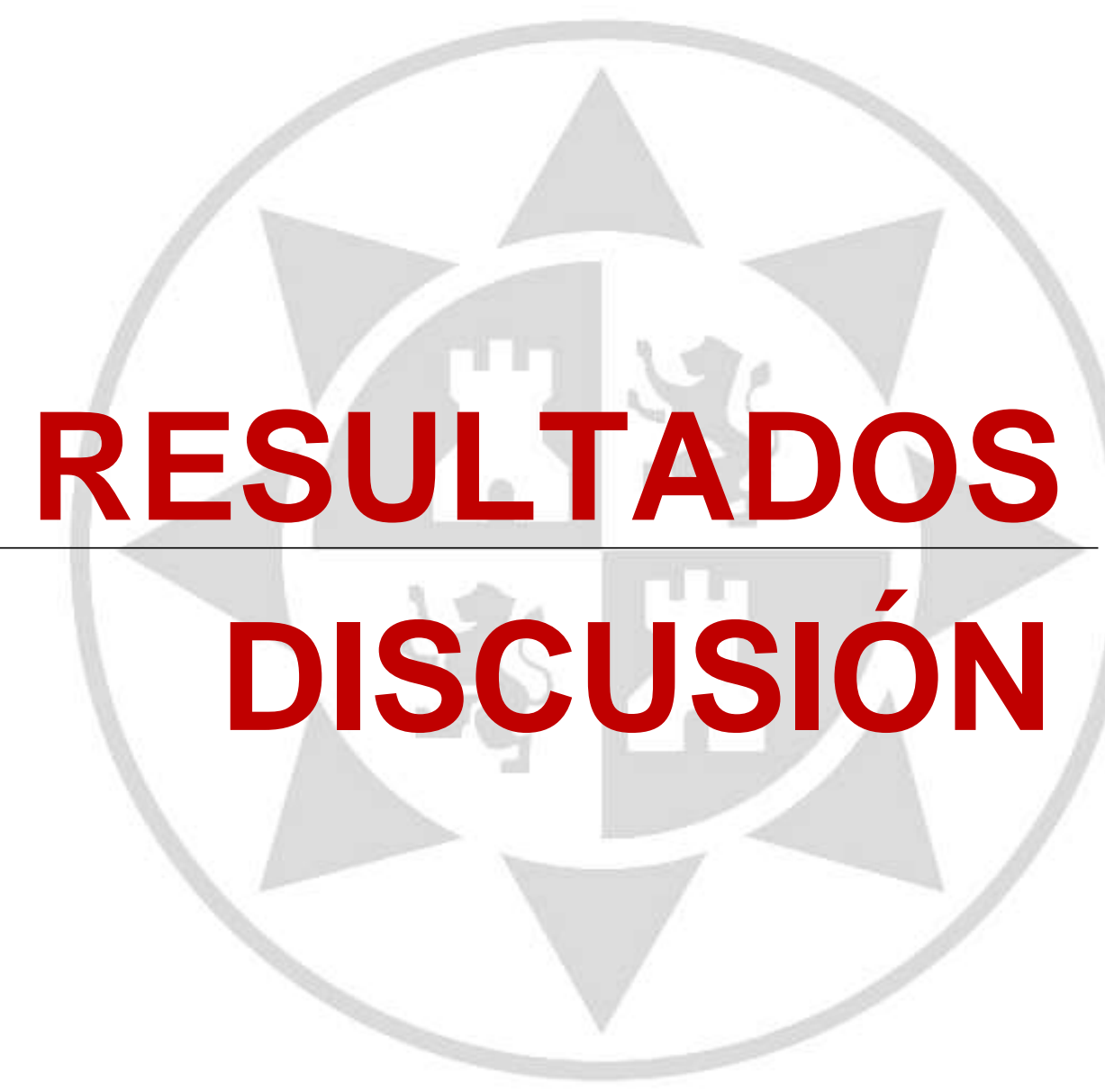




\section{RESULTADOS Y DISCUSIÓN}

Esta tesis se ha presentado mediante compendio de publicaciones, por lo que los resultados y discusión de los mismos vienen incluidos en los artículos que componen este trabajo y se exponen en los Capítulos del I al IV siguientes:

\section{Capítulo I}

Artículo: Laura Buendía-Moreno, María Ros-Chumillas, Laura Navarro-Segura, María José Sánchez-Martínez, Sonia Soto-Jover, Vera Antolinos, Ginés Benito MartínezHernández, Antonio López-Gómez. 2019. Effects of an Active Cardboard Box Using Encapsulated Essential Oils on the Tomato Shelf Life. Food and Bioprocess Technology, 12(9): 1548-1558, https://doi.org/10.1007/s11947-019-02311-0.

\section{Capítulo II}

Artículo: Laura Buendía-Moreno, Sonia Soto-Jover, María Ros-Chumillas, Vera Antolinos, Laura Navarro-Segura, María José Sánchez-Martínez, Ginés Benito Martínez-Hernández, Antonio López-Gómez. 2019. An innovative active cardboard for box bulk packaging of fresh bell pepper extends its shelf life. Postharvest Biology and Technology. Presentado para su publicación: en proceso de revisión.

\section{Capítulo III}

Artículo: Laura Buendía-Moreno, Sonia Soto-Jover, María Ros-Chumillas, Vera Antolinos, Laura Navarro-Segura, María José Sánchez-Martínez, Ginés Benito Martínez-Hernández, Antonio López-Gómez. 2019. Innovative cardboard active packaging with a coating including encapsulated essential oils to extend Cherry tomato shelf life. LWT- Food Science and Technology, 116, 108584. https://doi.org/10.106/j.Iwt.2019.108584.

\section{Capítulo IV}

Artículo: Laura Buendía-Moreno, María José Sánchez-Martínez, Vera Antolinos, María Ros-Chumillas, Laura Navarro-Segura, Sonia Soto-Jover, Ginés Benito MartínezHernández, Antonio López-Gómez. 2019. Active cardboard box with a coating including essential oils entrapped within cyclodextrins and/or halloysite nanotubes. A case study 
for fresh tomato storage. Food Control, 107, 106763. https://doi.org/10.1016/j.foodcont.2019.106763.

Además, se han presentado comunicaciones en los siguientes Congresos Internacionales:

- Antonio López-Gómez, Sonia Soto-Jover, María Ros-Chumillas, María José Sánchez-Martínez, Laura Navarro-Segura, Laura Buendía-Moreno, Jesús Grande-Finch (2018). Eficacia de un envase de cartón activo antimicrobiano en la conservación refrigerada de pimiento fresco a granel. IX Congreso Ibérico, VII Congreso Iberoamericano de Ciencias y Técnicas del Frío, CYTEF-2018, Valencia, España, 19-21 Junio, 130.

- Antonio López-Gómez, Sonia Soto-Jover, María Ros-Chumillas, María José Sánchez-Martínez, Laura Navarro-Segura, Laura Buendía-Moreno, Jesús Grande-Finch (2018). Envase de cartón activo antimicrobiano para reducir la podredumbre del tomate fresco envasado a granel y conservado en refrigeración. IX Congreso Ibérico, VII Congreso Iberoamericano de Ciencias y Técnicas del Frío, CYTEF-2018, Valencia, España, 19-21 Junio, 131. 


\section{CAPÍTULO I.}

"Efectos de un envase active de cartón que utiliza aceites esenciales encapsulados sobre la vida útil del tomate"
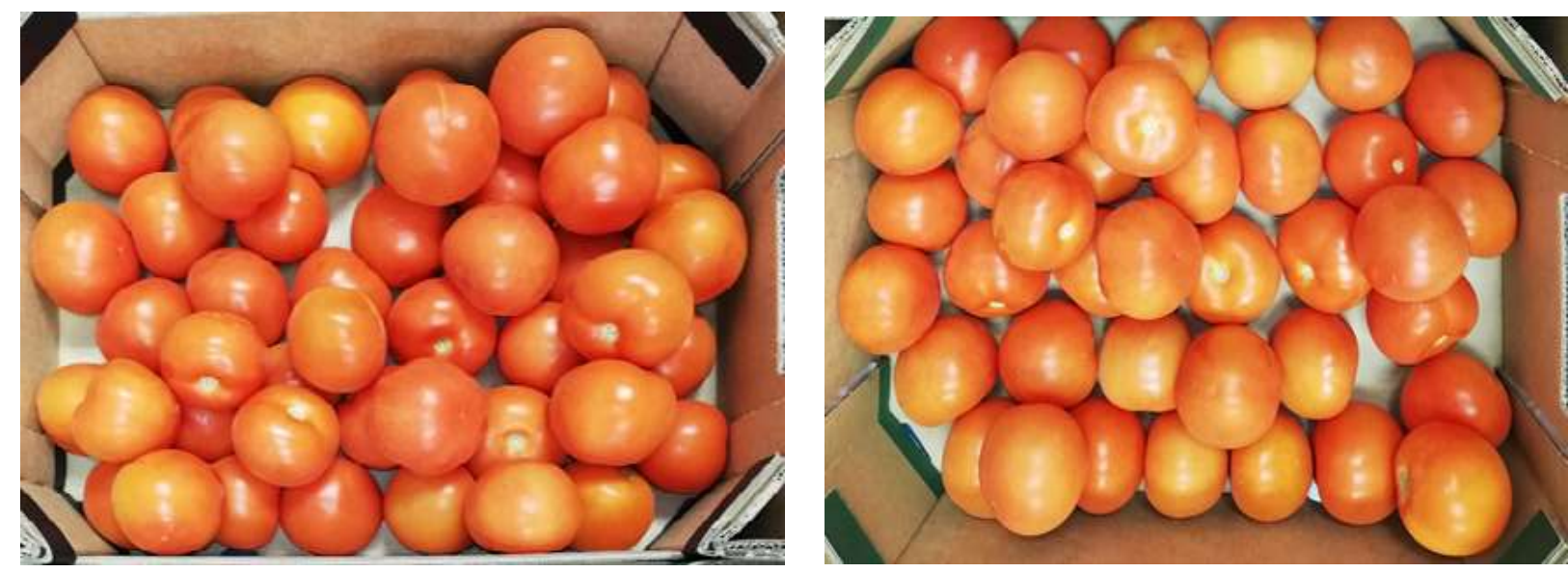

Este Capítulo se corresponde con el artículo siguiente:

Laura Buendía-Moreno, María Ros-Chumillas, Laura Navarro-Segura, María José Sánchez-Martínez, Sonia Soto-Jover, Vera Antolinos, Ginés Benito MartínezHernández, Antonio López-Gómez. 2019. Effects of an Active Cardboard Box Using Encapsulated Essential Oils on the Tomato Shelf Life. Food and Bioprocess Technology, 12(9), 1548-1558, https://doi.org/10.1007/s11947-019-02311-0.

Food safety and Refrigeration Engineering Group, Department of Agricultural Engineering, Universidad Politécnica de Cartagena, Paseo Alfonso XIII, 48, 30203, Cartagena, Murcia, Spain `E-mail address: antonio.lopez@upct.es (A. López-Gómez). 


\section{Resumen}

En este capítulo se estudia el efecto de un envase activo de cartón, que incluye AEs encapsulados en $\beta-C D$, sobre la calidad de tomates frescos conservados a $8{ }^{\circ} \mathrm{C}$ y un 90 $\%$ de HR durante 22 días. La mezcla de AEs fue la constituida por carvacrol-oréganocanela $(80: 20: 10 \mathrm{v} / \mathrm{v})$. Tras este período de almacenamiento, los tomates fueron conservados a temperatura ambiente $\left(25^{\circ} \mathrm{C}\right)$ durante 3 días simulando así el proceso de comercialización de los mismos. Los tomates, variedad Caniles, fueron almacenados en dos tipos de envases diferentes. Por un lado, se utilizó un envase de cartón convencional (control) que incluye un recubrimiento interno con una laca polimérica de uso alimentario en base agua; y por otro lado, un envase activo de cartón con un recubrimiento activo que incluye una combinación de AEs nanoencapsulados en $\beta-C D$, que se aplica junto con la emulsión en base agua de polímero acrílico.

A lo largo de la vida útil de los tomates frescos se realizaron determinaciones microbiológicas y fisicoquímicas (sólidos solubles, $\mathrm{pH}$ y acidez titulable), color, firmeza, incidencia de frutos que presentan podredumbres, análisis sensorial y para finalizar, se determinó la presencia de residuos de AEs sobre el fruto y el envase.

En cuanto a los resultados obtenidos, el color del tomate se mantuvo mejor en el envase activo durante los primeros seis días de almacenamiento a $8^{\circ} \mathrm{C}$. En lo relativo a la incidencia de frutos con podredumbres, se observó que los tomates almacenados en envases control presentaron un $36 \%$ de frutos podridos mientras que los envases activos redujeron el porcentaje de frutos podridos a un $22 \%$, al final de su vida útil. Respecto de la calidad sensorial, los tomates envasados en cajas activas fueron mejor valorados que los envasados en caja control, durante toda la vida útil del producto.

En lo que se refiere a la migración de AEs al fruto, se ha comprobado que fue muy baja (menos de $1 \mu \mathrm{g} / \mathrm{g}$ ) durante todo el período de conservación, por lo que el panel sensorial no detectó sabores extraños en el fruto. Sin embargo, el contenido de AEs en el envase activo fue reduciéndose a lo largo de la conservación porque los AEs eran liberados desde el complejo de inclusión atrapado en el recubrimiento de la caja activa de cartón. En conclusión, este sistema de envasado activo que incluye AEs encapsulados se ha validado como solución para extender la vida útil de tomates frescos a granel. La liberación controlada de estos AEs nanoencapsulados (incluidos en el recubrimiento activo que se aplica sobre la cara interna del envase de cartón) permite un elevado control del deterioro de estos frutos, además de mejorar su calidad sensorial, mientras que la calidad microbiológica y fisicoquímica no se vio afectada. 


\section{CAPÍTULO II.}

"Envase de cartón activo e innovador para el envasado a granel de pimientos frescos que prolonga la vida útil de los mismos"

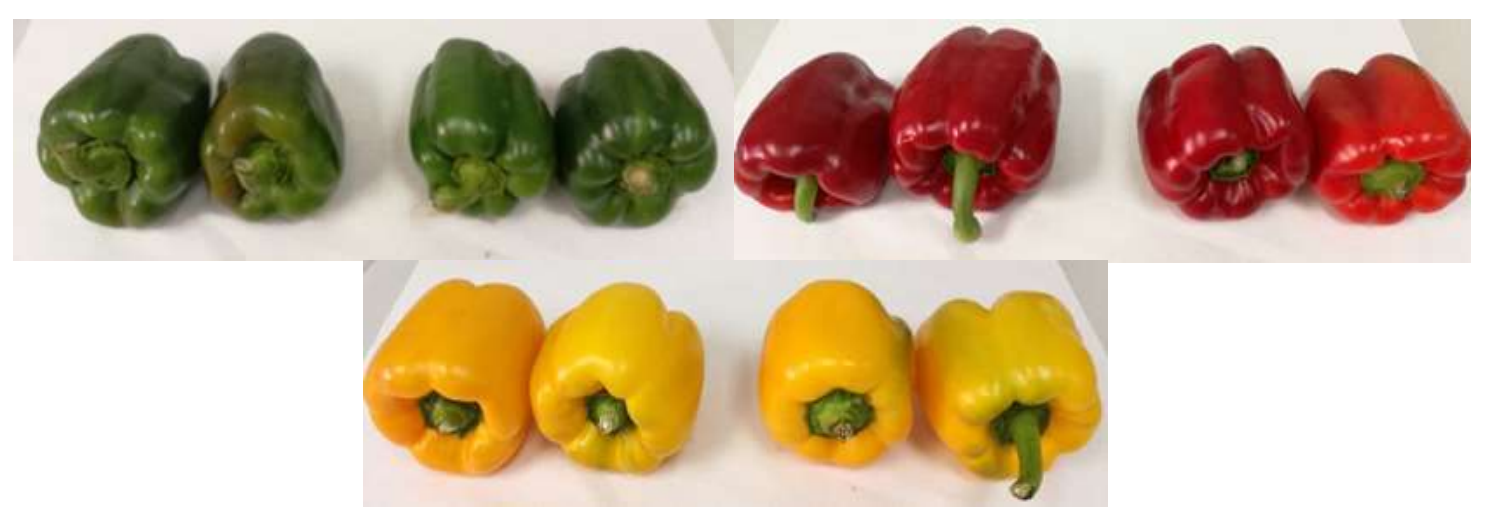

Este Capítulo se corresponde con el artículo siguiente:

Laura Buendía-Moreno, Sonia Soto-Jover, María Ros-Chumillas, Vera Antolinos, Laura Navarro-Segura, María José Sánchez-Martínez, Ginés Benito MartínezHernández, Antonio López-Gómez. 2019. An innovative active cardboard for box bulk packaging of fresh bell pepper extends its shelf life. Postharvest Biology and Technology. Presentado para su publicación: en proceso de revisión.

Artículo enviado a la revista Postharvest Biology and Technology el 14 de Noviembre de 2019.

Food safety and Refrigeration Engineering Group, Department of Agricultural Engineering, Universidad Politécnica de Cartagena, Paseo Alfonso XIII, 48, 30203, Cartagena, Murcia, Spain `E-mail address: antonio.lopez@upct.es (A. López-Gómez). 


\section{Resumen}

En este capítulo se estudia el efecto del envase activo antimicrobiano de cartón que actúa mediante la liberación controlada de los AEs en forma de vapor, sobre la vida útil de pimientos frescos, de la variedad California, durante su almacenamiento a $8{ }^{\circ} \mathrm{C}$ y un $90 \%$ de HR. Este envase activo de cartón corrugado está recubierto con una polímero acrílico en base agua, que incluye AEs encapsulados en $\beta$-CD. La mezcla de AEs fue la constituida por carvacrol-orégano-canela $(80: 20: 10 \mathrm{v} / \mathrm{v})$. Los pimientos fueron almacenados envasados a granel, en las condiciones anteriores, hasta el final de su vida útil. Pimientos verdes, rojos y amarillos fueron envasados en dos tipos de envases diferentes. Un envase de cartón convencional (Control (CTRL)) con recubrimiento interno impermeabilizante a base de una laca polimérica (aplicado como una emulsión en base agua); y por otro lado, un envase activo de cartón (Active Packaging (AP)) con un recubrimiento activo que incluye $A E s$ encapsulados en $\beta-C D$, y a su vez, embebidos, en el mismo recubrimiento impermeabilizante de polímero acrílico utilizado para los envases control.

Durante la vida útil de los pimientos frescos se realizaron determinaciones microbiológicas y fisicoquímicas (sólidos solubles, pH y acidez titulable), color, firmeza, incidencia de frutos que presentan podredumbres, análisis sensorial y para finalizar, se determinó la presencia de residuos de AEs sobre el fruto y el envase.

En cuanto a los resultados obtenidos, los pimientos almacenados en envases activos mostraron una reducción de dos unidades logarítmicas, en el recuento de enterobacterias y mohos en la superficie del fruto, con respecto a los pimientos conservados en envases control después de 18 días de conservación. La incidencia de frutos con podredumbre fue muy controlada por el envasado activo presentando un porcentaje inferior al $5 \%$ después de 18 días de conservación, mientras que las muestras control mostraron incidencias de podredumbres en torno al 10-15\%. El uso del envase activo no afectó negativamente a la calidad fisicoquímica de los pimientos, ya que mostraron mejor firmeza tanto los pimientos rojos como los verdes almacenados en envases activos, a los 18 días de conservación refrigerada.

En cuanto a la migración de AEs al fruto, esta fue muy baja (por debajo de 1 ppm) durante todo el período de conservación, por lo que el panel sensorial no detectó sabores extraños en los pimientos. 


\section{Manuscript Details}

\section{Manuscript number}

Title

Article type
POSTEC_2019_1120

AN INNOVATIVE ACTIVE CARDBOARD BOX FOR BULK PACKAGING OF FRESH BELL PEPPER

Research Paper

\section{Abstract}

An antimicrobial active packaging based on controlled essential oils (EOs) vapour release was studied to extend the shelf life of fresh bell peppers bulk-packaged with this active box during storage at $8{ }^{\circ} \mathrm{C}(90 \%$ relative humidity $(\mathrm{RH}))$. The active packaging consisted of a corrugated cardboard box coated with a water-based acrylic emulsion including a $\beta$-cyclodextrin $(\beta C D$ ) inclusion complex of a EO mix (carvacrol:oregano:cinnamon 70:10:20 v:v:v). The EO mix was efficiently encapsulated within the $\beta C D$ inclusion complex by $94 \%$. Green, red and yellow peppers packaged within the active box showed 1-2 lower log units of enterobacteria than the control (without the active coating) packaging after $11-18 \mathrm{~d}$ at $8{ }^{\circ} \mathrm{C}(90 \% \mathrm{RH})$. Furthermore, green/red and yellow peppers showed lower (approximately 1 log unit) mould counts than control samples after 6 and $11 \mathrm{~d}$, respectively. The decay incidence of samples was also highly controlled by the active packaging with percentages lower than $5 \%$ after $18 \mathrm{~d}$ while control samples showed decay incidences of $10-15 \%$. The use of this active box did not negatively affect the physicochemical quality of peppers even showing red and green peppers of the active box better firmness than control samples after $18 \mathrm{~d}$. The shelf life of peppers stored with the active box reached $18 \mathrm{~d}$ while samples stored with the control box were rejected. Conclusively, this active packaging allowed to extend the shelf life of green, red and yellow peppers for $18 \mathrm{~d}$ at $8{ }^{\circ} \mathrm{C}$ and $90 \% \mathrm{RH}$.

\section{Keywords}

\section{Corresponding Author \\ Corresponding Author's Institution}

Order of Authors

Suggested reviewers
Active coating; encapsulated essential oils; $\beta$-cyclodextrin; inclusion complex; quality.

Antonio Lopez Gomez

UNIVERSIDAD POLITECNICA DE CARTAGENA

Laura Buendía-Moreno, Sonia Soto-Jover, María Ros-Chumillas, Vera Antolinos-López, Laura Navarro-Segura, María José Sánchez-Martínez, Ginés Benito Martínez Hernández, Antonio Lopez Gomez

Domingos Almeida, Olga Martin-Belloso, Giancarlo Colelli 


\section{Submission Files Included in this PDF}

\section{File Name [File Type]}

Cover letter F3 box in peppers_PBT.docx [Cover Letter]

Highlights F3 boxes PBT.docx [Highlights]

Conservación activa pimiento fresco PBT.docx [Manuscript File]

Figure 1_in vitro antimicrobial.JPG [Figure]

Figure 2_decay.JPG [Figure]

Figure 3_Sensory.docx [Figure]

Table 1 pure EOs in vitro.docx [Table]

Table 2 Micro in vivo industrial final (1).docx [Table]

Table 3 FQ.docx [Table]

Supplementary material 1_TGA.docx [e-Component]

Supplementary material 2_DSC.docx [e-Component]

Supplementary material 3_FTIR.docx [e-Component]

Supplementary material 4_SEM complexes.docx [e-Component]

Supplementary material 6_SEM carton.docx [e-Component]

Supplementary material 5_Physical properties of boxes.docx [e-Component]

To view all the submission files, including those not included in the PDF, click on the manuscript title on your EVISE Homepage, then click 'Download zip file'. 

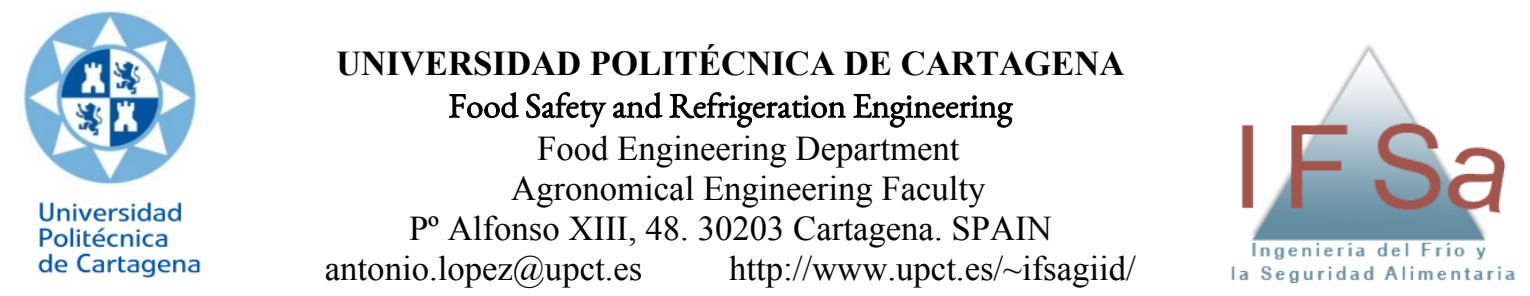

$14^{\text {th }}$ November, 2019

Dear editor:

I am pleased to submit our article 'An innovative active cardboard box for bulk packaging of fresh bell pepper'. The authors Laura Buendía-Moreno, Sonia Soto-Jover, María Ros-Chumillas, Vera Antolinos, Laura Navarro-Segura, María José Sánchez-Martínez, Ginés Benito Martínez-Hernández, Antonio López-Gómez agree to its submission to the highly appreciated journal Postharvest Biology and Technology. This work is an original research carried out by the authors. All authors agree with the contents of the manuscript and its submission to this Journal. All Authors listed have contributed significantly to the work and agree to be in the author list. No part of the research has been published in any form elsewhere.

Decontamination of fresh fruit and vegetables is a topic of high interest to ensure the food safety of these plant products. Essential oils (EOs) decontamination data obtained under in vitro conditions show these natural decontaminants as a promising alternative to $\mathrm{NaOCl}$. Nevertheless, low EO effectiveness is observed when applied in vivo in plant products. Increment of EO doses would lead to consumer rejection owed to characteristic off-flavours from EOs. In that sense, EO effectiveness may be increased applying nanotechnology. In that sense, cyclodextrins encapsulate EOs with a high efficiency allowing a controlled release of EOs with a potential application in active antimicrobial packaging of fruit and vegetables. In that sense, active cardboard boxes with cyclodextrinencapsulated EOs may extend product shelf life through a control of microbial growth. In this study, active boxes including a EOs/ $\beta$-cyclodextrin inclusion complex allowed to extend the shelf life of bell peppers for 18 days at $8{ }^{\circ} \mathrm{C}$ while samples packaged with untreated boxes were unmarketable after 11 days at $8^{\circ} \mathrm{C}$.

We hope that you agree on the merits and appropriateness of this study for publication in your Journal.

Thank you and we look forward to your comments.

Sincerely,

Dr. Antonio López Gómez

Agricultural Engineering Department

Universidad Politécnica de Cartagena

P. Alfonso XIII, 48. E-30203 Cartagena. Murcia. Spain

Phone +34968325516 


\section{AN INNOVATIVE ACTIVE CARDBOARD BOX FOR BULK PACKAGING OF FRESH BELL PEPPER}

- Carvacrol:oregano:cinnamon at 70:10:20 (EO mix) highly reduced saprophyte moulds.

- Active cardboard with an EO mix-inclusion complex was developed and characterised.

- Decay of peppers after $18 \mathrm{~d}$ was reduced from $10-15$ to $<5 \%$ using active cardboard.

- Firmness was better preserved using active cardboard being quality highly kept.

- Active cardboard extended bell peppers' shelf life up to $18 \mathrm{~d}\left(8^{\circ} \mathrm{C}\right)$. 


\section{AN INNOVATIVE ACTIVE CARDBOARD BOX FOR BULK PACKAGING OF}

2 FRESH BELL PEPPER

3

4 Laura Buendía-Moreno, Sonia Soto-Jover, María Ros-Chumillas, Vera

5 Antolinos-López, Laura Navarro-Segura, María José Sánchez-Martínez, Ginés Benito

6 Martínez-Hernández, Antonio López-Gómez*

7

8 Food Safety and Refrigeration Engineering Group, Department of Agronomical

9 Engineering, Universidad Politécnica de Cartagena, Paseo Alfonso XIII, 48, 30203, 10 Cartagena, Murcia, Spain.

* To whom correspondence should be addressed: Tel: +34-968-325516; Email: antonio.1opez@upct.es. Website: http://www.upct.es/ ifsagiid/

\section{ABSTRACT}

An antimicrobial active packaging based on controlled essential oils (EOs) vapour release was studied to extend the shelf life of fresh bell peppers bulk-packaged with this active box during storage at $8{ }^{\circ} \mathrm{C}(90 \%$ relative humidity $(\mathrm{RH}))$. The active packaging consisted of a corrugated cardboard box coated with a water-based acrylic emulsion including a $\beta$-cyclodextrin $(\beta \mathrm{CD})$ inclusion complex of a EO mix (carvacrol:oregano:cinnamon 70:10:20 v:v:v). The EO mix was efficiently encapsulated within the $\beta \mathrm{CD}$ inclusion complex by $94 \%$. Green, red and yellow peppers packaged within the active box showed 1-2 lower log units of enterobacteria than the control (without the active coating) packaging after $11-18 \mathrm{~d}$ at $8{ }^{\circ} \mathrm{C}(90 \% \mathrm{RH})$. Furthermore, green/red and yellow peppers showed lower (approximately 1 log unit) mould counts than control samples after 6 and 
$11 \mathrm{~d}$, respectively. The decay incidence of samples was also highly controlled by the active packaging with percentages lower than $5 \%$ after $18 \mathrm{~d}$ while control samples showed decay incidences of $10-15 \%$. The use of this active box did not negatively affect the physicochemical quality of peppers even showing red and green peppers of the active box better firmness than control samples after $18 \mathrm{~d}$. The shelf life of peppers stored with the active box reached $18 \mathrm{~d}$ while samples stored with the control box were rejected. Conclusively, this active packaging allowed to extend the shelf life of green, red and yellow peppers for $18 \mathrm{~d}$ at $8{ }^{\circ} \mathrm{C}$ and $90 \% \mathrm{RH}$.

Keywords: Active coating; encapsulated essential oils; $\beta$-cyclodextrin; inclusion complex; quality.

\section{INTRODUCTION}

Bell pepper (Capsicum annuum L.) is an annual herbaceous vegetable crop from the Solanaceae family. Spain is the fifth largest producer of bell pepper in the world ( $3 \%$ of the world production) with a national production of 1,293,700 $\mathrm{t}$ in 2018 (MAPA, 2018). The wide variety of colours, sizes and shapes, together with its characteristic flavour and high nutritional properties, have led to the growing consumer interest in this vegetable (Meir et al., 1995). The production of bell pepper is mainly (85\%) destined to the fresh market consumption and most of it is sold in bulk packaging (Reche-Mármol, 2010). control the pathological decay in bell pepper to extend its shelf life. The storage conditions recommended for bell pepper are $7.5-8{ }^{\circ} \mathrm{C}$ and $90 \%$ relative humidity (RH) 
2014). Nevertheless, complementary techniques are needed to control the microbial growth of the product during storage, meeting at the same time the actual consumer interest in natural treatments free from additives.

Essential oils (EOs) are natural substances obtained from plant material (flowers, leaves, seeds, buds, twigs, bark, herbs, wood, fruits and roots), which show excellent in vitro antimicrobial properties. Carvacrol, the major component of oregano EO, and the oregano-cinnamon EO combination have shown excellent antimicrobial activities against a wide variety of microorganisms including moulds (Burt, 2004). Due to the hydrophobic nature of EOs, their use is highly limited in water-based treatments of fruit and vegetables. Therefore, the needed EO concentrations to achieve effective antimicrobial effects need to be highly increased when applied in in vivo conditions. Nevertheless, high EO concentrations lead to off-flavours typical from EOs being such products rejected by the consumer. The entrapment of EOs by nanoencapsulation has been widely studied in the last decades to increase the EO efficiency through a controlled EO release that limits the microbial growth of food products during storage (Marques et al., 2019). Cyclodextrins (CDs) are cyclic oligomers of $\alpha-D^{-}$-glucopyranose. CDs have been intensively studied in food science for several purposes such as the controlled release of antimicrobials, protection of nutritional/health-promoting compounds, stabilization of flavours, elimination of undesired tastes and browning reactions, among other applications (Marques et al., 2019; Pothakamury and Barbosa-Cánovas, 1995; Seglie et al., 2012). The most important CDs at industrial level are $\alpha^{-}$and $\beta C D$, being the latter one highly extended due to its low cost. $\beta \mathrm{CD}$ molecule is made up of $7 \mathrm{D}$-glucose monomers linked by $\alpha(1,4)$ bonds, exhibiting the shape of a truncated hollow cone. $\beta \mathrm{CD}$ is approved as a food additive in Europe (E459), USA and Japan, being established an acceptable daily $\beta \mathrm{CD}$ intake of $5 \mathrm{mg} \mathrm{kg}^{-1}$ day $^{-1}$ (Mortensen et al., 2016). The $\beta \mathrm{CD}$ 
cavities are hydrophobic, whereas the external faces are hydrophilic. In that sense, the EO entrapment within an $\beta \mathrm{CD}$ inclusion complex lets to the increment of the EO stability by reduction of the EO volatility and preservation of their biological properties, while a controlled EO release is allowed (Ayala-Zavala et al., 2008; Marques et al., 2019).

Active antimicrobial packaging is an emerging technology that allows to extend the food shelf life through a controlled release of the encapsulated antimicrobial compounds (Khaneghah et al., 2018). Corrugated cardboard is widely used in the European Union as a packaging material for bulk packaging of fresh fruit and vegetables. Cardboard is frequently coated with waterproof lacquers to reinforce its mechanical properties since fruit and vegetables need to be stored at high $\mathrm{RH}$ to minimise the water loss during storage. In that sense, active cardboard boxes coated with lacquers including nanoencapsulated antimicrobial compounds may highly extend the shelf life of fresh fruit and vegetables.

The objective of this work was to analyse the effect of an innovative active (antimicrobial) cardboard box coated with encapsulated EOs (carvacrol:oregano EO:cinnamon EO mix) (named EOs $-\beta \mathrm{CD}$ inclusion complex) on the microbial, physicochemical and sensory quality of fresh bell peppers (green, red and yellow) bulk-packaged with this packaging and stored at $8{ }^{\circ} \mathrm{C}(90 \% \mathrm{RH})$. Previously, the used EO mix for the EOs- $\beta \mathrm{CD}$ inclusion complex was selected based on their in vitro antimicrobial activities against common moulds in bell peppers and pathogens. Furthermore, the active cardboard box was also characterized (in vitro antimicrobial activity and physical/mechanical properties) and the EO residues from the active box in peppers were monitored during the product storage.

\section{MATERIALS AND METHODS}

\subsection{Materials}


102 Carvacrol, oregano EO and cinnamon EO were obtained from Lluch Essence S.L. 103 (Barcelona, Spain). $\beta \mathrm{CD}$ was obtained from Roquette (Lestrem, Francia). Waterproof 104 lacquer (a water-based acrylic emulsion named UKAPHOB HR 530; $30 \%$ solids) 105 (authorised for food contact surfaces according to EC (2004)) was acquired from 106 Schill+seilacher GMBH (Böblingen, Germany). Boxes $(395 \times 295 \times 210 / 140 / 47 \mathrm{~mm})$ of 107 corrugated cardboard (made with Kraft paper) were manufactured by the company SAECO (Molina de Segura, Spain). All the material for the microbial analyses was acquired from Scharlau Chemie (Barcelona, Spain).

Purified isolates of the following moulds were kindly supplied by J.A. Martínez

111 (Department of Agricultural Engineering, Universidad Politécnica de Cartagena, Spain):

112 B. cinerea, A. alternata, Penicillium spp., Aspergillus niger and Fusarium spp. 113 Furthermore, decayed bell peppers with visual mycelial growth were also taken from 114 Fruca company (Balsapintada, Spain) to prepare a mould cocktail. For pathogens, 115 Escherichia coli (CECT 7619), Listeria monocytogenes LM88, Salmonella enterica subsp. enterica (CECT 4300) (stored at $-80{ }^{\circ} \mathrm{C}$ in glycerine:water solution 1:3 117 volume:volume $(v: v)$ ) were kindly supplied by A. Palop (Department of Agricultural 118 Engineering, Universidad Politécnica de Cartagena, Spain).

119 Bell peppers (Capsicum annuum L.) (green, red and yellow) were grown in the Southeast of Spain by the company Fruca (Balsapintada, Spain). Peppers were grown under greenhouse conditions according to integrated pest management cultural practices. Peppers were hand-harvested in May 2018 and transported to Fruca installations where they were packaged under the different packaging treatments (control and active boxes) and stored in the cold rooms of this company at $8{ }^{\circ} \mathrm{C}(90 \% \mathrm{RH})$.

\subsection{In vitro antimicrobial effect of EOs}


127 The antimicrobial activities of the EOs (carvacrol, oregano EO and cinnamon EO; either single or different EO mixes), EOs- $\beta \mathrm{CD}$ inclusion complexes (prepared using different EO mixes as described in the following section) and the active packaging (including the selected $\mathrm{EOs}-\beta \mathrm{CD}$ inclusion complex as described in the following sections) were studied. The studied carvacrol:oregano EO:cinnamon EO mixes were: 80:20:0 (v:v:v) (EOs1 mix), 80:0:20 (EOs2 mix), 70:10:20 (EOs3 mix) and 60:20:20 (EOs4 mix). As observed, all these EO mixes included a high carvacrol proportion due to its excellent antimicrobial activity against the studied pathogens to ensure the food safety of the product (EC, 2007). EOs1 and EOs2 mixes were selected to study the oregano EO and cinnamon EO contribution to the antimicrobial activity of carvacrol. Meanwhile, EOs3 and EOs4 mixes were selected to study the most appropriate oregano EO proportion to supplement the antimicrobial activity of carvacrol.

Mould and pathogen inocula were prepared as described in the following lines. For moulds, fragments (approximately $3 \mathrm{~mm}$ of diameter) of the mould isolates were diluted in Potato Dextrose broth and it was used as the mould inoculum. For pathogens, two subcultures of the frozen pathogen strains were made in nutrient broth at $37^{\circ} \mathrm{C}$ until the stationary phase was reached (after $24 \mathrm{~h}$ ) at each subculture. The second subculture was selected as the pathogen inoculum. Microbial inocula were adjusted to $4-5 \log$ colony forming units (CFU) $\mathrm{mL}^{-1}$ by 10 -fold dilution series using buffered peptone water. Then, the adjusted inoculum was spread-plated $(0.1 \mathrm{~mL})$ on Petri dishes containing Plate Count 147 Agar.

148 The antimicrobial activity of EO (single or mixes) were studied by the modified technique 149 ('disc diffusion by vapour contact') of the disc diffusion method (Edwards-Jones et al., 2004). Briefly, EOs were spotted at $300 \mathrm{mg} \mathrm{m}^{-2}$ onto $3.5-\mathrm{cm}$ diameter filter paper discs. The EO concentration $\left(300 \mathrm{mg} \mathrm{m}^{-2}\right.$ ) was selected as the most effective to achieve high 
antimicrobial activities according to our previous experiments with several EOs (data not shown). Control samples were performed using paper discs without EOs. The EOs-impregnated discs were fixed with sterile adhesive tape (Deltalab; Rubí, Spain) in the centre of the lid of the inoculated Petri dishes. The Petri dishes were then sealed using the sterile adhesive tape. The sealed Petri dishes were face-down incubated at $37{ }^{\circ} \mathrm{C} / 48$ $\mathrm{h}$ (pathogens) or $25^{\circ} \mathrm{C} / 7 \mathrm{~d}$ (moulds).

The antimicrobial activity of the EOs $-\beta \mathrm{CD}$ inclusion complexes was also studied with the modified technique ('disc diffusion by vapour contact'). In this case, the prepared EOs $-\beta C D$ inclusion complex powder was manually extended in the centre (on a $2 \mathrm{~cm}$ diameter surface) of the lid of the inoculated Petri dishes. The Petri dishes were sealed and stored as described above. Control samples were performed applying only $\beta \mathrm{CD}$ powder (without EOs).

The antimicrobial activity of the active paperboard (Kraft paperboard) coated with the selected EOs $-\beta \mathrm{CD}$ inclusion complex (EOs3 as described in the Results and discussion section)) was also studied with the modified technique ('disc diffusion by vapour contact'). Briefly, Kraft paperboard discs of $6.5 \mathrm{~cm}$ diameter were manually coated with the selected EOs $-\beta C D$ inclusion complex at $4 \mathrm{~mL} \mathrm{~m}^{-2}$. The prepared paper discs were fixed to the lid of the inoculated Petri dishes with the sterile adhesive tape, sealed and incubated as described above. Control samples were performed using Kraft paperboard discs with diluted (according to section 2.3) lacquer (without the EOs- $\beta \mathrm{CD}$ inclusion complex).

All in vitro treatments were performed in triplicate (3 Petri dishes) and microbial counts were expressed as $\log \mathrm{CFU} \mathrm{mL} \mathrm{mL}^{-1}$. The microbial reductions were expressed as the $\log$ unit differences compared to the correspondent control. 


\subsection{Preparation of EOs- $\beta C D$ inclusion complex and characterization}

178 The EO mix selected for the EOs- $\beta \mathrm{CD}$ inclusion complex was carvacrol:oregano:cinnamon 70:10:20 v:v:v (EOs3 mix) due to its high antimicrobial activity compared to other three EO mixes (EOs1, EOs2 and EOs4 mix) (see Results and discussion section). The EOs3- $\beta \mathrm{CD}$ inclusion complex (hereinafter named as " $\mathrm{EO}-\beta \mathrm{CD}$ inclusion complex") was prepared using the kneading method (Kamimura et al., 2014; Manolikar and Sawant, 2003). Briefly, $0.15 \mathrm{~g}$ of the EOs mix was mixed with $1.14 \mathrm{~g}$ of $\beta C D$ in a 1:1 molar ratio in a mortar (including $3 \mathrm{~mL}$ of ethanol) and kneaded for $45 \mathrm{~min}$. Then, the obtained EOs $-\beta \mathrm{CD}$ inclusion complex was kept for $48 \mathrm{~h}$ in a desiccator under vacuum at room temperature and then stored at $-20^{\circ} \mathrm{C}$ until its use.

The entrapment efficiency (EE) of EOs in the EOs $-\beta C D$ inclusion complex was determined by Differential Scanning Calorimetry (DSC) using a DSC device (model 822E, Mettler-Toledo GmbH, Schwerzenbach, Switzerland). Briefly, samples (2 mg) of this inclusion complex were placed in aluminium pans $(40 \mu \mathrm{L})$. Then, the specimens were heated, under a nitrogen atmosphere (flow rate of $50 \mathrm{~mL} \mathrm{~min}^{-1}$ ), from 30 to $400{ }^{\circ} \mathrm{C}$ with a heating rate of $10^{\circ} \mathrm{C} \mathrm{min}{ }^{-1}$. EE was calculated based on an evaporation enthalpy fit of the inclusion complex as described in Eqs. 1 and 2:

$$
\begin{gathered}
E E=\frac{h_{e E O S}}{h_{E O S}} \times 100 \\
h_{\text {eEOS }}=\frac{h_{\text {complex }} \times E O s_{\text {complex }}}{100}
\end{gathered}
$$

where $h_{e E O S}$ is the enthalpy of the entrapped EOs, $h_{E O S}$ is the enthalpy of the added EOs, $h_{\text {complex }}$ is the enthalpy of the $\mathrm{EOs}-\beta \mathrm{CD}$ inclusion complex and $\mathrm{EOs}_{\text {complex }}$ is the percentage of added EOs in the $\mathrm{EO}-\beta \mathrm{CD}$ inclusion complex.

Thermogravimetric/Differential Thermal Analyses (TG/DTA) were conducted to analyse the thermal stability of the EOs $-\beta \mathrm{CD}$ inclusion complex. TG/DTA analyses were performed using a TG analyser (model TGA 50, Mettler-Toledo GmbH, Schwerzenbach, 
Switzerland) in a temperature range from 30 to $600{ }^{\circ} \mathrm{C}$, a heating rate of $5{ }^{\circ} \mathrm{C} \mathrm{min}-1$ and under a nitrogen atmosphere with a flow rate of $50 \mathrm{~mL} \mathrm{~min}^{-1}$.

Fourier Transform Infrared spectroscopy (FTIR) analyses were performed with an FTIR spectrometer (Thermo Scientific Nicolet 5700, Berlin, Germany). Samples (2 mg) were mixed with $200 \mathrm{mg}$ of $\mathrm{KBr}$ and this mixture was pressed to form tablets with a thickness of $1 \mathrm{~mm}$. FTIR analyses were conducted in absorbance mode and wavenumbers between 400 and $4,000 \mathrm{~cm}^{-1}$.

The microscopic morphology of active and control materials from boxes was studied using a scanning electron microscope (SEM) (Hitachi S-3500N SEM). Samples were previously coated with gold in a sputter coater (SC7640, Quorum Technologies, East Sussex, England) and then observed with the SEM at $15 \mathrm{kV}$.

\subsection{Preparation of the active box and characterization}

The EOs $-\beta \mathrm{CD}$ inclusion complex was previously dissolved in water-diluted lacquer (final solid concentration of $8.5 \%$ ). The lacquer dilution was made to compensate the addition of the EOs $-\beta \mathrm{CD}$ inclusion complex since lacquers with solids $>30 \%$ may difficult their industrial application on the cardboard surface. The lacquer containing the EOs $-\beta C D$ inclusion complex was applied on the cardboard by spraying at industrial scale in the company SAECO (Molina de Segura, Spain). Cardboard coating was made at $4 \mathrm{~mL}$ $\mathrm{m}^{-2}$ following the manufacturer recommendations to obtain a homogeneous coating on the paperboard surface while reaching adequate waterproof characteristics.

The following mechanical properties of boxes were analysed by the Packaging, Transport 
resistance (UNE 49706:02), edgewise crush resistance (UNE EN ISO 3037:13), puncture resistance (UNE ISO 3036:13) and static coefficient of friction (TAPPI T 816om:92).

The water absorptivity and water vapour permeability (WVP) of the paperboard from boxes were also measured in our laboratory. The water absorptivity was determined as previously described (Han et al., 1999; Taboada-Rodríguez et al., 2013). Briefly, paperboard samples were placed on WVP methylacrylate cups (46 $\mathrm{mm}$ internal diameter and $27 \mathrm{~mm}$ depth) containing distilled water $(18 \mathrm{~mL})$. Then, the cups were placed in a forced (speed $3 \mathrm{~m} \mathrm{~s}^{-1}$ ) convection chamber at $25^{\circ} \mathrm{C}$ and 50-60\% RH. Cup weights were registered every hour up to $8 \mathrm{~h}$. The water vapour transmission rate (WVTR) was calculated by linear regression of the steady state portion of weight loss $v s$ time curve. The WVP $\left(\mathrm{g} \mathrm{m} \mathrm{m}^{-2} \mathrm{~s}^{-1} \mathrm{~Pa}^{-1}\right)$ was determined by multiplying the WVTR by the thickness (m) of the cardboard and then dividing by the water vapour partial pressure difference between the two sides of the cardboard (Gennadios et al., 1994).

Morphology of the box surface was also studied by SEM. Box samples for SEM analyses were previously coated with gold as described above, and then observed at $15 \mathrm{kV}$ with the SEM.

\subsection{Quality of fresh bell peppers bulk-packaged in the active box during storage}

Packaging of fresh bell peppers and cold storage were made in the company Fruca (Balsapintada, Spain). Control (CTRL) (without the selected EOs- $\beta$ CD coating) and active (with the selected EOs- $\beta \mathrm{CD}$ coating) boxes were used for bulk-packaging of green, red and yellow bell peppers. Such boxes were manually filled with 24 bell peppers. The boxes including the product were then stored at $8{ }^{\circ} \mathrm{C}(90 \% \mathrm{RH})$ up to $18 \mathrm{~d}$. Three replicates (three boxes) per packaging treatment (CTRL or active boxes) and pepper variety (green, red and yellow) were taken at each sampling time (1, 6, 11 and $18 \mathrm{~d}$ ). A 
total of 72 boxes were prepared. Microbial (and decay incidence), physicochemical, firmness and sensory quality analyses were performed each sampling time as described in the following subsections.

\subsubsection{Microbial quality and decay incidence}

Microbial loads of bell peppers were analysed as previously described (López-Gómez et al., 2019; Martínez-Hernández et al., 2017). Briefly, two peppers were mixed with buffered peptone water (1:2 weight:volume $(w: v))$ and then homogenised for $1 \mathrm{~h}$ at 120 serial dilutions in buffered peptone water. Then, aliquots $(1 \mathrm{~mL})$ of the microbial dilutions were pour-plated in Plate Count Agar and Violet Red Bile Glucose Agar for mesophiles/psychrophiles and enterobacteria, respectively. For moulds, microbial aliquots $(0.1 \mathrm{~mL})$ were spread-plated on Rose Bengale Agar. Mesophiles, psychrophiles, enterobacteria and moulds were incubated at $31{ }^{\circ} \mathrm{C} / 48 \mathrm{~h}, 4^{\circ} \mathrm{C} / 7 \mathrm{~d}, 37^{\circ} \mathrm{C} / 24 \mathrm{~h}$ and $25^{\circ} \mathrm{C} / 7$ $\mathrm{d}$, respectively. Results were expressed as $\log \mathrm{CFU} \mathrm{g^{-1 }}$. Each of the three replicates was analysed in duplicate.

\subsubsection{Physicochemical quality and firmness}

The juice from bell peppers was obtained with a blender (model MX2050; Braun, Germany). The Soluble solids content (SSC) of the obtained juice was determined with a digital handheld refractometer (Atago N1; Tokyo, Kanto, Japan) at $20{ }^{\circ} \mathrm{C}$ and it was expressed as $\%$. The $\mathrm{pH}$ of the juice was measured with a $\mathrm{pH}-$ meter (Basic20, Crison; Alella, Cataluña, Spain). The titratable acidity (TA) of the diluted juice (5 $\mathrm{mL}$ of juice and $45 \mathrm{~mL}$ of distilled water) was determined with an automated titrator (model T50; 
as equivalents of citric acid in $\mathrm{g} \mathrm{kg}^{-1}$. Each of the three replicates was analysed in

277

278

279

280

281

282

283

284

285

286

287

288

289

290

291

292

293

294

295

296

297

298

299 duplicate.

The firmness of bell peppers was determined with a texturometer (model TA XT Plus; TA Instruments; Surrey, UK). First, pepper strips $(1 \times 3 \mathrm{~cm})$ were cut (longitudinal direction) with a sharp knife from two opposite sides of each pepper sample. Then, the strips were allowed to equilibrate at room temperature for $30 \mathrm{~min}$ prior to the firmness measurements. The firmness of pepper strips was determined with a compression test using a 4.5-kg load cell and a 4-mm-diameter cylinder stainless probe. Each sample was compressed $8 \mathrm{~mm}$ at three equidistant (longitudinal axis) points of each strip using a test speed of $20 \mathrm{~mm} \mathrm{~min}^{-1}$. The peak force $(\mathrm{N})$ necessary to achieve the target distance was recorded. The firmness was determined in two strips (3 equidistant points per each strip) per each pepper. Five peppers were analysed per each replicate (box).

\subsubsection{Sensory quality}

Sensory analyses were performed according to international standards (ASTM, 1986). Tests were conducted in a standard room (ISO, 2007) equipped with ten individual taste booths. Pepper strips $(10 \times 3 \mathrm{~cm})$ were served at room temperature in transparent glass plates coded with three random digit numbers. Still mineral water was used as a palate cleanser. The panel consisted of twelve assessors (six women/six men, aged 22-68 years) who were trained in discriminative quality attributes. Colour, flavour, texture and overall quality were assessed using a 9-point hedonic scale of acceptability (9: excellent; 5: fair, limit of usability (LU); 1: extremely bad).

\subsection{EO residues in fresh bell peppers bulk-packaged in the active box}


EO residues in peppers were analysed during storage. Carvacrol residues were analysed

301

302

303

304

305

306

307

308 since carvacrol was the major EO component of the used EO mix. Briefly, pepper strips (13 g) were mixed with $20 \mathrm{~mL}$ of hexane, vortex for $1 \mathrm{~min}$ and then homogenised for $1 \mathrm{~h}$ at $120 \mathrm{rpm}$ in an orbital shaker at $4{ }^{\circ} \mathrm{C}$. The homogenised mixture was filtrated $(0.22-\mu \mathrm{m}$ syringe filters) and analysed with a gas chromatograph coupled to a mass spectrometer (GC-MS model 6890 (Agilent Technologies; Palo Alto (USA)). Carvacrol separation was achieved on a $30 \mathrm{~m} \times 0.25 \mathrm{~mm} \times 0.25 \mu \mathrm{m}$ capillary column (CP8982 VF17ms; Agilent Technologies). The carrier gas was helium with a constant flow of $2.8 \mathrm{~mL} \mathrm{~min}{ }^{-1}$ and pressure of $264.8 \mathrm{kPa}$. The injection was performed in splitless mode. The oven temperature was held at $50{ }^{\circ} \mathrm{C}$ for 1 min after injection, then programmed to reach $235^{\circ} \mathrm{C}$ after $10 \mathrm{~min}$ and held at $235^{\circ} \mathrm{C}$ until $29.5 \mathrm{~min}$. MS was set in electronic impact mode (70 $\mathrm{eV}$ ) with a mass range of 40-400 amu. Source and MS quad temperatures were 230 and $150{ }^{\circ} \mathrm{C}$, respectively. Carvacrol peak was identified by its mass spectra compared to data from the NIST05a.L database (National Institute for Standards and Technology). Carvacrol was quantified with a carvacrol standard (Sigma, USA) and expressed in fresh weight basis as $\mathrm{mg} \mathrm{kg}^{-1}$. Three peppers were analysed per each replicate (box) every sampling time.

\subsection{Statistical analyses}

Differences between treatments were tested at a 0.05 level of probability with the $\mathrm{R}$ studio software. The effects of variety, treatments and storage time were tested with a three-way (variety, treatment and storage time) analysis of variance, followed by a multiple comparison test (Tukey HSD) to identify the differences between factors. Results are reported as mean values \pm standard error. 


\section{RESULTS AND DISCUSSION}

326

327

\subsection{In vitro antimicrobial effect of EOs and the EOs- $\beta C D$ inclusion complex}

The antimicrobial activities of carvacrol, oregano EO and cinnamon EO were studied against several pathogens and moulds commonly found in bell peppers (López-Gálvez et al., 1997). Carvacrol was more effective than oregano EO and cinnamon EO against the studied pathogens achieving reductions of 0.8, 0.9 and 1.1 for E. coli, Salmonella spp. and L. monocytogenes, respectively (Table 1). Cinnamon EO and oregano EO showed low antimicrobial activities against such pathogens. Attending to moulds, carvacrol also achieved high microbial inactivations ( $>3 \log$ units) against A. alternata and Penicillium spp. Oregano EO was the only studied EO effective against $A$. niger showing a reduction of $1.8 \log$ units. The increment of the antimicrobial activity of EOs when combining a major EO component (e.g. carvacrol) with its respective whole EO (i.e. oregano EO) has been widely reported (Burt, 2004). It has been hypothesized that the minor EOs components are critical for the antimicrobial activity of the whole EOs through a possible synergistic effect or potentiating influence. Interestingly, cinnamon EO was effective against B. cinerea and Fusarium spp. reaching a high mould inactivation (>3 log units). Our previous studies have also shown that cinnamon EO has a high antimicrobial effect against specific saprophyte moulds of citrus fruit, which are resistant to other EOs such as carvacrol and oregano EO (unpublished data). Consequently, EO mixes may have a broad antimicrobial effect against several microorganisms. In that sense, four EO mixes (EOs1, EOs2, EOs3 and EOs4) including a high carvacrol proportion were studied against a cocktail prepared with saprophyte moulds isolated from bell peppers.

The antimicrobial activities of the four EO mixes against the mould cocktail are shown in Figure 1. Furthermore, the antimicrobial activities of these EOs mixes entrapped in the $\beta \mathrm{CD}$ inclusion complex (pure inclusion complex and once it was applied on the active 
packaging material) were also studied against this mould cocktail (Figure 1). As observed, cinnamon EO presence in the EO mixes was necessary to achieve significant microbial reductions since EOs1 discs did not achieve significant $(p>0.05)$ reductions compared to control samples (Figure 1). Although EOs2, EOs3 and EOs4 discs showed similar $(p>0.05)$ reductions among them, a different behaviour was observed when they were applied within the $\beta \mathrm{CD}$ inclusion complexes (either pure complex or once applied on the active packaging material). Particularly, EOs3 showed the highest microbial reductions when it was applied either as the pure complex or on the active packaging material. In that sense, the slow EOs3 release from the $\beta \mathrm{CD}$ inclusion complex achieved the best control of studied saprophyte moulds of peppers being this inclusion complex selected for the in vivo experiments.

\subsection{Characterization of the EOs- $\beta C D$ inclusion complex}

The selected EOs $-\beta \mathrm{CD}$ inclusion complex showed an EE of $94.4 \%$ according to Eqs. 1 and 2. Such high EO entrapment within the $\beta \mathrm{CD}$ may be owed to the low molecular weight of EOs (Asbahani et al., 2015). The obtained EE of the inclusion complex is in agreement with previous data (up to EE of $99.8 \%$ ) using also the kneading method to entrap EOs within $\beta C D$ (Marreto et al., 2008). The latter authors attributed this high EE to the absence of heating steps and long complexation times, typical from other encapsulation methods like the slurry procedure, which may lead to an important EO evaporation.

The TG/DTA analyses of the EOs- $\beta$ CD inclusion complex shows data regarding EO entrapment and thermal stability of the inclusion complex when compared to the pure $\beta \mathrm{CD}$ (Supplementary material 1). An initial water/EO loss from 100 to $180{ }^{\circ} \mathrm{C}$ was observed for both pure $\beta \mathrm{CD}$ and the $\mathrm{EOs}-\beta \mathrm{CD}$ inclusion complex. $\beta \mathrm{CD}$ decomposition 
started to occur at $275{ }^{\circ} \mathrm{C}$ as previously reported (Marreto et al., 2008). The EO entrapment within the $\beta \mathrm{CD}$ inclusion complex is corroborated by the acute mass loss observed between 180 and $270{ }^{\circ} \mathrm{C}$, which is attributed to the EO release (Marreto et al., 2008).

The EO entrapment within the $\beta \mathrm{CD}$ inclusion complex was further confirmed by DSC thermograms (Supplementary material 2). The pure EOs3 mix showed an endothermic phase starting at $237-240{ }^{\circ} \mathrm{C}$ reaching a peak at $248.3{ }^{\circ} \mathrm{C}$, which corresponded to the EO boiling point (Asbahani et al., 2015). The observed exothermic peaks from 300 to $340{ }^{\circ} \mathrm{C}$ were possibly owed to melting and thermal decomposition of the $\beta \mathrm{CD}$ itself as previously found (Kamimura et al., 2014; Seo et al., 2010). The low negative enthalpy values (140.6 and 291.2 $\mathrm{J} \mathrm{g}^{-1}$ for the EOs- $\beta \mathrm{CD}$ inclusion complex and EOs3, respectively) are typical from low energy interactions like those occurred within the $\mathrm{EOs}-\beta \mathrm{CD}$ inclusion complex: 1) hydrophobic interactions (resulted from the displacement of water molecules from the $\beta \mathrm{CD}$ cavity), 2) increment of van der Walls interactions between the molecules, and 3) formation of hydrogen bonds, among others (Marreto et al., 2008; Mourtzinos et al., 2007).

The interactions between host and guest molecules occurred in the EOs $-\beta \mathrm{CD}$ inclusion complex were further studied by FTIR analyses (Supplementary material 3). The pure EOs3 showed characteristic FTIR peaks of its components (Supplementary material 3): carvacrol, oregano EO and cinnamon EO. The typical FTIR absorptions from carvacrol and oregano EO were found at 3,367 ( $-\mathrm{OH}$ stretch), 2,826-2,959 (C-H stretch), 1,591 (alkene $\mathrm{C}=\mathrm{C}$ ), and $1,400 \mathrm{~cm}^{-1}$ (aromatic $\mathrm{C}=\mathrm{C}$ ). Furthermore, observed 1,510 and 1,605 $\mathrm{cm}^{-1}$ peaks are characteristic from the cinnamon EO, which correspond to the stretching absorption of benzene ring and the stretching of $\mathrm{C}=\mathrm{O}$ of the aldehyde group (Munhuweyi et al., 2018). Stretching vibration peaks for the aromatic hydroxyl groups were identified 
at $1,250 \mathrm{~cm}^{-1}$. Out of plane stretching peaks due to aromatic $\mathrm{C}-\mathrm{H}$ bonds were observed

401

402

403

404

405

406

407

408

409

410

411

412

413

414

415

416

417

418

419

420

421

422

423

424 in the $900-650 \mathrm{~cm}^{-1}$ range. The aromatic CC stretching was also elucidated at $800 \mathrm{~cm}^{-1}$. The FTIR spectra of the EOs $-\beta C D$ inclusion complex showed peaks shifts and intensity changes comparing to the FTIR spectra of pure EOs3. The characteristic peaks of $\beta \mathrm{CD}$ were identified at 3,300 (-OH stretch), 2,925 (vibration of $\mathrm{C}-\mathrm{H}$ stretch), 1,643 (bending of $\mathrm{H}-\mathrm{O}-\mathrm{H}), 1,157$ (vibrations of the asymmetric stretch of the $\mathrm{C}-\mathrm{O}-\mathrm{C}$ ) and $1,023 \mathrm{~cm}^{-1}$ (symmetric stretching link $\mathrm{C}-\mathrm{O}-\mathrm{C}$ ) (Wang et al., 2014) when studying the pure $\beta \mathrm{CD}$ (Supplementary material 3). Nevertheless, the FTIR spectra of the EOs- $\beta$ CD inclusion complex showed minimal differences compared with the $\beta \mathrm{CD}$ spectra. The latter differences between spectra of pure $\mathrm{EOs} 3, \beta \mathrm{CD}$ and the $\mathrm{EO}-\beta \mathrm{CD}$ inclusion complex have been also reported (Marques et al., 2019).

The morphology of free (pure) $\beta \mathrm{CD}$ and the $\mathrm{EOs}-\beta \mathrm{CD}$ inclusion complex was studied by SEM (Supplementary material 4). The morphology of $\beta C D$ was not substantially changed after the EO inclusion as observed in the SEM captions. Small particles on crystal surfaces were also observed due to agglomeration processes of other particles as it has been described (Songkro et al., 2012).

\subsection{Characterization of the active box}

The mechanical and hydrophobic properties of the CTRL and the active box including the EOs $-\beta \mathrm{CD}$ inclusion complex are shown as Supplementary material 5 . The active box showed lower bottom bending and edgewise crush resistances than the CTRL box due to the lacquer application. Nevertheless, such resistance reductions would not compromise the needed box resistance for fruit and vegetable packaging. On the other side, the active box showed higher static coefficients of friction compared to the CTRL box, which is beneficial from the production and logistic view since friction must be adequate. As 
expected, the active box presented lower water absorptivity and vapour permeabilities than the CTRL box due to the waterproof properties of the used lacquer. SEM captions of boxes (Supplementary material 6) showed that the lacquer application did not alter the morphology or fibre crosslinking of the packaging material. Furthermore, a homogeneous particle distribution of the EOs $-\beta \mathrm{CD}$ inclusion complex was observed on the active box surface.

\subsection{Microbial quality and decay incidence of fresh bell peppers bulk-packaged with} the active box

The antimicrobial benefits of the controlled EO release from the EOs $-\beta C D$ inclusion complex were observed during the storage of bell peppers packaged with this active box (Table 2). The pepper variety factor showed statistical interactions with the packaging treatment factor on mesophilic, psychrophilic and mould loads (Table 2). In that sense, green and red peppers packaged within the active box showed higher log reductions (compared to the CTRL box) than yellow peppers. This pepper variety effect on the antimicrobial properties of the active box may be owed to the contents of specific phytochemicals from red and green peppers with high antimicrobial properties like ascorbic acid, carotenoids, etc. (Simonne et al., 1997). The highest bacteriostatic effects were observed on red peppers at day 6 being reduced as the storage time increased. Particularly, the triple factor interaction (pepper variety $\times$ packaging treatment $\times$ storage time) was significant $(p<0.05)$ for psychrophiles showing red peppers from the active box 2.2, 1.3 and 0.8 lower $\log$ units than CTRL after 6, 11 and $18 \mathrm{~d}$, respectively (Table 2).

447 Furthermore, the maximum bacteriostatic activity of the active box with green peppers at days 6-11 (up to $1.4,3.1$ and 1.3 lower $\log$ units than CTRL for mesophiles, 
$2 \log$ units at day 18, respectively. At day 11, the highest bacteriostatic effect was observed for yellow peppers packaged within the active box with 0.9 and 0.5 lower mesophilic and psychrophilic log units compared to the CTRL box. Attending to moulds, green and red peppers packaged in the active box showed 1 and 0.6 lower log units, respectively, compared to the CTRL box at day 6. Contrary, the antimicrobial effect of the active box on mould loads of yellow peppers was only observed after $18 \mathrm{~d}$ with $1 \log$ unit lower compared to CTRL samples. The reduction of such bacteriostatic effect for some microbial groups at the end of storage may be owed to several reasons: 1) reduction of EO content from the inclusion complex (as a result of the controlled release), 2) a possible increasing resistance of the survival bacteria to the studied EO, and 3) nutrient leakage from damaged plant tissues (due to product senescence during storage), which enhances microbial growth masking the bacteriostatic benefits from the active packaging. The decay incidence of samples during storage is shown in Figure 2. As observed, bell peppers stored within the active box showed a lower decay incidence during storage compared to CTRL samples. The decay incidence of samples packaged in the active box was lower than $5 \%$ after $18 \mathrm{~d}$ while such incidence raised to $10-15 \%$ in CTRL samples. Due to the observed decay control with the active box, samples were further observed up to $21 \mathrm{~d}$ at $8^{\circ} \mathrm{C}$ (data not shown). Decay incidence of samples packaged in the active box was still highly controlled after $21 \mathrm{~d}$ with incidences of $2-6 \%$ while such incidence raised to $16-19 \%$ for CTRL samples.

Conclusively, the controlled EO release from the $\beta \mathrm{CD}$ inclusion complex led to a bacteriostatic effect clearly observed during storage of bell peppers using the active box. The decay incidence was highly controlled using this active packaging as observed. Fruit and vegetables are usually submitted to temperatures higher than $8{ }^{\circ} \mathrm{C}$ during retail periods (distribution centres, freight, transportation, supermarkets, etc.). At such storage 
temperatures, higher than the recommended ones, EO release from the inclusion complex may be higher. The latter behaviour has been explained since molecular Brownian motion is accelerated with a rise of temperature that improves the speed of EO releasing from the inclusion complex (Ren et al., 2018). In that sense, the EO release from the active packaging may be increased under abusive storage temperatures leading to a better control of the microbial growth, which is enhanced at such adverse storage temperatures for fruit and vegetables. In that sense, further studies are needed to test the antimicrobial activity of this active packaging at different storage temperatures.

\subsection{Physicochemical and sensory quality of fresh bell peppers bulk-packaged with}

\section{the active box}

The pepper variety factor showed a significant effect on the studied physiochemical parameters (Table 3). As expected, red peppers showed initial SSC and TA higher than green and yellow peppers due to sugar and organic acid biosynthesis during pepper ripening. Sugar biosynthesis during ripening in yellow peppers is lower than red peppers as previously reported (Tsegay et al., 2013), and hereby observed (Table 3). The organic acid biosynthesis during colour turning of pepper ripening was also observed from the higher $\mathrm{pH}$ of red and yellow peppers compared to green pepper. TA and SSC of red and yellow peppers increased during storage. Organic acid biosynthesis using sugars as the energy pool is expected during senescence processes of fruit and vegetables. Nevertheless, the observed SSC increment during storage may be explained by the product dehydration (visually not observed) and increase of the activity of hydrolytic enzymes. The firmness of samples decreased during storage due to cell wall softening caused by softening enzymes like pectin methylesterase as it has been reported (Goulao et al., 2010; Rao et al., 2011). In general, packaging of peppers with the active box did 
not induce high SSC (changes $<0.5 \mathrm{SSC}$ units) and TA differences (changes $<0.05 \mathrm{TA}$ units) comparing to CTRL samples at day 18. Although yellow peppers stored in the active box showed 1 SSC unit lower than CTRL samples at day 18, no flavour differences between these packaging treatments were appreciated by the panel test (Figure 3).

The overall quality of CTRL red and green peppers was below the limit of usability after $18 \mathrm{~d}$ being limited the shelf life of these samples to $11 \mathrm{~d}$ at $8{ }^{\circ} \mathrm{C}$ (Figure 3 ). Nevertheless, samples stored within the active box showed overall quality scores over the limit of usability ranging from 7 to 8 after $18 \mathrm{~d}$. Particularly, CTRL green peppers showed the lowest colour score of 3.7 at day 18 while red peppers, regardless of packaging treatment, showed the highest colour scores. Red and green peppers stored within the active box preserved the product firmness (Table 3, Figure 3) better than CTRL samples after $18 \mathrm{~d}$. This higher product firmness using the active box may be explained by the lower metabolism of cell wall carbohydrates occurred during fungal infection of the product as previously reported (Conway, 1987; Serrano et al., 2005). Nevertheless, no high firmness differences between packaging treatments were observed in yellow peppers after $18 \mathrm{~d}$ (Table 3, Figure 3). The latter finding may be explained by the lower initial firmness of this pepper variety (Table 3) leading to less appreciable firmness changes during storage. In that sense, the use of the active box would not negatively affect the physicochemical quality and firmness of samples, showing even better sensory scores that may ensure the consumer acceptance of packaged peppers for $18 \mathrm{~d}$ at $8{ }^{\circ} \mathrm{C}$. Nevertheless, peppers packaged with CTRL boxes showed a shelf life of $11 \mathrm{~d}$ at $8^{\circ} \mathrm{C}$.

\subsection{EOs residues in fresh bell peppers bulk-packaged with the active box}

Carvacrol (the major EOs component of the used EO mix) residues in peppers stored within the active box were below $1 \mathrm{mg} \mathrm{L}^{-1}$ during all storage period (data not shown). 
525 Such low EO concentrations were not appreciated in the sensory analyses. To the best of

526

527 our knowledge, there are no concerns related to oral toxicity by carvacrol in humans. Nevertheless, EOs rich in carvacrol should be used with caution with anticoagulant drugs or other bleeding disorders due to the antiplatelet aggregation activity of carvacrol (Tisserand and Young, 2014). On the other hand, a rabbit oral lethal dose of $100 \mathrm{mg} \mathrm{kg}^{-1}$ was reported for carvacrol (Opdyke, 1979). Nevertheless, carvacrol content of a pepper portion of $200 \mathrm{~g}$ is far from a theoretical extrapolated lethal dose (from rabbit oral lethal dose) of $8 \mathrm{~g}$ of carvacrol for a human adult of $80 \mathrm{~kg}$. In that sense, the carvacrol migrations from the active box to the product would not be detected by consumers and would not represent a health hazard.

\section{CONCLUSIONS}

Active packaging is an emerging technology that may extend the shelf life of food, and fruit and vegetables in particular, through a controlled release of antimicrobial compounds. $\beta$-cyclodextrins can be used to encapsulate essential oils with a high entrapment efficiency forming inclusion complexes to be incorporated in the active paperboard box coating. The controlled release of essential oils allowed to extend the shelf life of bell peppers for $18 \mathrm{~d}$ at $8^{\circ} \mathrm{C}$. The active box did not negatively affect the physicochemical quality of peppers while firmness and sensory quality were better maintained compared to non-active packaging. Low essential oil concentrations were found in the samples after $18 \mathrm{~d}$ being not detected by the sensory analyses. Storage temperatures higher than the recommended ones may lead to a higher release of essential oils from the inclusion complex allowing a higher control of the product microbial growth at such inappropriate storage temperatures. Nevertheless, the latter hypothesis needs to be corroborated in further studies at different temperatures. 
551 ACKNOWLEDGEMENTS

552 The industrial and laboratory experiments hereby presented have been financed through 553 a 2017-2018 RIS3Mur Project (Call RIS3Mur August 12, 2016, Department of 554 Economic Development, Tourism and Employment, Government of Region of Murcia, 555 Spain), Approval Number 2 / 16SAE00006.

556 


\section{REFERENCES}

558 Asbahani, A. El, Miladi, K., Badri, W., Sala, M., Addi, E.H.A., Casabianca, H., 559 Mousadik, A. El, Hartmann, D., Jilale, A., Renaud, F.N.R., Elaissari, A., 2015. 560 Essential oils: From extraction to encapsulation. Int. J. Pharm. 483, 220-243. https://doi.org/10.1016/J.IJPHARM.2014.12.069

ASTM, 1986. Physical requirement guidelines for sensory evaluation laboratories. ASTM International, Philadelphia PA (USA).

Ayala-Zavala, J.F., Soto-Valdez, H., González-León, A., Álvarez-Parrilla, E., Martín9385-1

EC, 2007. Commission Regulation (EC) No 2073/2005 of 15 November 2005 on microbiological criteria for foodstuffs. Off. J. Eur. Union 32, 12-29.

EC, 2004. Commission Regulation Regulation (EU) No 1935/2004 of 14 January 2011 
on materials and articles intended to come into contact with food and repealing Directives 80/590/EEC and 89/109/EEC. Off. J. Eur. Union 338, 4-17.

584

585

586

587

588

589

590

591

592

593

594

595

596

597

598

599

600

601

602

603

604

605

606

Edwards-Jones, V., Buck, R., Shawcross, S.G., Dawson, M.M., Dunn, K., 2004. The effect of essential oils on methicillin-resistant Staphylococcus aureus using a dressing model. Burns 30, 772-777. https://doi.org/10.1016/J.BURNS.2004.06.006

Gennadios, A., Weller, C.., Gooding, C.., 1994. Measurement errors in water vapor permeability of highly permeable, hydrophilic edible films. J. Food Eng. 21, 395409. https://doi.org/10.1016/0260-8774(94)90062-0

Goulao, L.F., Almeida, D.P.F., Oliveira, C.M., Almeida, D.P.F., Oliveira, C.M., 2010. Effect of enzymatic reactions ontexture of fruits and vegetables, in: Bayindirli, A. (Ed.), Enzymes in Fruit and Vegetable Processing. CRC Press, Boca Raton (USA), pp. 85-136. https://doi.org/10.1201/9781420094343-8

Han, J H, Krochta, J M, Han, Jung H, Krochta, John M, 1999. Wetting properties and water vapor permeability of whey-protein-coated paper. Trans. ASAE 42, 13751382. https://doi.org/10.13031/2013.13300

ISO, 2007. ISO 8589:2007 - Sensory analysis - General guidance for the design of test rooms.

Kamimura, J.A., Santos, E.H., Hill, L.E., Gomes, C.L., 2014. Antimicrobial and antioxidant activities of carvacrol microencapsulated in hydroxypropyl-betacyclodextrin. LWT - Food Sci. Technol. 57, 701-709. https://doi.org/10.1016/J.LWT.2014.02.014

Khaneghah, A.M., Hashemi, S.M.B., Limbo, S., 2018. Antimicrobial agents and packaging systems in antimicrobial active food packaging: An overview of approaches and interactions. Food Bioprod. Process. 111, 1-19. https://doi.org/10.1016/J.FBP.2018.05.001 
López-Gálvez, G., El-Bassuoni, R., Nie, X., Cantwell, N., 1997. Quality of red and green fresh-cut peppers stored in CAs, in: Gorny, J.R. (Ed.), Fresh-Cut Fruits and Vegetables and MAP. University of Davis, Davis CA (USA), pp. 152-157.

López-Gómez, A., Ros-Chumillas, M., Antolinos, V., Buendía-Moreno, L., NavarroSegura, L., Sánchez-Martínez, M.J., Martínez-Hernández, G.B., Soto-Jover, S., 2019. Fresh culinary herbs decontamination with essential oil vapours applied under vacuum conditions. Postharvest Biol. Technol. 156, 110942. https://doi.org/10.1016/J.POSTHARVBIO.2019.110942

Manolikar, M.., Sawant, M.., 2003. Study of solubility of isoproturon by its complexation with $\beta$-cyclodextrin. Chemosphere 51, 811-816. https://doi.org/10.1016/S00456535(03)00099-7

MAPA, 2018. Superficies y producciones de cultivos. Avances [WWW Document]. URL https://www.mapa.gob.es/es/estadistica/temas/estadisticasagrarias/agricultura/superficies-producciones-anuales-cultivos/ (accessed 4.23.19).

Marques, C.S., Carvalho, S.G., Bertoli, L.D., Villanova, J.C.O., Pinheiro, P.F., dos Santos, D.C.M., Yoshida, M.I., de Freitas, J.C.C., Cipriano, D.F., Bernardes, P.C., 2019. $\beta$-Cyclodextrin inclusion complexes with essential oils: Obtention, characterization, antimicrobial activity and potential application for food preservative sachets. Food Res. Int. 119, 499-509. https://doi.org/10.1016/j.foodres.2019.01.016

Marreto, R.N., Almeida, E.E.C.V., Alves, P.B., Niculau, E.S., Nunes, R.S., Matos, C.R.S., Araújo, A.A.S., 2008. Thermal analysis and gas chromatography coupled mass spectrometry analyses of hydroxypropyl- $\beta$-cyclodextrin inclusion complex containing Lippia gracilis essential oil. Thermochim. Acta 475, 53-58. https://doi.org/10.1016/J.TCA.2008.06.015 
Martínez-Hernández, G.B., Amodio, M.L., Colelli, G., 2017. Carvacrol-loaded chitosan nanoparticles maintain quality of fresh-cut carrots. Innov. Food Sci. Emerg. Technol. 41, 56-63. https://doi.org/10.1016/j.ifset.2017.02.005

Meir, S., Rosenberger, I., Aharon, Z., Grinberg, S., Fallik, E., 1995. Improvement of the postharvest keeping quality and colour development of bell pepper (cv. 'Maor') by packaging with polyethylene bags at a reduced temperature. Postharvest Biol. Technol. 5, 303-309. https://doi.org/10.1016/0925-5214(94)00035-Q

Mortensen, A., Aguilar, F., Crebelli, R., Di Domenico, A., Dusemund, B., Frutos, M.J., Galtier, P., Gott, D., Gundert-Remy, U., Leblanc, J., Lindtner, O., Moldeus, P., Mosesso, P., Parent-Massin, D., Oskarsson, A., Stankovic, I., Waalkens-Berendsen, I., Woutersen, R.A., Wright, M., Younes, M., Boon, P., Chrysafidis, D., Gürtler, R., Tobback, P., Arcella, D., Rincon, A.M., Lambré, C., 2016. Re-evaluation of $\beta$-cyclodextrin (E 459) as a food additive. EFSA J. 14. https://doi.org/10.2903/j.efsa.2016.4628

Mourtzinos, I., Salta, F., Yannakopoulou, K., Chiou, A., Karathanos, V.T., 2007. Encapsulation of olive leaf extract in $\beta$-cyclodextrin. J. Agric. Food Chem. 55, 8088-8094. https://doi.org/10.1021/jf0709698

Munhuweyi, K., Caleb, O.J., van Reenen, A.J., Opara, U.L., 2018. Physical and antifungal properties of $\beta$-cyclodextrin microcapsules and nanofibre films containing cinnamon and oregano essential oils. LWT 87, 413-422. https://doi.org/10.1016/J.LWT.2017.09.012

Opdyke, D.L.J., 1979. Monographs on fragrance raw materials. Food Cosmet. Toxicol. 17, 743-745. https://doi.org/10.1016/0015-6264(79)90288-8

Pothakamury, U.R., Barbosa-Cánovas, G. V., 1995. Fundamental aspects of controlled release in foods. Trends Food Sci. Technol. 6, 397-406. 
https://doi.org/10.1016/S0924-2244(00)89218-3

Rao, T.V.R., Gol, N.B., Shah, K.K., 2011. Effect of postharvest treatments and storage temperatures on the quality and shelf life of sweet pepper (Capsicum annum L.). Sci. Hortic. (Amsterdam). 132, 18-26. https://doi.org/10.1016/J.SCIENTA.2011.09.032

Reche-Mármol, J., 2010. Cultivo del pimiento dulce en invernadero [WWW Document]. URL https://www.juntadeandalucia.es/export/drupaljda/1337160265Cultivo_Pimiento_I nvernadero.pdf (accessed 4.23.19).

Ren, X., Yue, S., Xiang, H., Xie, M., 2018. Inclusion complexes of eucalyptus essential oil with $\beta$-cyclodextrin: Preparation, characterization and controlled release. J. Porous Mater. 25, 1577-1586. https://doi.org/10.1007/s10934-018-0571-x

Seglie, L., Spadaro, D., Trotta, F., Devecchi, M., Gullino, M.L., Scariot, V., 2012. Use of 1-methylcylopropene in cyclodextrin-based nanosponges to control grey mould caused by Botrytis cinerea on Dianthus caryophyllus cut flowers. Postharvest Biol. Technol. 64, 55-57. https://doi.org/10.1016/j.postharvbio.2011.09.014

Seo, E.-J., Min, S.-G., Choi, M.-J., 2010. Release characteristics of freeze-dried eugenol encapsulated with $\beta$-cyclodextrin by molecular inclusion method. J. Microencapsul. 27, 496-505. https://doi.org/10.3109/02652041003681398

Serrano, M., Martínez-Romero, D., Castillo, S., Guillén, F., Valero, D., 2005. The use of natural antifungal compounds improves the beneficial effect of MAP in sweet cherry storage. Innov. Food Sci. Emerg. Technol. 6, 115-123. https://doi.org/10.1016/J.IFSET.2004.09.001

Simonne, A.H., Simonne, E.H., Eitenmiller, R.R., Mills, H.A., Green, N.R., 1997. Ascorbic acid and provitamin a contents in unusually colored bell peppers (Capsicum annuumL.). J. Food Compos. Anal. 10, 299-311. 
683

684

685

686

687

688

689

690

691

692

693

694

695

696

697

698

699

700

701

702

703

Songkro, S., Hayook, N., Jaisawang, J., Maneenuan, D., Chuchome, T., Kaewnopparat, N., 2012. Investigation of inclusion complexes of citronella oil, citronellal and citronellol with $\beta$-cyclodextrin for mosquito repellent. J. Incl. Phenom. Macrocycl. Chem. 72, 339-355. https://doi.org/10.1007/s10847-011-9985-7

Taboada-Rodríguez, A., García-García, I., Cava-Roda, R., López-Gómez, A., MarínIniesta, F., 2013. Hydrophobic properties of cardboard coated with polylactic acid and ethylene scavengers. J. Coatings Technol. Res. 10, 749-755. https://doi.org/10.1007/s11998-013-9493-3

Tisserand, R., Young, R., 2014. Constituent profiles, in: Essential Oil Safety. Churchill Livingstone, pp. 483-647. https://doi.org/10.1016/B978-0-443-06241-4.00014-X

Tournas, V.H., 2005. Moulds and yeasts in fresh and minimally processed vegetables, and sprouts. Int. J. Food Microbiol. 99, 71-77. https://doi.org/10.1016/j.ijfoodmicro.2004.08.009

Tsegay, D., Tesfaye, B., Ibrahim, M.A., Yirga, H., Bayleyegn, A., 2013. Cell growth curves for different cell lines and their relationship with biological activities. Int. J. Biotechnol. Mol. Biol. Res. 4, 60-70. https://doi.org/10.5897/IJBMBR2013.0154

Wang, X., Luo, Z., Xiao, Z., 2014. Preparation, characterization, and thermal stability of $\beta$-cyclodextrin/soybean lecithin inclusion complex. Carbohydr. Polym. 101, 10271032. https://doi.org/10.1016/j.carbpol.2013.10.042 
Table 1. In vitro microbial reductions (log units) of moulds and pathogens with pure EOs $(n=3 \pm S D)$.

Table 2. Microbial loads ( $\log \mathrm{CFU} \mathrm{g}^{-1}$ ) of fresh bell peppers (green, red and yellow) bulkpackaged with different packaging treatments (AP: active packaging box coated with the EOs $-\beta \mathrm{CD}$ inclusion complex; CTRL: active packaging box without the EOs $-\beta \mathrm{CD}$ inclusion complex) stored at $8^{\circ} \mathrm{C}(\mathrm{n}=3 \pm \mathrm{SD})$.

Table 3. Physicochemical quality (soluble solid content (\%), SSC; $\mathrm{pH}$ and titratable acidity $\left.\left(\mathrm{mg} \mathrm{kg}^{-1}\right), \mathrm{TA}\right)(\mathrm{n}=3 \pm \mathrm{SD})$ and firmness $(\mathrm{N})(\mathrm{n}=5 \pm \mathrm{SD})$ of fresh bell peppers (green, red and yellow) bulk-packaged with different packaging treatments (AP: active packaging box coated with the EOs $-\beta \mathrm{CD}$ inclusion complex; CTRL: active packaging box without the EOs $-\beta \mathrm{CD}$ inclusion complex) stored at $8^{\circ} \mathrm{C}$.

Figure 1. In vitro microbial reductions (log units) against a mould cocktail by disc diffusion (vapour contact variant) using different pure EOs mixes or included in the EOs $-\beta C D$ inclusion complex (pure complex or active material sprayed with the corresponding EOs $-\beta C D$ complex $)(n=3 \pm S D)$. Different letters denote significant differences $(p<0.05)$ among treatments. ns: not significant reductions $(p>0.05)$ compared to control.

727 Figure 2. Decay incidence (\%) of fresh bell peppers (green, red and yellow) bulkpackaged with different packaging treatments (AP: active packaging box coated with the 
729 EOs $-\beta \mathrm{CD}$ inclusion complex (bars with points); CTRL: active packaging box without 730 the EOs $-\beta \mathrm{CD}$ inclusion complex (empty bars)) stored at $8{ }^{\circ} \mathrm{C}$. ${ }^{*}$ denotes significant 731 differences $(p<0.05)$ between AP and CTRL packaging treatments for the same sampling 732 day.

733

734 Figure 3. Sensory scores of fresh bell peppers (green, red and yellow) bulk packaged 735 with different packaging treatments (AP: active packaging box coated with the EOs- $\beta \mathrm{CD}$ 736 inclusion complex; CTRL: active packaging box without the EOs- $\beta$ CD inclusion 737 complex) stored for $11(\mathrm{~A})$ and $18 \mathrm{~d}(\mathrm{~B})$ at $8{ }^{\circ} \mathrm{C}(\mathrm{n}=3)$. 
SUPPLEMENTARY MATERIAL

740

741 Supplementary material 1. Thermogravimetric/Differential Thermal Analysis

742 (TG/DTA) of $\beta \mathrm{CD}(\mathrm{A})$ and $\mathrm{EOs}-\beta \mathrm{CD}$ inclusion complex (B).

743

744 Supplementary material 2. Differential scanning calorimetry (DSC) thermogram of 745 EOs (red line) and EOs- $\beta$ CD inclusion complex (black line).

746

747 Supplementary material 3. Fourier transform infrared (FTIR) spectra for pure EOs mix 748 (a), $\beta$-cyclodextrin (b), and EOs $-\beta \mathrm{CD}$ inclusion complex (c).

749

750

Supplementary material 4. Scanning electron micrographs (SEM) of (a) free $\beta C D$ and 751

(b) EOs $-\beta \mathrm{CD}$ inclusion complex.

752

753

Supplementary material 5. Mechanical and hydrophobic properties of active (coated 754 with the EOs $-\beta \mathrm{CD}$ inclusion complex) and control boxes (without the EOs $-\beta \mathrm{CD}$ 755 inclusion complex).

756

757 Supplementary material 6. SEM captions of non-sprayed paperboard box (left), control 758 paperboard box (centre) (coated with lacquer without the EOs- $\beta \mathrm{CD}$ inclusion complex) and active paperboard box (right) (coated with lacquer with the EOs- $\beta \mathrm{CD}$ inclusion complex). 


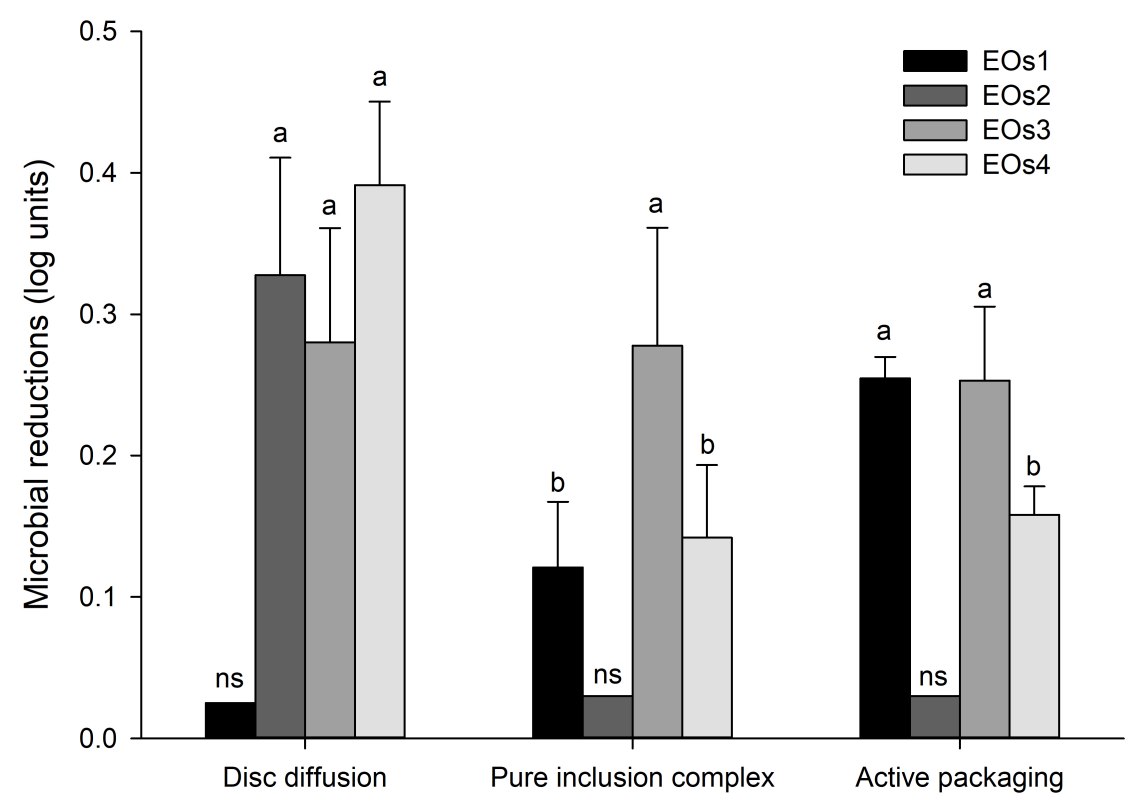




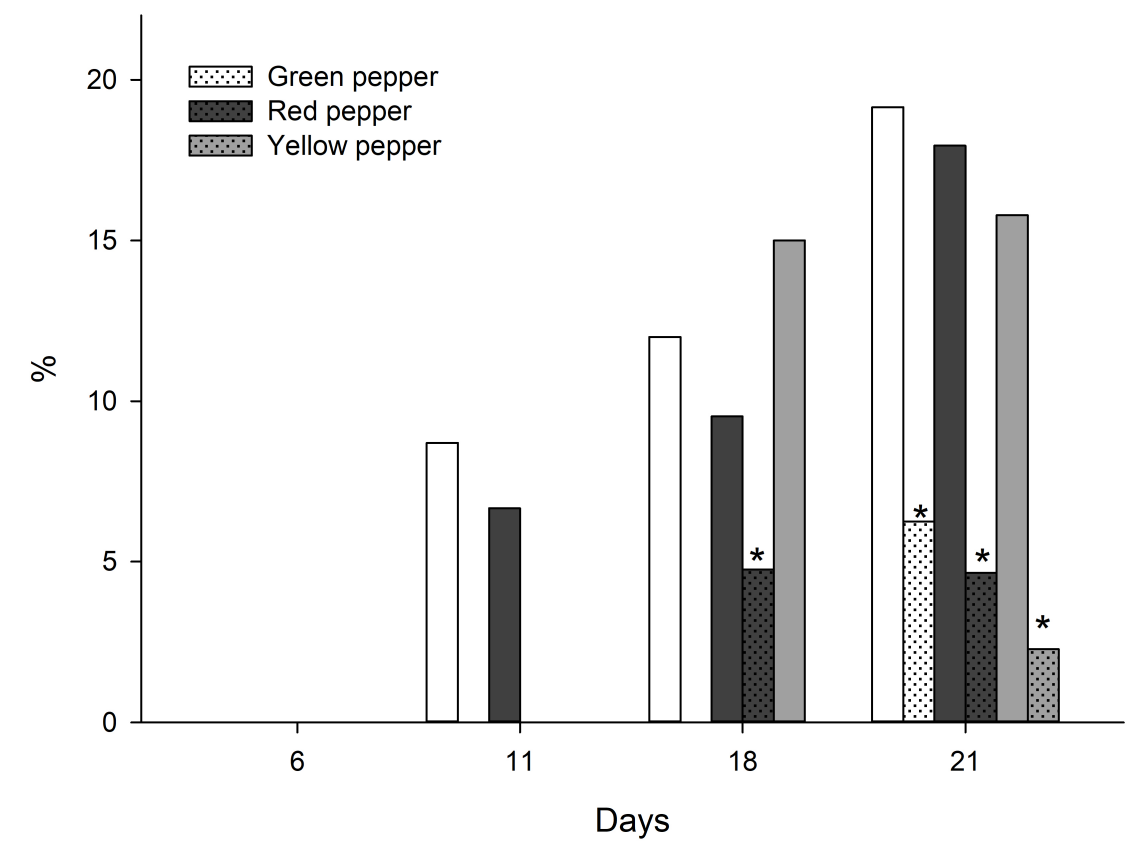



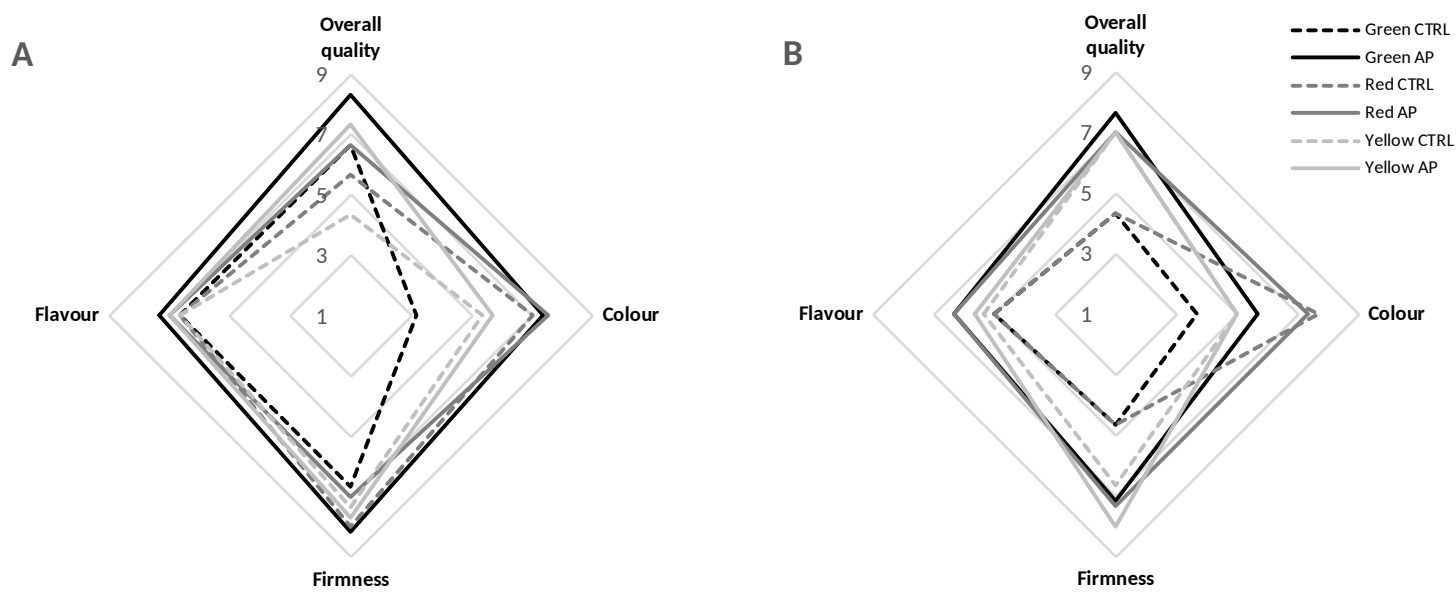
Table 1.

2

\begin{tabular}{lccc}
\hline & Carvacrol & Oregano EO & Cinnamon EO \\
\hline Pathogens & & & \\
Escherichia coli & $0.78 \pm 0.15$ & $0.31 \pm 0.06$ & $0.37 \pm 0.01$ \\
Listeria monocytogenes & $1.06 \pm 0.28$ & $\mathrm{~ns}$ & $0.66 \pm 0.36$ \\
Salmonella spp. & $0.86 \pm 0.09$ & $\mathrm{~ns}$ & $\mathrm{~ns}$
\end{tabular}

Moulds

$\begin{array}{lccr}\text { Botrytis cinerea } & \mathrm{ns} & 1.41 \pm 0.05 & + \\ \text { Alternaria alternata } & + & \mathrm{ns} & + \\ \text { Penicillium spp. } & + & \mathrm{ns} & + \\ \text { Aspergillus niger } & \mathrm{ns} & 1.79 \pm 0.68 & \mathrm{~ns}\end{array}$

3 ns: not significant reductions ( $p>0.05)$ compared to control; + reductions higher than $3 \log$ units. 
Table 2.

\begin{tabular}{|c|c|c|c|c|c|c|}
\hline Pepper & Packaging & $\begin{array}{c}\text { Storage } \\
\text { days }\end{array}$ & Mesophiles & Psychrophiles & Enterobacteria & Moulds \\
\hline \multirow[t]{8}{*}{ Green } & \multirow[t]{4}{*}{ CTRL } & 1 & $4.23 \pm 0.22$ & $2.43 \pm 0.02$ & $5.28 \pm 0.07$ & $1.50 \pm 0.71$ \\
\hline & & 6 & $5.01 \pm 0.12$ & $5.64 \pm 0.39$ & $5.22 \pm 0.21$ & $2.98 \pm 0.28$ \\
\hline & & 11 & $5.80 \pm 0.02$ & $6.11 \pm 0.80$ & $5.56 \pm 0.79$ & $3.43 \pm 0.10$ \\
\hline & & 18 & $6.23 \pm 0.12$ & $6.13 \pm 0.09$ & $5.62 \pm 0.07$ & $4.24 \pm 0.29$ \\
\hline & \multirow[t]{4}{*}{ AP } & 1 & $4.23 \pm 0.22$ & $2.43 \pm 0.02$ & $5.28 \pm 0.07$ & $1.50 \pm 0.71$ \\
\hline & & 6 & $4.31 \pm 0.38$ & $3.09 \pm 0.13$ & $3.91 \pm 0.13$ & $2.00 \pm 0.01$ \\
\hline & & 11 & $4.39 \pm 0.55$ & $3.00 \pm 0.01$ & $4.54 \pm 0.09$ & $2.80 \pm 0.28$ \\
\hline & & 18 & $5.27 \pm 0.10$ & $4.95 \pm 0.07$ & $3.66 \pm 0.51$ & $4.16 \pm 0.03$ \\
\hline \multirow[t]{8}{*}{ Red } & \multirow[t]{4}{*}{ CTRL } & 1 & $5.52 \pm 0.06$ & $3.27 \pm 0.26$ & $5.89 \pm 0.01$ & $2.57 \pm 0.38$ \\
\hline & & 6 & $6.46 \pm 0.25$ & $6.41 \pm 0.02$ & $6.07 \pm 0.26$ & $3.21 \pm 0.13$ \\
\hline & & 11 & $6.46 \pm 0.38$ & $6.38 \pm 0.01$ & $5.96 \pm 0.02$ & $3.70 \pm 0.10$ \\
\hline & & 18 & $6.77 \pm 0.22$ & $6.06 \pm 0.33$ & $6.02 \pm 0.03$ & $4.20 \pm 0.05$ \\
\hline & \multirow[t]{4}{*}{ AP } & 1 & $5.52 \pm 0.06$ & $3.27 \pm 0.26$ & $5.89 \pm 0.01$ & $2.57 \pm 0.38$ \\
\hline & & 6 & $4.82 \pm 0.04$ & $4.26 \pm 0.50$ & $3.52 \pm 0.62$ & $2.59 \pm 0.16$ \\
\hline & & 11 & $5.11 \pm 0.38$ & $5.06 \pm 0.51$ & $4.69 \pm 0.62$ & $3.42 \pm 0.60$ \\
\hline & & 18 & $5.48 \pm 0.62$ & $5.29 \pm 0.63$ & $5.40 \pm 0.37$ & $4.20 \pm 0.01$ \\
\hline \multirow[t]{8}{*}{ Yellow } & \multirow[t]{4}{*}{ CTRL } & 1 & $5.83 \pm 0.14$ & $3.61 \pm 0.40$ & $4.21 \pm 0.34$ & $2.12 \pm 0.16$ \\
\hline & & 6 & $5.22 \pm 0.42$ & $3.61 \pm 0.19$ & $4.10 \pm 0.02$ & $2.57 \pm 0.38$ \\
\hline & & 11 & $4.50 \pm 0.28$ & $3.50 \pm 0.71$ & $4.23 \pm 0.07$ & $2.65 \pm 0.49$ \\
\hline & & 18 & $5.38 \pm 0.60$ & $5.37 \pm 0.10$ & $4.42 \pm 0.82$ & $4.71 \pm 0.11$ \\
\hline & \multirow[t]{4}{*}{ AP } & 1 & $5.83 \pm 0.14$ & $3.61 \pm 0.40$ & $4.21 \pm 0.34$ & $2.12 \pm 0.16$ \\
\hline & & 6 & $5.08 \pm 0.08$ & $4.90 \pm 0.05$ & $3.95 \pm 0.32$ & $2.59 \pm 0.16$ \\
\hline & & 11 & $3.57 \pm 0.38$ & $3.00 \pm 0.04$ & $4.16 \pm 0.36$ & $3.07 \pm 0.84$ \\
\hline & & 18 & $5.61 \pm 0.11$ & $4.94 \pm 0.65$ & $3.00 \pm 0.05$ & $3.69 \pm 0.30$ \\
\hline & \multicolumn{2}{|l|}{ Variety (A) } & $(0.31) \ddagger$ & $(0.38) \ddagger$ & $(0.53) \ddagger$ & $(0.28) \dagger$ \\
\hline & \multicolumn{2}{|c|}{ Packaging treatment (B) } & $(0.21) \ddagger$ & $(0.26) \ddagger$ & $(0.37) \ddagger$ & $(0.14)^{*}$ \\
\hline & \multicolumn{2}{|c|}{ Storage time $(\mathrm{C})$} & $(0.33) \ddagger$ & $(0.40) \ddagger$ & $(0.31)^{*}$ & $(0.40) \div$ \\
\hline & \multicolumn{2}{|l|}{$\mathrm{A} \times \mathrm{B}$} & $(0.43) \ddagger$ & $(0.52) \ddagger$ & ns & ns \\
\hline & \multicolumn{2}{|l|}{$\mathrm{A} \times \mathrm{C}$} & $(0.66) \ddagger$ & $(0.80) \ddagger$ & ns & ns \\
\hline & \multicolumn{2}{|l|}{$\mathrm{B} \times \mathrm{C}$} & $(0.46) \ddagger$ & $(0.56) \ddagger$ & $(0.44)^{*}$ & ns \\
\hline & \multicolumn{2}{|l|}{$\mathrm{A} \times \mathrm{B} \times \mathrm{C}$} & ns & $(1.13) \ddagger$ & ns & ns \\
\hline
\end{tabular}

ns: not significant $(p>0.05) ; *, \dagger, \frac{\dagger}{\dagger}$ significance for $P \leq 0.05,0.01$, and 0.001 , respectively. 
Table 3.

\begin{tabular}{|c|c|c|c|c|c|c|}
\hline $\begin{array}{l}\text { Pepper } \\
\text { variety }\end{array}$ & Packaging & $\begin{array}{c}\text { Storage } \\
\text { days }\end{array}$ & $\mathrm{SSC}$ & $\mathrm{pH}$ & TA & Firmness \\
\hline \multirow[t]{8}{*}{ Green } & \multirow[t]{4}{*}{ CTRL } & 1 & $5.0 \pm 0.1$ & $6.21 \pm 0.01$ & $1.2 \pm 0.1$ & $27.1 \pm 0.1$ \\
\hline & & 6 & $5.0 \pm 0.2$ & $5.49 \pm 0.09$ & $1.2 \pm 0.1$ & $27.2 \pm 0.1$ \\
\hline & & 11 & $4.8 \pm 0.4$ & $5.27 \pm 0.05$ & $1.0 \pm 0.1$ & $27.2 \pm 1.9$ \\
\hline & & 18 & $4.8 \pm 0.4$ & $5.66 \pm 0.03$ & $1.3 \pm 0.3$ & $19.5 \pm 0.9$ \\
\hline & \multirow[t]{4}{*}{ AP } & 1 & $5.0 \pm 0.1$ & $6.21 \pm 0.01$ & $1.2 \pm 0.1$ & $27.1 \pm 0.1$ \\
\hline & & 6 & $4.5 \pm 0.1$ & $5.67 \pm 0.11$ & $0.9 \pm 0.1$ & $27.8 \pm 1.6$ \\
\hline & & 11 & $3.8 \pm 0.4$ & $5.76 \pm 0.06$ & $1.9 \pm 0.3$ & $26.0 \pm 3.0$ \\
\hline & & 18 & $5.3 \pm 0.4$ & $4.89 \pm 0.05$ & $0.9 \pm 0.1$ & $22.7 \pm 0.8$ \\
\hline \multirow[t]{8}{*}{ Red } & \multirow[t]{4}{*}{ CTRL } & 1 & $6.0 \pm 0.2$ & $5.25 \pm 0.10$ & $2.6 \pm 0.2$ & $19.3 \pm 2.1$ \\
\hline & & 6 & $6.5 \pm 0.1$ & $5.04 \pm 0.05$ & $2.2 \pm 0.1$ & $16.6 \pm 2.0$ \\
\hline & & 11 & $6.8 \pm 0.3$ & $4.33 \pm 0.16$ & $3.0 \pm 0.1$ & $17.0 \pm 0.9$ \\
\hline & & 18 & $7.0 \pm 0.2$ & $5.14 \pm 0.01$ & $2.3 \pm 0.2$ & $15.3 \pm 0.8$ \\
\hline & \multirow[t]{4}{*}{ AP } & 1 & $6.0 \pm 0.2$ & $5.25 \pm 0.10$ & $2.6 \pm 0.2$ & $19.3 \pm 2.1$ \\
\hline & & 6 & $6.3 \pm 0.4$ & $5.05 \pm 0.04$ & $2.2 \pm 0.1$ & $22.3 \pm 2.4$ \\
\hline & & 11 & $6.0 \pm 0.2$ & $4.90 \pm 0.01$ & $3.0 \pm 0.1$ & $20.0 \pm 0.8$ \\
\hline & & 18 & $7.3 \pm 0.4$ & $4.64 \pm 0.10$ & $2.7 \pm 0.2$ & $19.1 \pm 0.6$ \\
\hline \multirow[t]{8}{*}{ Yellow } & \multirow[t]{4}{*}{ CTRL } & 1 & $5.2 \pm 0.1$ & $5.04 \pm 0.06$ & $2.0 \pm 0.1$ & $15.9 \pm 2.0$ \\
\hline & & 6 & $6.8 \pm 0.3$ & $5.03 \pm 0.01$ & $2.0 \pm 0.1$ & $16.7 \pm 1.1$ \\
\hline & & 11 & $7.1 \pm 0.2$ & $4.52 \pm 0.18$ & $2.5 \pm 0.1$ & $16.7 \pm 0.1$ \\
\hline & & 18 & $6.0 \pm 0.4$ & $4.89 \pm 0.08$ & $2.4 \pm 0.3$ & $14.3 \pm 1.0$ \\
\hline & \multirow[t]{4}{*}{ AP } & 1 & $5.2 \pm 0.1$ & $5.04 \pm 0.06$ & $2.0 \pm 0.1$ & $15.9 \pm 2.0$ \\
\hline & & 6 & $6.8 \pm 0.4$ & $5.04 \pm 0.01$ & $2.3 \pm 0.1$ & $17.3 \pm 1.0$ \\
\hline & & 11 & $7.0 \pm 0.1$ & $4.89 \pm 0.01$ & $3.0 \pm 0.2$ & $13.4 \pm 1.1$ \\
\hline & & 18 & $5.0 \pm 0.4$ & $4.74 \pm 0.31$ & $1.9 \pm 0.2$ & $12.6 \pm 1.5$ \\
\hline & \multicolumn{2}{|l|}{ Variety (A) } & $(0.22) \ddagger$ & $(0.10) \$$ & $(0.1) \dagger$ & $(1.4) \div$ \\
\hline & \multicolumn{2}{|c|}{ Packaging treatment (B) } & $(0.15) \dagger$ & ns & $(0.1) \dagger$ & $(0.5) \div$ \\
\hline & \multicolumn{2}{|c|}{ Storage time $(\mathrm{C})$} & $(0.23) \div$ & $(0.10) \div$ & $(0.2) \ddagger$ & $(1.4) \div$ \\
\hline & \multicolumn{2}{|l|}{$\mathrm{A} \times \mathrm{B}$} & $\mathrm{ns}$ & ns & $\mathrm{ns}$ & $(1.4) \dagger$ \\
\hline & \multicolumn{2}{|l|}{$\mathrm{A} \times \mathrm{C}$} & $(0.46) \div$ & $(0.20) \div$ & $(0.3) \ddagger$ & $(2.9) \div$ \\
\hline & \multicolumn{2}{|l|}{$\mathrm{B} \times \mathrm{C}$} & $(0.18)^{*}$ & $(0.14) \$$ & $(0.2) \dagger$ & $\mathrm{ns}$ \\
\hline & \multicolumn{2}{|l|}{$\mathrm{A} \times \mathrm{B} \times \mathrm{C}$} & $(0.65) \dagger$ & $(0.21) \dagger$ & $(0.4) \dagger$ & ns \\
\hline
\end{tabular}

ns: not significant $(p>0.05) ; *, \dagger, \ddagger$ significance for $P \leq 0.05,0.01$, and 0.001 , respectively. 


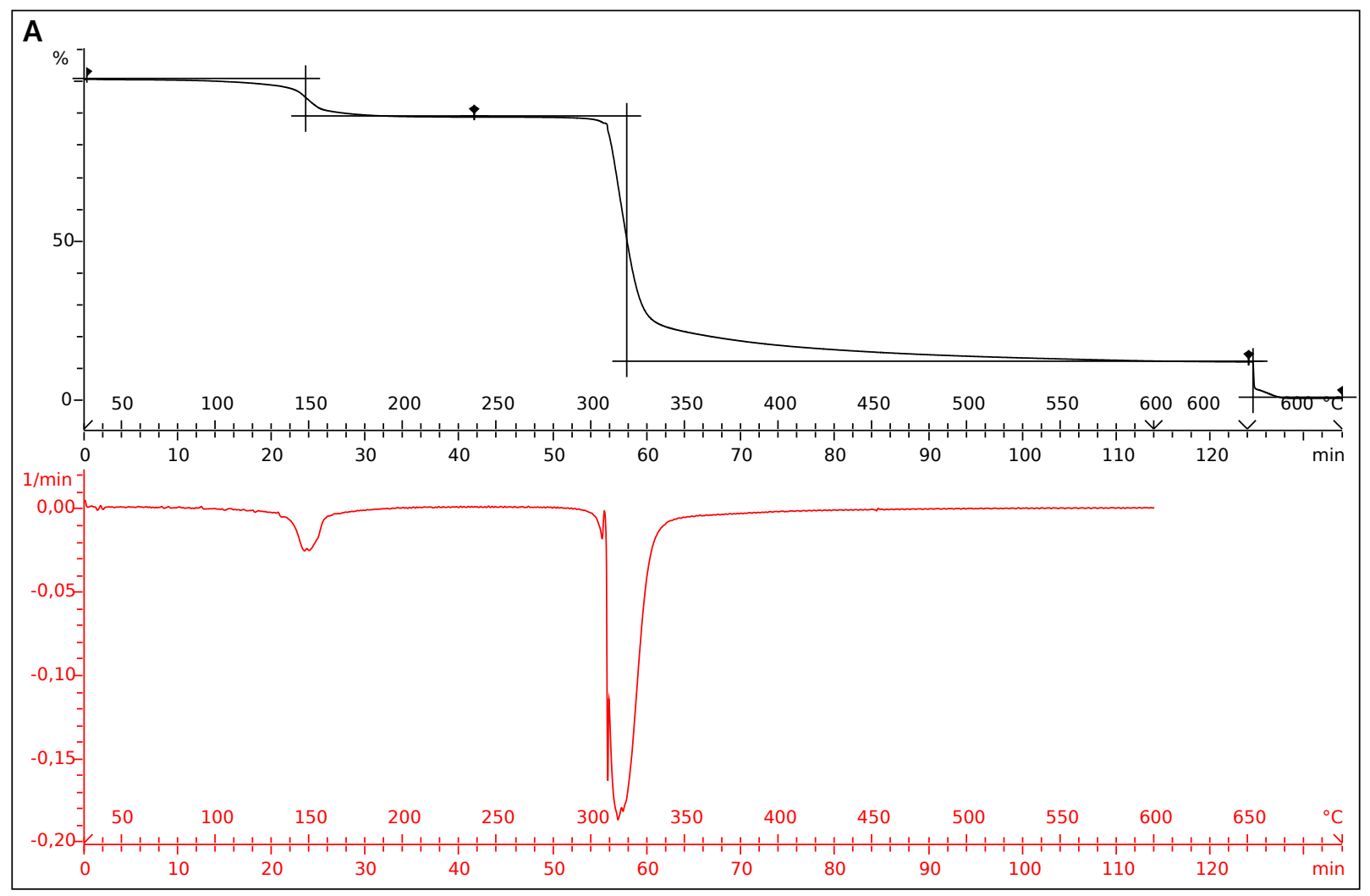




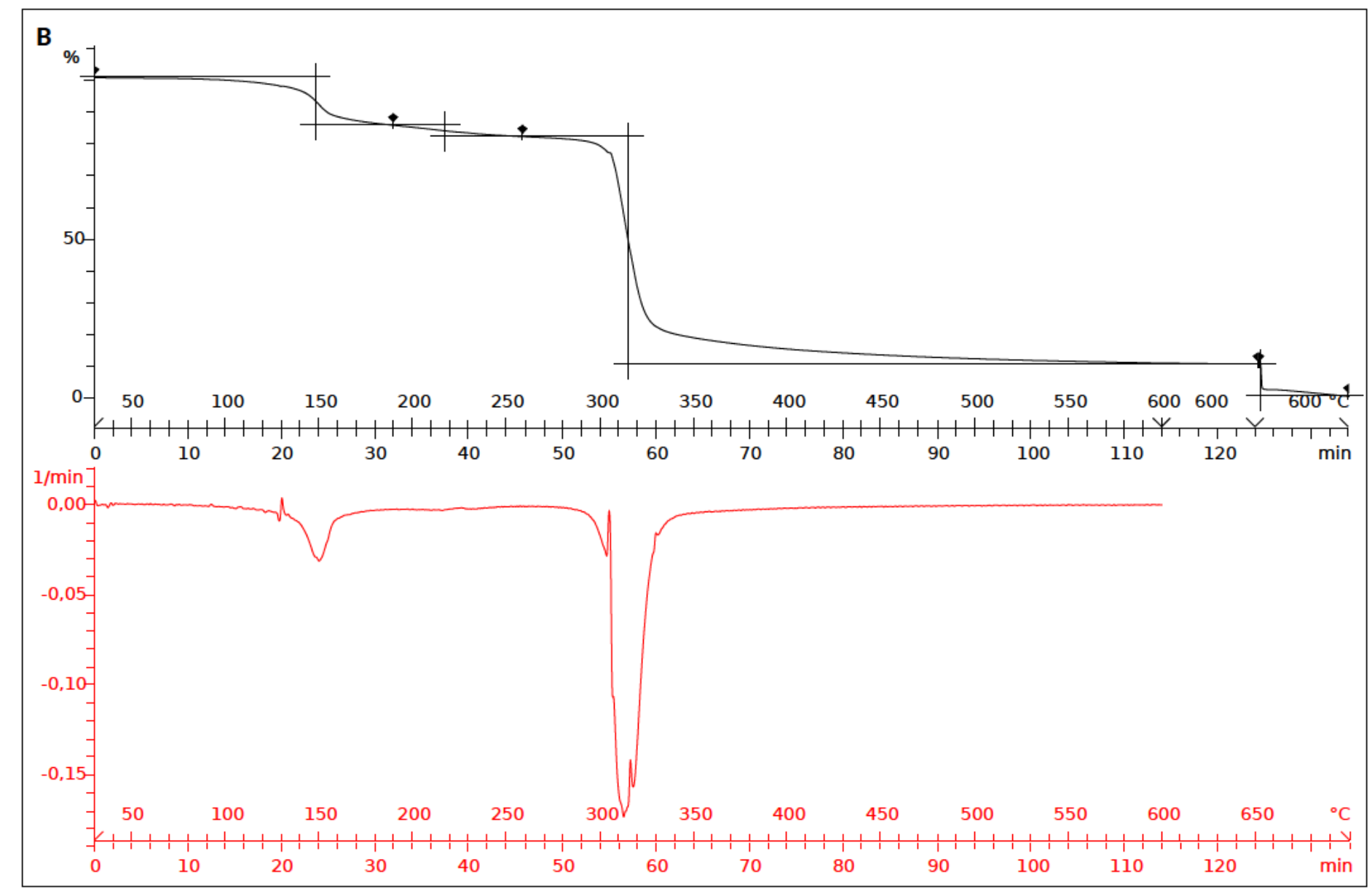




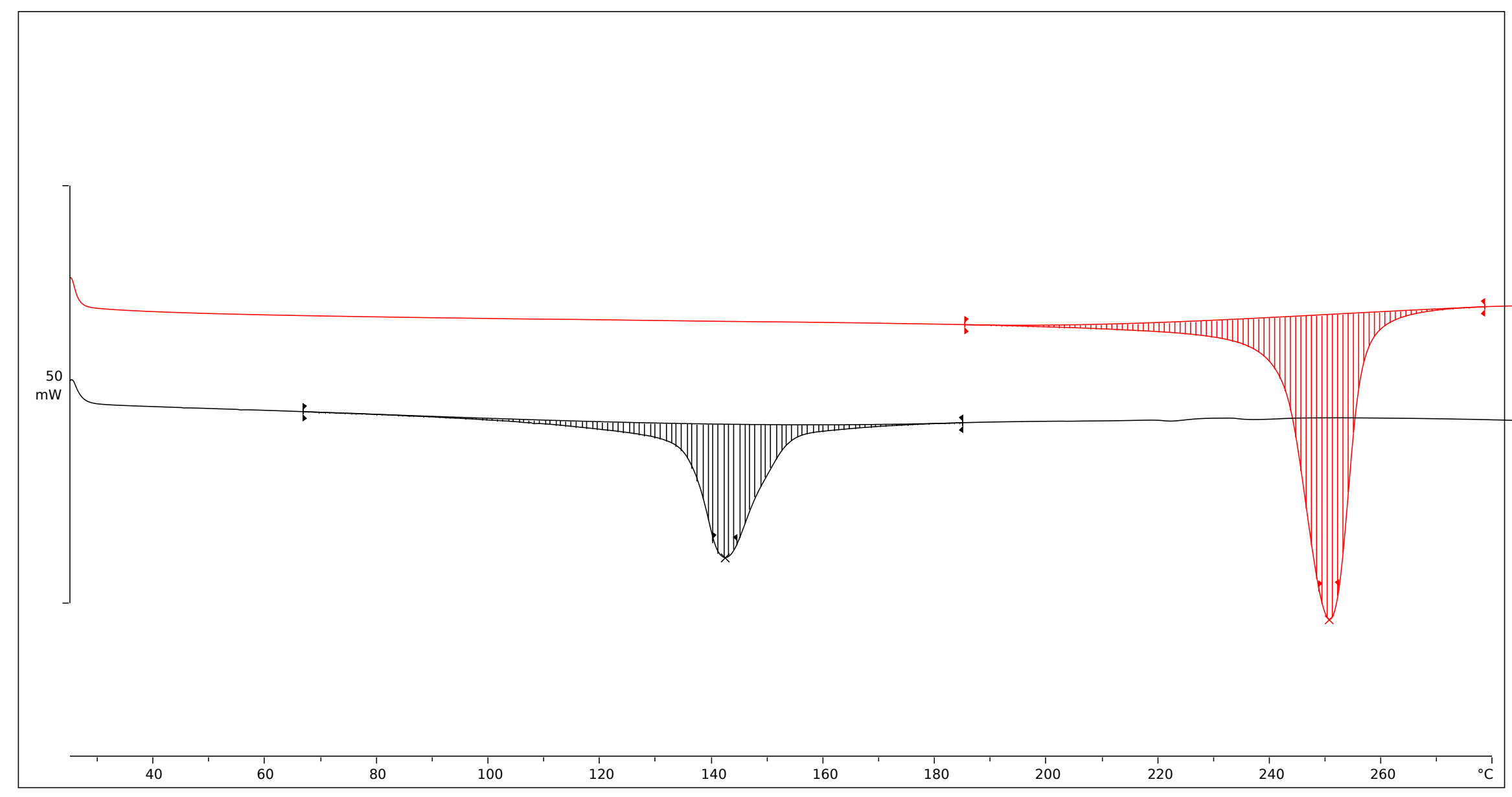




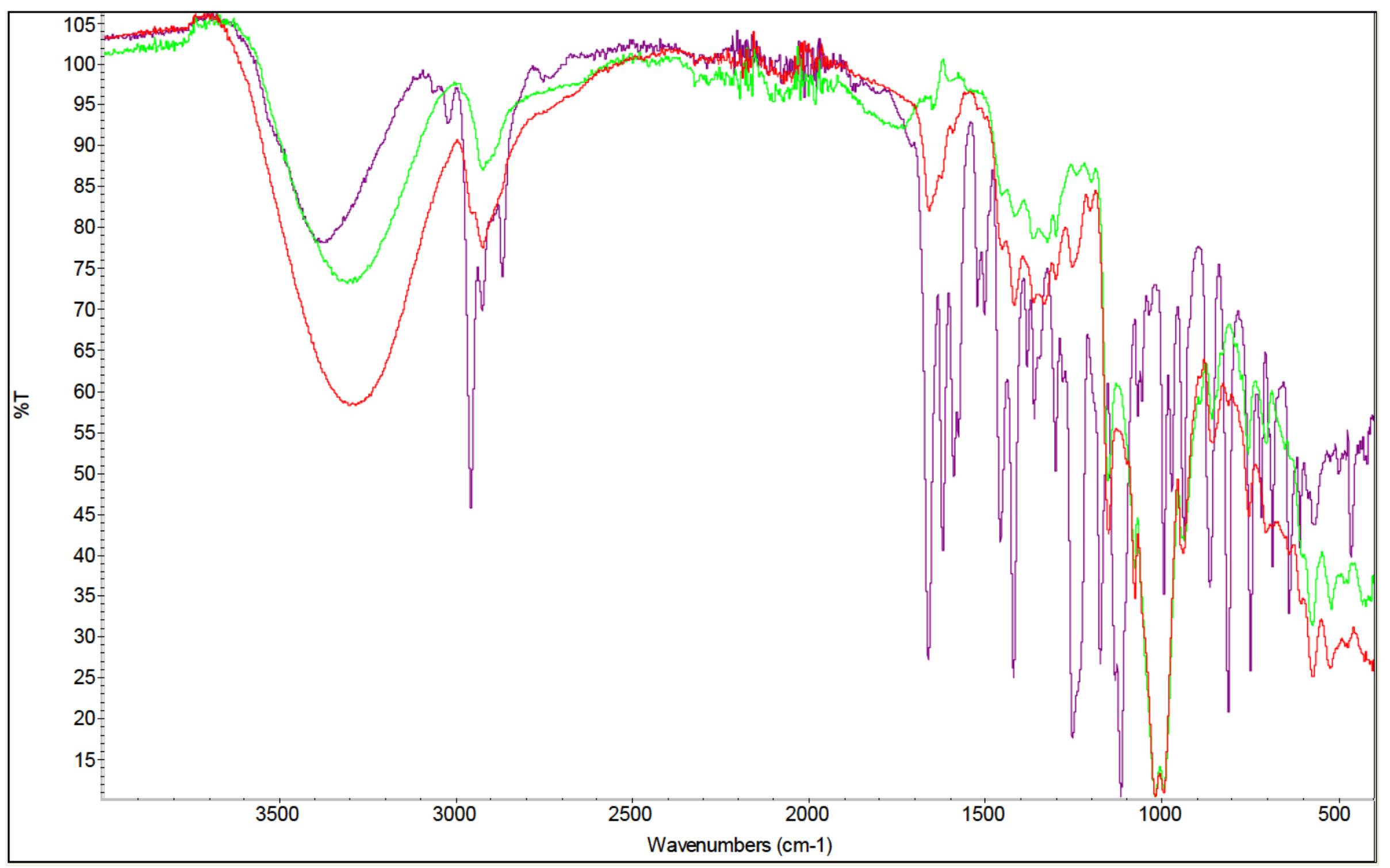

EOS, $\beta C D$ and $C D+F 3$ 

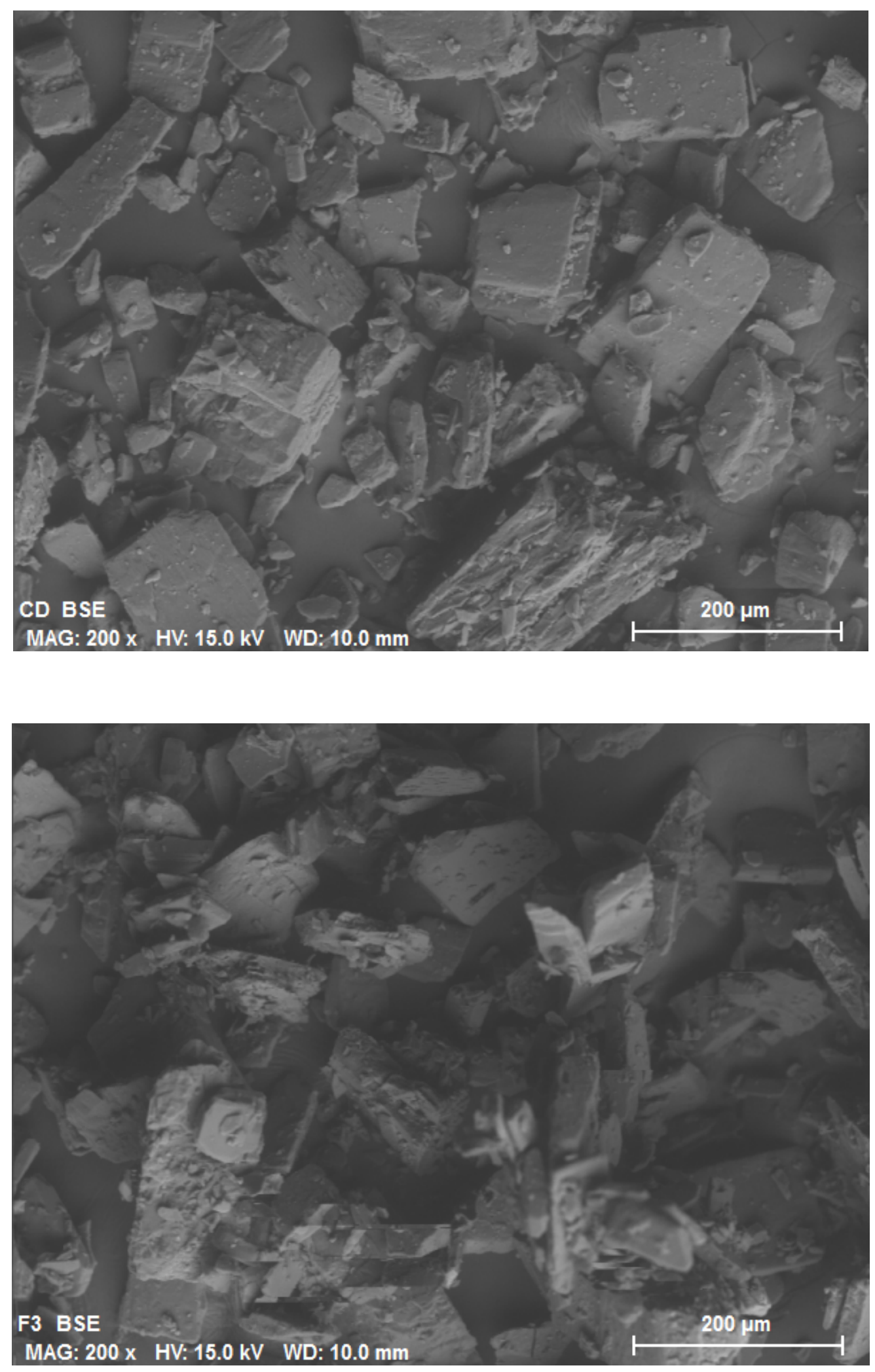


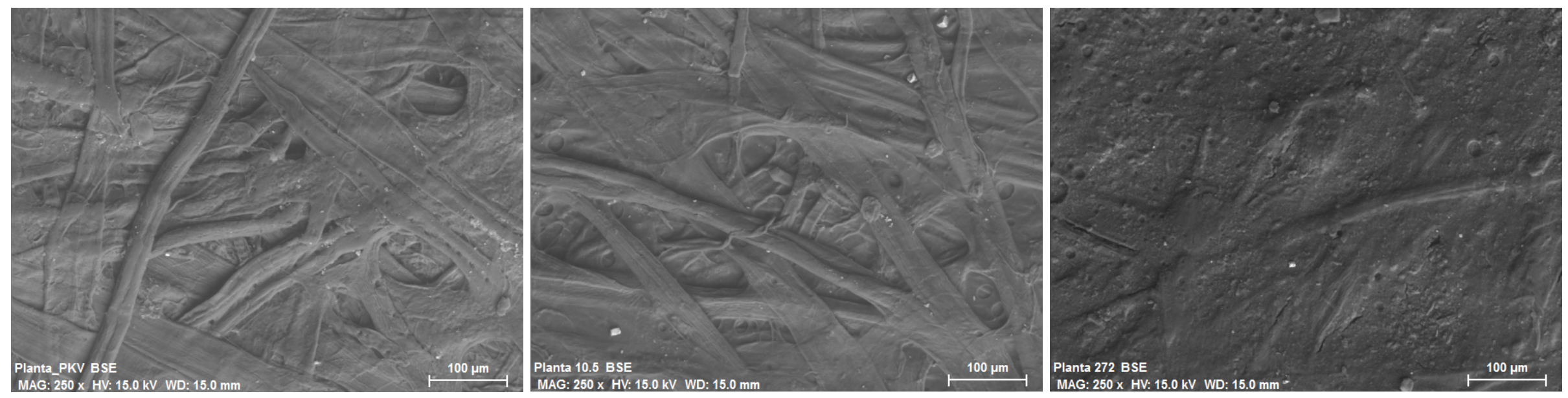


1 Supplementary material 5.

2

\begin{tabular}{|c|c|c|}
\hline & Control box & Active box \\
\hline Compression resistance ${ }^{1}$ & $383.2 \pm 39.6(8.3 \pm 1.1)$ & $350.8 \pm 34.9(9.3 \pm 0.7)$ \\
\hline Vibration at fixed low frequency ${ }^{2}$ & Apt & Apt \\
\hline Bottom bending resistance ${ }^{3}$ & $4.7 \pm 0.2$ & $3.5 \pm 0.3^{*}$ \\
\hline Edgewise crush resistance ${ }^{4}$ & $9.0 \pm 1.0$ & $6.5 \pm 0.7 *$ \\
\hline Puncture resistance 5 & $10.2 \pm 0.5$ & $10.1 \pm 0.4$ \\
\hline Static coefficient of friction ${ }^{6}$ & $0.42 \pm 0.04 / 0.28 \pm 0.05$ & $0.54 \pm 0.04 * / 0.39 \pm 0.07 *$ \\
\hline Moisture content ${ }^{6}$ & $6.72 \pm 0.10$ & $6.95 \pm 0.09 *$ \\
\hline Water absorptivity ${ }^{7}$ & $109.2 \pm 7.1$ & $97.4 \pm 4.3 *$ \\
\hline Water vapor permeability ${ }^{8}$ & $1.002 \times 10^{-9}$ & $1.395 \times 10^{-10}$ \\
\hline
\end{tabular}




\section{CAPÍTULO III.}

"Envase activo e innovador de cartón constituido por un revestimiento que incluye aceites esenciales encapsulados para extender la vida útil del tomate cherry"
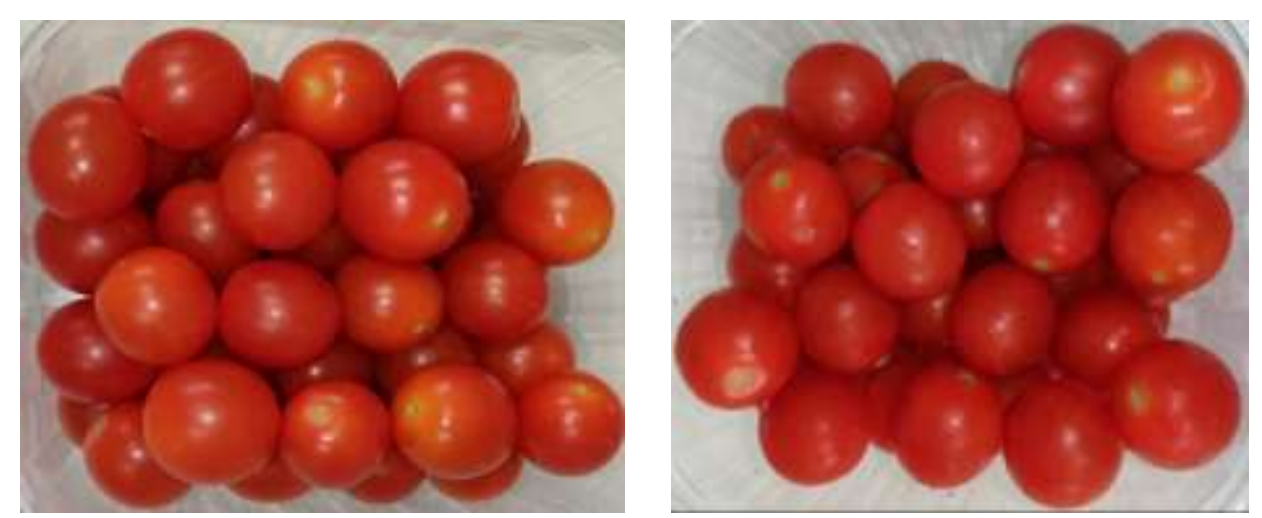

Este Capítulo se corresponde con el siguiente artículo publicado:

Laura Buendía-Moreno, Sonia Soto-Jover, María Ros-Chumillas, Vera Antolinos, Laura Navarro-Segura, María José Sánchez-Martínez, Ginés Benito MartínezHernández, Antonio López-Gómez. 2019. Innovative cardboard active packaging with a coating including encapsulated essential oils to extend Cherry tomato shelf life. LWT- Food Science and Technology, 116, 108584. https://doi.org/10.106/j.lwt.2019.108584.

Food safety and Refrigeration Engineering Group, Department of Agricultural Engineering, Universidad Politécnica de Cartagena, Paseo Alfonso XIII, 48, 30203, Cartagena, Murcia, Spain *E-mail address: antonio.lopez@upct.es (A. López-Gómez) 


\section{Resumen}

En este capítulo se estudia el efecto de una bandeja de cartón activa que incluye AEs encapsulados en $\beta-C D$, sobre la calidad de tomates cherry conservados a $8{ }^{\circ} \mathrm{C}$ y un 90 $\%$ de HR durante 24 días. La mezcla de AEs utilizada fue la constituida por carvacrolorégano-canela $(80: 20: 10 \mathrm{v} / \mathrm{v})$. Los tomates cherry fueron envasados mediante un sistema de flow-pack usando como envoltura un film de PLA macroperforado. Los tomates cherry fueron almacenados en distintos tipos de envases. Por un lado, se utilizaron cestas o barquetas de PE comerciales (Normal (NORM)), bandejas de cartón microcorrugado no activo con un recubrimiento interno de laca polimérica de uso alimentario (Control (CTRL)); y por otro lado, una bandeja o cesta activa de cartón microcorrugado con un recubrimiento activo a base de AEs nanoencapsulados en $\beta-C D$, embebidos en el polímero acrílico (Activo (ACT)).

Durante la vida útil de los tomates cherry se realizaron determinaciones microbiológicas y fisicoquímicas (sólidos solubles, pH y acidez titulable), color, firmeza, incidencia de frutos que presentan podredumbres, análisis sensorial y para finalizar, se determinó la presencia de residuos de AEs sobre el fruto y el envase activo.

En cuanto a los resultados obtenidos, la firmeza de los tomates cherry se mantuvo correcta durante los 24 días de análisis, pero la incidencia de frutos con podredumbres fue reducida del $8 \%$ al $1 \%$ en el día 24 , en frutos almacenados en bandejas activas de cartón. El color del tomate también se conservó mejor con la bandeja de cartón activa. Los análisis sensoriales revelaron que la vida útil del tomate cherry se extendió de 20 a 24 días a $8 \stackrel{\circ}{\circ}$.

Se detectaron residuos de AEs (medidos por su componente mayoritario carvacrol,) en el fruto en los días $6(50 \mu \mathrm{g} / \mathrm{kg}), 9(40 \mu \mathrm{g} / \mathrm{kg})$ y $16(30 \mu \mathrm{g} / \mathrm{kg})$ de conservación, aunque siempre por debajo de 1 ppm. Los días 20 y 24 de conservación no se encontraron residuos de AEs sobre la piel del tomate cherry. Sin embargo, el contenido de AEs en la bandeja activa osciló entre 102 y $140 \mathrm{mg} / \mathrm{m}^{2}$ hasta el día 16 de conservación. Los días 20 y 24 de conservación ya no se detectaron residuos de AEs sobre las bandejas activas de cartón. 


\section{CAPÍTULO IV.}

\section{"Envase de cartón activo formado por un revestimiento que incluye aceites esenciales encapsulados en ciclodextrinas y/o nanotubos de Halloysita. Un caso de estudio para el almacenamiento de tomate fresco"}
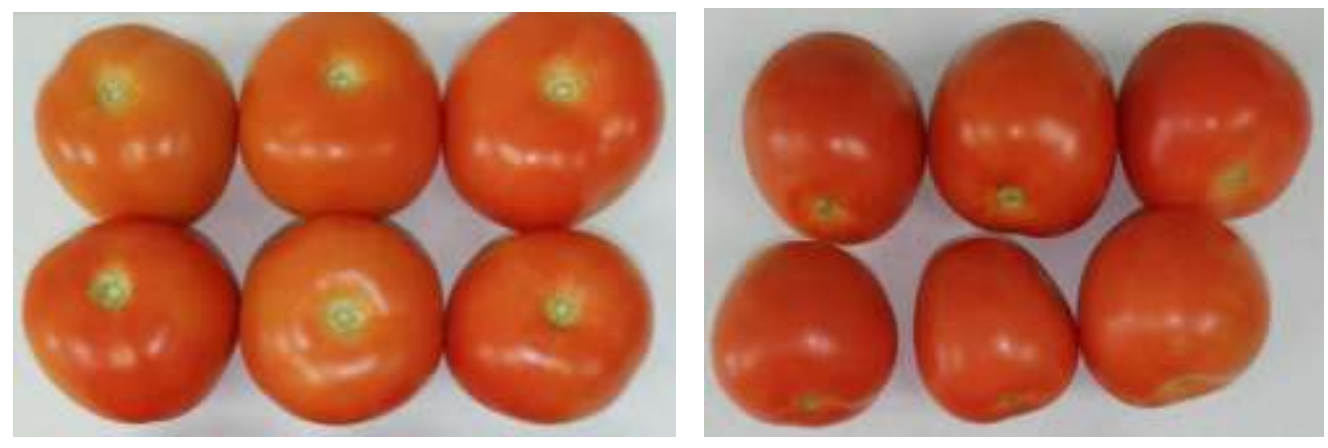

Este Capítulo se corresponde con el artículo siguiente:

Laura Buendía-Moreno, María José Sánchez-Martínez, Vera Antolinos, María RosChumillas, Laura Navarro- Segura, Sonia Soto-Jover, Ginés Benito MartínezHernández, Antonio López-Gómez. 2019. Active cardboard box with a coating including essential oils entrapped within cyclodextrins and/or halloysite nanotubes. A case study for fresh tomato storage. Food Control, 107, 106763. https://doi.org/10.1016/j.foodcont.2019.106763.

Food safety and Refrigeration Engineering Group, Department of Agricultural Engineering, Universidad Politécnica de Cartagena, Paseo Alfonso XIII, 48, 30203, Cartagena, Murcia, Spain *E-mail address: antonio.lopez@upct.es (A. López-Gómez) 


\section{Resumen}

En este capítulo se estudia el efecto de un envase de cartón activo que incluye AEs encapsulados en $\beta-C D$ y HNT, sobre la calidad de tomates variedad Caniles conservados a $8 \stackrel{\circ}{\circ}$ durante 6 días (simulación de transporte corto), seguido de 5 días a $25 \stackrel{\circ}{\mathrm{C}}$ (comercialización). La mezcla de AEs utilizados fue la constituida por carvacrolorégano-canela (80:20:10 v/v). En particular, las cajas de cartón activas fueron recubiertas con una emulsión acrílica que contiene los $A E s$ encapsulados en $\beta-C D$, en nanotubos de HNT o en una combinación entre ambos. Por un lado, se utilizaron cajas recubiertas con la emulsión acrílica sola (Control (CTRL)), cajas recubiertas con la emulsión acrílica constituida por HNT (HNT), cajas de cartón con un recubrimiento activo a base de AEs encapsulados en HNT y a su vez, embebidos en el polímero acrílico (HNT-AEs), cajas de cartón con un recubrimiento activo a base de AEs encapsulados en $\beta$-CD y a su vez, embebidos en el polímero acrílico ( $\beta$-CD-AEs), y por último cajas de cartón con un recubrimiento activo formado por AEs encapsulados tanto en $\beta$-CD como en HNT, y a su vez embebidos en el polímero acrílico ( $\beta$-CD-HNT-AEs).

Durante la vida útil de los tomates frescos se realizaron determinaciones microbiológicas y fisicoquímicas (sólidos solubles, $\mathrm{pH}$ y acidez titulable), color, firmeza, incidencia de frutos que presentan podredumbres, análisis sensorial y para finalizar, se determinó la presencia de residuos de AEs sobre el fruto y el envase activo.

En cuanto a los resultados obtenidos, la calidad fisicoquímica, microbiológica y el color de los tomates no se vieron afectados negativamente cuando se envasaron en cajas activas. La firmeza tampoco se vio afectada después de 6 días a $8{ }^{\circ} \mathrm{C}$. Además, la incidencia de frutos con podredumbres dentro de los envases control fue del $15 \%$, mientras que en los envases activos con $A E s+\beta-C D$ el porcentaje de incidencia era solo en torno al $3 \%$ al final de su vida útil. Para el resto de condiciones se obtuvieron los siguientes resultados: los envases con HNT vacíos presentaban una reducción de podredumbres de hasta el $10 \%$ con respecto al control. Sin embargo, cuando los AEs son encapsulados en HNT no se aprecia una diferencia con respecto al control en cuanto al porcentaje de podridos. Pero cuando se usa una combinación de los agentes encapsulantes, $\beta-C D+$ HNT se produce una reducción del $7 \%$ de frutos podridos con respecto al control. Se detectaron residuos de carvacrol (el componente mayoritario de la mezcla de AEs utilizada) sobre el envase activo de cartón utilizado. El contenido inicial de carvacrol osciló entre 28 y $31 \mathrm{mg} / \mathrm{m}^{2}$ dependiendo del tratamiento utilizado. Después de 6 días a $8 \stackrel{\circ}{\circ}$, el contenido de AEs de los envases activos se redujo a valores de entre 10,1 y $18,7 \mathrm{mg} / \mathrm{m}^{2}$ para $\beta$-CD-AEs, $\beta$-CD / HNT-AEs y HNT-AEs, sin observarse diferencias significativas en los dos últimos tratamientos. 


\section{CONCLUSIONES}




\section{CONCLUSIONES}

1. Se ha validado, a escala de planta piloto y a nivel industrial, el prototipo de envase activo de cartón desarrollado, con carácter antimicrobiano, que incluye agentes antimicrobianos encapsulados para el envasado de tomates y pimientos frescos, para así aumentar la calidad, seguridad alimentaria y vida útil de estos productos.

2. Este envase de cartón con carácter activo, que incorpora AEs encapsulados en su matriz, es una solución tecnológica que prolonga la vida útil de tomates y pimientos frescos envasados a granel, ya que no solo consigue retrasar la proliferación de microorganismos sobre la superficie del fruto, sino que aumenta también la seguridad alimentaria microbiana de tomates y pimientos frescos.

3. El uso de este tipo de envase activo antimicrobiano de cartón podría extenderse a otras frutas y verduras frescas enteras. Además, el complejo de inclusión podría incluirse en la matriz de los materiales utilizados para la fabricación de envases destinados a la alimentación ejerciendo su acción antimicrobiana durante la conservación del producto.

4. Mediante estudios microbiológicos, fisicoquímicos (sólidos solubles, $\mathrm{pH}$ y acidez titulable), análisis sensorial, de color, pérdida de peso, firmeza e incidencia de frutos podridos, se podría concluir que el uso del envase activo antimicrobiano de cartón, validado en esta Tesis, para la conservación de productos hortícolas, mejora la firmeza siendo este parámetro indicativo del deterioro del fruto, e inhibe el desarrollo de microorganismos alterantes $y$, por tanto, se consigue un aumento de la conservación en las condiciones adecuadas de temperatura y humedad relativa.

5. El uso de películas de PLA macroperforadas para el envasado en flow-pack, utilizado en los capítulos III y IV, evitó la deshidratación de los frutos durante todo el período de almacenamiento a $8 \stackrel{\circ}{\circ}$ y $90 \%$ de humedad relativa. 
6. Tras el estudio realizado sobre la cinética de liberación de vapores, mediante cromatografía de gases, de las combinaciones de AEs seleccionadas, se demuestra que no existen residuos apreciables de los mismos sobre el fruto, ya que se presentan siempre por debajo de $1 \mathrm{ppm}$. Se puede concluir que los AEs nanoencapsulados aplicados en el recubrimiento de los envases activos de cartón no migran al fruto en cantidades apreciables organolépticamente durante su período de almacenamiento.

7. El uso de un envase activo de cartón que incluye nanotubos de HNT vacíos en combinación con las $\beta$-CDs cargadas con AEs dio lugar a un bajo porcentaje de incidencia de frutos podridos conservados a $8 \stackrel{\circ}{\circ}$ y un $90 \%$ de $\mathrm{HR}$, con respecto a los tomates conservados en envases con los agentes de encapsulación aplicados por separado. Así, se puede concluir que si a la capacidad antimicrobiana de los AEs encapsulados en CDs, se le suma la capacidad de adsorción de etileno por parte de los HNT vacíos, el desarrollo de la podredumbre del fruto puede ser baja, y por tanto garantizarse una mayor calidad del producto. 